\title{
Determining the uncertainty of areal mean surface elevation measured with a terrestrial laser \\ scanner and with a total station in permafrost environments near Lac de Gras, NWT, Canada
}

by

Christian Peart, B.Sc

A thesis submitted to the Faculty of Graduate and Postdoctoral Affairs in partial fulfillment of the requirements for the degree of

\author{
Masters of Science \\ in \\ Geography
}

Department of Geography and Environmental Studies

Carleton University

Ottawa, Ontario

2019

(C) 2019

Christian Peart 


\section{Abstract}

Quantifying topographic change in permafrost environments is important because it can provide insight about the loss of excess ice. Ground-based methods that detect change in surface elevation, however, are often applied at individual points rather than over an area, giving rise to questions about their representativeness. Remote sensing methods can overcome this problem, although confounding signals may arise from changing vegetation and microtopography. Comparing remotely sensed areal surface elevation or elevation change with ground-based observations also requires areal estimates rather than point measurements. This study examines the uncertainty of mean elevation measured with a terrestrial laser scanner and with a total station on 28 plots with different surface characteristics in a tundra environment. Observations from terrestrial laser scanning and surveying with a total station are analyzed statistically to reveal confidence intervals for the derived mean elevations. In the absence of a true reference elevation for the plots investigated, the difference between both mean elevations is quantified as well as the likelihood of representing the same surface. The results provide method specific detection limits for vertical movements of small plots $(15 \mathrm{~m} \times 15 \mathrm{~m})$ with differing surface characteristics. The difference between means derived from both methods provides additional context about how well we can define what the surface is that we are observing. On average, terrestrial laser scanning can potentially detect vertical movements in the centimeter range $(1.4-24.0 \mathrm{~cm})$ and the total station method in the low decimeter range $(3.5-47.1 \mathrm{~cm})$. For all plots, the mean elevations derived from laser scanning and total station surveying are statistically different at the $95 \%$ confidence level. Strong differences between plots exist and are influenced by surface 
characteristics. 


\section{Acknowledgements}

First and foremost I would like to acknowledge my supervisor Dr. Stephan Gruber. He provided me such care, feedback, and support through this journey. This thesis would not have occurred if it was not for him. The information he has passed on to me is immeasurable. Thank you for dealing with me and making me into a better scholar. I would like to thank my committee member Dr. Murray Richardson for all the important feedback that he has provided to make the project what it is.

Financial and/or organizational support for this thesis was provided by: Dominion Diamond Ekati Corporation, Northwest Territories Geological Survey, CanNor/SINED, CAMIRO, NSERC Engage program, ArcticNET, Northern Scientific Training Program, and Sub-Arctic Surveys.

Field assistance was mainly provided by Luca Heim, Malek Singer, and Mark Empey. I thank you guys for all the great times we had in and out of the field. On top of the field assistance Luca provided the procedures and invaluable knowledge of operating the equipment. This thesis has used a variety of software (e.g., Overleaf, RStudio, Python, ArcMap, GIMP, and Inkscape) and I would thank the different online communities for all the support.

Finally, I would like to thank the geography community at Carleton University. You all helped me through the good and bad times and were always there for me. I thank you all from the bottom of my heart. 


\section{Contents}

Abstract

Acknowledgements $\quad$ iv

$\begin{array}{lll}\text { Contents } & \text { v }\end{array}$

List of figures ix

List of tables xiii

1 Introduction $\quad 1$

1.1 Context . . . . . . . . . . . . . . . . . . . 1

1.2 Relevance of quantifying ground ice and surface subsidence . . . . . . 4

1.3 Detecting and measuring permafrost subsidence . . . . . . . . 5

1.4 Research gaps . . . . . . . . . . . . . . . . . . . 8

1.5 Research aim, objectives, and questions . . . . . . . . . . . . . 9

1.6 Approach ............................. 9

1.7 Thesis structure . . . . . . . . . . . . . . . . . . . 10

2 Background 11

2.1 Introduction . . . . . . . . . . . . . . . . . . . 11

2.2 Permafrost and the active layer f . . . . . . . . . . . . . 11

2.2 .1 Distribution of permafrost . . . . . . . . . . . 11

2.2 .2 A three layer model . . . . . . . . . . . . . . . . . . . 12

2.2 .3 Permafrost change . . . . . . . . . . . . . . . . . . 14 
2.2.4 Water and ice in frozen soils . . . . . . . . . . . . . . . 15

2.2.5 Frost heave and subsidence . . . . . . . . . . . . . . 18

2.2.6 Spatial and temporal variability of subsidence and heave . . . 20

2.3 Surface: defining a scale of analysis . . . . . . . . . . . . . . 20

2.4 Surveying of heave or subsidence . . . . . . . . . . . . . . 21

2.4.1 Frost/thaw tubes . . . . . . . . . . . . . . 22

2.4.2 Frost heave frame . . . . . . . . . . . . . . . . . . 22

2.4 .3 Optical leveling . . . . . . . . . . . . . . 23

2.4.4 Total station . . . . . . . . . . . . . . . . . 23

2.4.5 Global navigation satellite systems . . . . . . . . . . 23

2.5 Remote sensing of heave or subsidence . . . . . . . . . . . . 25

2.5.1 Comparing remote sensing techniques . . . . . . . . . . 25

2.5.1.1 $\operatorname{InSAR} \ldots \ldots \ldots \ldots \ldots$

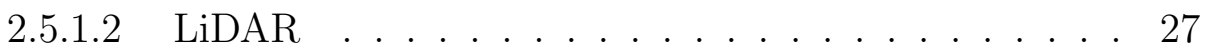

2.5.1.3 Photogrammetry . . . . . . . . . . . . . . . 29

2.5.2 Processing of remotely sensed elevation data . . . . . . . . 29

3 Study region $\quad 32$

3.1 Introduction . . . . . . . . . . . . . . . . . 32

3.2 Location . . . . . . . . . . . . . . . . . . . . . . 32

3.3 Surficial geology . . . . . . . . . . . . . . . . . . . . . 34

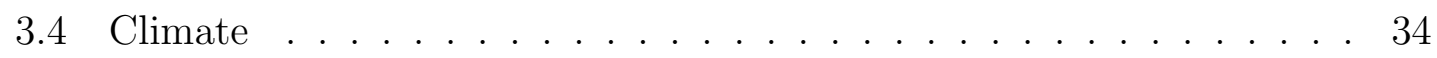

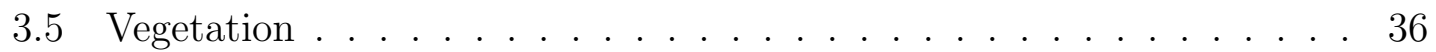

3.6 Active layer and permafrost . . . . . . . . . . . . . . 36

$\begin{array}{lll}4 & \text { Methods } & 37\end{array}$

4.1 Study design . . . . . . . . . . . . . . . . . . . . 37

4.1 .1 Selection of sites . . . . . . . . . . . . . . 37

4.1.2 Grouping of plots . . . . . . . . . . . . . . . 38

4.2 Instruments and materials used . . . . . . . . . . . . . . . . 42 
4.3 Survey methods . . . . . . . . . . . . . . . . . . . . . . 42

4.3 .1 Plot preparation . . . . . . . . . . . . . . . 42

4.3.2 Local benchmarks . . . . . . . . . . . . . . . . . . . 43

4.3 .3 Local grid . . . . . . . . . . . . . . . . . 46

4.3 .4 Scanning . . . . . . . . . . . . . . 46

4.3 .5 Point surveys . . . . . . . . . . . . . . . . . . . . 47

4.4 Processing . . . . . . . . . . . . . . . . . . 50

4.4 .1 Exporting scans . . . . . . . . . . . . . 50

4.4 .2 Point clouds to grids . . . . . . . . . . . . . . . 50

4.4.3 Raster and total station processing . . . . . . . . . . . 52

4.4.4 Potential minimum vertical detection limit . . . . . . . . . 56

\section{Experiments conducted to test method uncertainty and surface} $\begin{array}{ll}\text { ambiguity } & 57\end{array}$

5.1 Introduction . . . . . . . . . . . . . . . . 57

5.2 Man-made environment: laser scanning a highway . . . . . . . . . . 57

5.3 Surface ambiguity of natural tundra surfaces . . . . . . . . . . . . 60

5.4 Tundra plots near Lac de Gras . . . . . . . . . . . . . . . . . . 63

6 Results $\quad 64$

6.1 Introduction . . . . . . . . . . . . . . . . . . 64

6.2 Laser scanning a relatively smooth man-made surface . . . . . . . . . 64

6.3 Surface ambiguity of natural tundra surfaces . . . . . . . . . . . . 67

6.4 Tundra plots near Lac de Gras . . . . . . . . . . . . . . . . . . . . 70

$\begin{array}{lll}7 & \text { Interpretation } & 75\end{array}$

7.1 Introduction . . . . . . . . . . . . . . . . . . 75

7.2 Laser scanning a relatively smooth man-made surface . . . . . . . . 75

7.3 Surface ambiguity of natural tundra surfaces . . . . . . . . . . . 76

7.4 Tundra plots near Lac de Gras . . . . . . . . . . . . . . . . . . . . . 77

7.5 Other phenomena . . . . . . . . . . . . . . . 79 
7.6 Summary of experiments . . . . . . . . . . . . . . . 82

8 Discussion $\quad 83$

8.1 Introduction . . . . . . . . . . . . . . . 83

8.2 Laser scanning a relatively smooth man-made surface . . . . . . . . 83

8.3 Surface ambiguity of natural surfaces . . . . . . . . . . . . . . 84

8.4 Tundra plots near Lac de Gras . . . . . . . . . . . . . . . . . . . 85

8.5 Usage of methods in the field . . . . . . . . . . . . . . 87

8.6 Limitations of the study . . . . . . . . . . . . . . . . . 88

9 Conclusion $\quad 90$

$\begin{array}{ll}\text { References } & 92\end{array}$

$\begin{array}{ll}\text { Appendices } & 107\end{array}$

$\begin{array}{ll}\text { A Field } & 108\end{array}$

A.1 Field form . . . . . . . . . . . . . . . . . . 108

A.2 Site specific characteristics . . . . . . . . . . . . . . . 110

B Complementary results $\quad 112$

B.1 Complete results of data . . . . . . . . . . . . . . . . 112

$\begin{array}{lr}\text { C Acronyms } & 126\end{array}$ 


\section{List of Figures}

2.1 Three layer model showing the active layer, the transition zone, and permafrost (a), (b) shows ice enrichment over many centuries. The black ellipses are ice lenses, the vertical black lines are ice veins. Note that the there is growth of the ice wedge into the transition zone and that the layers are not to scale (Modified from Shur et al., 2005). . . . 13

2.2 Types of change (geomorphic, vegetational, or climatic) that may cause subsidence (modified from French, 2007). . . . . . . . . . . . . 19

3.1 A map showing the study region of the Lac de Gras area. The grey hillshade is based on a DEM derived from airborne LiDAR provided by Dominion Diamond Mines. The green part are the land where no airborne LiDAR data was collected. The yellow dots are the location of the study plots. . . . . . . . . . . . . . . . . 33

3.2 A climograph for Ekati Airport (1999-2016) (Environment and Climate Change Canada, 2016), where maximum/minimum temperature are represented by the lines and the precipitation is represented by the

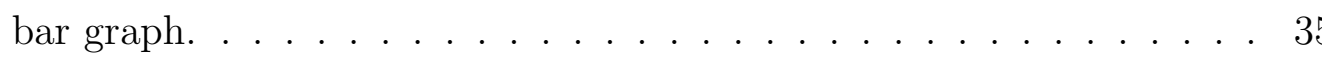

4.1 Examples of surface features and vegetation. (A) Bearberries on top of an esker, (B) dwarf birch on top of a mud boil, (C) Labrador tea surrounded by a blockfield, (D) lichen on an esker, (E) sedges on hummocks, and (F) sedges and ice-wedge polygons. . . . . . . . . . . 41 
4.2 A typical set up of a plot. The red arrows show the corners of the plot. The MS50 (the TLS and total station) is situated in the middle

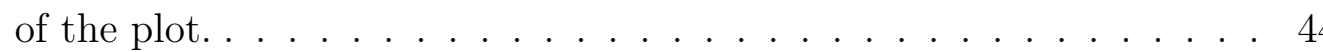

4.3 This figure shows the benchmark set up. (A) The components of a local benchmark. The Leica round prism attached to the adapter, which screwed onto the expansion bolt anchored into bedrock, which allowed for a permanent position of the benchmark and provided a fixed location for the re-occupation of a prism for future studies. In (B) a sketch of the cross section of bedrock, a local benchmark, and a hole beside the local benchmark are visible. B001 and H001 are the naming convections, where $\mathrm{B}$ represents benchmark and $\mathrm{H}$ represents hole. In (C) an installed local benchmark in bedrock with an orange spray-painted circle around it for ease of finding the benchmark are visible. The red arrow (to the left of the $\mathrm{C}$ ) indicates the position of the MS50. . . . . . . . . . . . . . . . 45

4.4 A typical collection of points surveys. A person moved around the plot while the MS50 followed the prism on the pole and obtains point data of the surface. . . . . . . . . . . . . . . . . . . . . 48

4.5 Each attachment gives a different representation of a surface. The needle attachment $(\mathrm{PN})$, the wide attachment $(\mathrm{PW})$, the medium attachment (PM) and the regular bottom of the pole (PR) are shown. A ruler was used for scale. The notations for the listed attachments are PN for needle point, PW for wide point, PM for medium point, and PR for regular point. . . . . . . . . . . . . . . . 49 
4.6 Here a point cloud from the MS50 is shown. It then was processed by the Python code to overlay a $15 \mathrm{~m} \times 15 \mathrm{~m}$. In the upper left hand corner there is less than 50 points in the $1 \mathrm{~m} \times 1 \mathrm{~m}$ cell, therefore, no data was returned for the cell. In the middle of the grid there was more than 50 points in the cell, which resulted in taking the lowest elevation point of that of the point cloud and applied it to the cell. . 51

4.7 Workflow to process TLS and total station measurements. At the top the TLS and total station data was collected. On the right hand side shows a simplified work flow of how TLS data was processed. On the right hand side the total station points are shown. Since the total station points did not have to undergo any filtering their points were processed with the filtered TLS data, bootstrapped, and then were

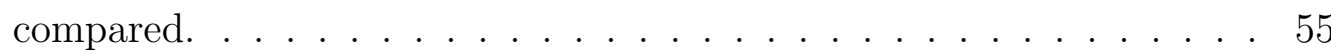

5.1 The portion of Highway 3 about $20 \mathrm{~km}$ west of Yellowknife that was surveyed. The grayscale represents the scans of Highway 3, with red dots outlining the edge of the road. . . . . . . . . . . . . 59

5.2 Experiment of different surface conditions in a $3 \mathrm{~m}$ by $3 \mathrm{~m}$ area. Three red circles show the different conditions. The left image shows a bare surface, the middle image shows short vegetation on the surface, and the right image shows tall vegetation. . . . . . . . . . . . . 61

5.3 Experimental site in Yellowknife with an organic surface. . . . . . . . 62

6.1 The 95\% confidence intervals for the various date of scans. June 2015 is at the top, followed by August 2015 below, and at the bottom is August 2016. Note, the scan names have been shorted and all the y-axes have been set to be the same range so they can be visually compared. ....................... 66 
6.2 Plot of deviation of the mean (shown as a point) in reference to PM in centimeters versus the relative $95 \%$ confidence intervals (shown as bars). The y-axis are the same on each plot so they can be visually compared. . . . . . . . . . . . . . . . 6 69

6.3 Beanplots of the total station and TLS method (that have been filtered based on lowest elevation point per grid cell) versus the relative elevation of PM. In each bean there are a 1000 samples because the bootstrap was set to 1000 replicates. The mean elevation is shown as a horizontal black line. . . . . . . . . . . . . . . . . 71

6.4 Plots of mean (shown as points) elevations (m) versus the $95 \%$ confidence intervals (shown as bars) of the different methods. . . . . . 72

6.5 Plot of the difference of relative mean areal elevation for the PM versus the TLS method based on group numbers. When the value of a point is greater than zero it means the contact method (PM) resulted in a greater relative mean areal elevation than the non-contact method (TLS). When the value of a point is less than zero it means the contact method (PM) resulted in a lower relative mean areal elevation than the non-contact method (TLS). A horizontal line at an elevation value of zero was constructed to quickly identify the number of points greater than or less than zero. . . . . . . . . . . . . . . . . . 74

7.1 QQ plot of the beanplot of PM from Figure 6.3. Most of the data is on the red reference line, as such, normality is assumed. . . . . . . . . 81 


\section{List of Tables}

1.1 Definitions of key terms. . . . . . . . . . . . . . . . 3

2.1 Selected surveying methods to compare usefulness of the data. . . . . 31

4.1 The number of plots associated with the dominant vegetation. It should be noted that the plots are not a full representation of the region. 39

4.2 The various types of surface features found within the study region. . 39

4.3 The grouping of plots based on surface features and vegetation. The maximum height of vegetation (all vegetation, not just dominant) was collected by hand with a measuring tape. . . . . . . . . . . . . . . 40

6.1 Scans and the associated data of the plot from Highway 3. The uncertainty is the range of the maximum confidence interval (CI) minus the minimum CI. . . . . . . . . . . . . . . . 65

6.2 Metrics collected from the surface ambiguity experiment. The means are statistically different at a 95\% confidence level (all p-values were less than $2.2 \times 10^{-16}$ ) when compared to the medium attachment $(\mathrm{PM})$ within one surface type. . . . . . . . . . . . . . . 68

6.3 Each plot with its associated key data. All plots are significantly different (at a $95 \%$ level, p-value of less than $2.2 \times 10^{-16}$ ) between the PM mean and TLS mean. . . . . . . . . . . . . . . . . 73

A.1 Location of sites . . . . . . . . . . . . . . . . . . 110

A.2 Maximum vertical error associated with resection per plot . . . . . 111 
B.1 All study sites with the different types of method used, the number of survey points/the number of grid cells with the minimum value, the mean elevation $(\mathrm{m})$, the deviation of the mean relative to the medium point attachment, the range of the scans means, the minimum vertical detection limit, and the confidence intervals. The total station methods are listed as PM, PR, PW, or PN for the respective attachments. The terrestrial LiDAR method is using all the combined scans as one scan. 113 


\section{Chapter 1}

\section{Introduction}

\subsection{Context}

In the last several decades, air and ground temperatures have increased in the Arctic and subarctic (IPCC, 2013; Blunden \& Arndt, 2017). This can lead to permafrost degradation, causing changes in topography (Jorgenson \& Osterkamp, 2005), terrain stability (Kokelj \& Jorgenson, 2013), soil chemistry (Kokelj \& Burn, 2005), hydrological processes (Frampton et al., 2013), as well as biogeochemical cycles (Grosse et al., 2011).

Permafrost is a subsurface, thermal phenomenon, defined as ground or ground materials that remain at or below $0^{\circ} \mathrm{C}$ for two or more years (ACGR, 1988). The layer above permafrost, which seasonally freezes and thaws is known as the active layer (French, 2007). The thickening of the active layer is of particular concern because the top of permafrost is often ice rich (Mackay, 1972; Kokelj \& Burn, 2005). If the active layer becomes thicker, melting of excess ice (ground ice that exceeds the total pore volume of the ground (ACGR, 1988)) occurs, which often

leads to the development of thermokarst terrain (Jorgenson \& Osterkamp, 2005; French, 2007; Kokelj \& Jorgenson, 2013;) and/or causes damage to infrastructure (Melvin et al., 2016). Therefore, the understanding of excess ice loss is critical to explain how permafrost systems react to disturbance or climate change. However, ground temperature alone does not provide a reliable quantification of the volume of 
excess-ice loss, supplementary methods must be used to determine this.

Hubbard et al. (2012) combined point measurements, airborne laser scanning (ALS), and geophysical datasets to see if there was a close linkage between microtopography, active layer thickness, permafrost and ground ice variability, which were confirmed by their results. Since there is a close linkage as previously mentioned, observations of the active layer and subsidence are related due to the fact that as the active layer becomes thicker, if excess ice is present at the top of permafrost, it melts and the ground subsides.

Methods that can detect small surface movements can be used to measure a vertical displacement over an area to obtain a volume of excess ice lost. Surveying (e.g., using a total station) and modern remote sensing are two methods to detect the small vertical displacement associated with the variation in the active layer (Little $e t$ al., 2003; Kääb, 2008; Jorgansson \& Grosse, 2016). In environments with permafrost or seasonally frozen ground there are small surface elevation changes associated with the seasonal heave and settlement of the freezing and thawing soil. The pore water in soils can change from dry to saturated, which can change elevation by especially in clay. These seasonal, vertical surface movements usually range from millimeters to centimeters in one year (Romanovsky et al., 2008, Fortier et al., 2011; Shiklomanov et al., 2013).

This thesis examines the usage of ground based Light Detection And Ranging (LiDAR) and surveying using a total station of plots with different surface characteristics near Lac de Gras, NWT in order to understand how accurately mean surface elevation can be derived in a typical permafrost environment (for an explanation of a typical permafrost environment see chapter three). Interpretation of elevation change as loss of ground ice from permafrost, is a next step and not the subject of this thesis. Furthermore, there are other reasons for elevation change aside from subsidence to consider (e.g., heave, temporal variability of the ground), which are discussed in chapter two. Key distinct definitions are shown in Table 1.1 to address this issue. 
Table 1.1: Definitions of key terms.

\begin{tabular}{ll}
\hline Terminology & Definition \\
\hline Subsidence & The downward settling of the ground's surface. In permafrost environments it is a result of excess ice loss \\
& (French, 2007). \\
& The upwards movement of the ground surface. In permafrost environments, the migration of water flows through \\
fine grained material to the freezing front of an ice lens, which then causes the ice lens to thicken, resulting in & upheaval of the grounds surface (Smith, 1984). \\
Frost heave & The general term for Earth's surface settling or heaving, with no known cause, also known as elevation change of \\
Vertical displacement & Earth's surface. \\
Thermokarst & The process by which characteristic landforms result from the thawing of ice-rich permafrost (ACGR, 1988). \\
\hline
\end{tabular}




\subsection{Relevance of quantifying ground ice and surface subsidence}

A mass of frozen soil that is subjected to an increase in temperature may undergo partial or complete phase change of the ice contained within it to water. If excess ice is present and melts, the ground will subside (Morgenstern \& Nixon, 1971). A higher excess ice content will result in a higher total amount of settlement. Small vertical downward displacements of the surface may indicate the beginning of sustained permafrost degradation. However, subsidence is the decrease in elevation over in time. Therefore, methods that detect surface displacement may help pinpoint locations of intense future change. However, the accuracy of measuring subsidence is strongly determined by the accuracy of the measurement of elevation.

In the Northwest Territories, surface displacements have interfered with transportation networks and pipelines. Furthermore, building foundations have shown signs of failure, deterioration, and, in some instances, buildings have become uninhabitable and roads impassable due to permafrost degradation (Government of the NWT, 2008). As permafrost degradation continues, risk to infrastructure increases, thereby increasing the vulnerability of residents and potentially resulting in large economic impacts. Melvin et al. (2016) modelled increasing damage to Alaskan public infrastructure from permafrost degradation to be in the billions of dollars by 2100 .

Detecting small surface displacements also allows for a better understanding of the ground heat balance. A loss of excess ice represents an advective flux of latent heat and it also alters the ground properties (e.g, mechanical strength, geochemistry) (Willams \& Smith, 1989; Kokelj \& Burn, 2005). Furthermore, detecting small surface displacements allows for the testing of different methods to detect surface changes. Generally, point measurements are discussed in permafrost literature (e.g., Little et al., 2003; Romanovsky et al., 2008, Fortier et al., 2011; Shiklomanov et al., 2013), however, they are often applied at individual points rather than over an area, giving rise to their representativeness of the area. Remote sensing methods can overcome 
this problem, although confounding signals may arise from changing vegetation and microtopography.

\subsection{Detecting and measuring permafrost subsidence}

Areal subsidence is quantified by subtracting two areal measurements of elevation (e.g., digital elevation models, point clouds, triangular irregular networks) from each other to determine the vertical displacement of the surface. Detection of subsidence requires computing a confidence interval of the areal mean elevation to determine an uncertainty (Brasington et al., 2000; Wheaton et al., 2008). To measure surface displacements, a variety of methods exist to capture the vertical movements of Earth's surface.

Contact methods of measuring surface elevation rely on a device coming into contact with the surface. Examples of contact methods include: levelling with permanent benchmarks anchored in permafrost (Mackay, 1973b), heavemeters (Smith, 1985), total stations (Quinton et al., 2011), and Differential Global Positioning System (DGPS) (Little et al., 2003). These methods can capture the small vertical displacement of the surface, but are limited to discrete point measurements. Additionally, physical contact may alter the surface and result in an error. For example, a survey pole may deform a soft surface or sink into the ground under its own weight.

Non-contact methods of measuring surface elevation acquire information about the surface without making physical contact. Non-contact methods include: LiDAR, Structure from Motion (SfM), and Differential Interferometric Synthetic Aperture Radar (DInSAR) (Kääb, 2008; Short et al., 2011; Jorgenson \& Grosse et al., 2016). These methods surpass contact methods because they can capture the local variation and do not disrupt the study site, but results from non-contact methods are confounded by returns from non-ground features (e.g., vegetation). There are methods that exist to help reduce the issue of separating ground from non-ground but no solution exists at present that is perfect (Meng et al., 2010; Sharma et al., 2010; Short et al., 2011). 
Detecting surface displacement (due to the loss of excess ice) is non-trivial, especially in heterogeneous landscapes where surface conditions are variable in space. Several problems relating to quantifying permafrost subsidence exist. They include, but are not limited to spatial variation, scale, disturbance of the surface, low rates of subsidence, the ambiguity of the definition of a surface, below the detection threshold, disturbance to the landscape (e.g., fire) and the confounding effects from vegetation cover.

Spatial variation and scale are closely related with each other. Spatial variation of subsidence exists because of snow cover, rainfall, soil properties, and vegetation characteristics (Smith, 1975). Small scale localized changes in the surfaces alter the surface and subsurface hydrology on a large scale (Frampton et al., 2013). As water moves on and through the surface it can affect the depth of thaw and permafrost degradation (Kane et al., 2001). This is an example of a positive feedback cycle, which allows for spatial patterns of subsidence and heave to develop. This results in difficulties in determining the vertical displacement of the surface over an area. Nelson et al. (1999) discovered that spatial variability of active layer thickness differed at two study sites. At one study site a high spatial resolution of measurement points was not required while at another site high variability occurred over a short distance (less than $3 \mathrm{~m}$ ), which required a high spatial density of points. This poses a problem, to achieve maximum effectiveness studies concerned with sampling, interpolating, or modeling thaw depth should be designed to accommodate the variability at multiple spatial scales (Nelson et al., 1999).

The rate of isotropic thaw subsidence is small (centimeters per year). The term isotropic thaw subsidence coined by Shiklomanov et al. (2013) it is the slow, widespread, relatively homogeneous, and low-magnitude thaw-induced lowering of the land surface. Over a period of eleven years, Shiklomanov et al. (2013) measured isotropic thaw subsidence to be $0.09 \mathrm{~m}$ and $0.19 \mathrm{~m}$ at two different study sites. Fortier et al. (2011) found that from 1991 to 2009 the access road to Umiujaq airport had subsided by a maximum of $0.85 \mathrm{~m}$ in several locations. Romanovsky et al. (2008) 
measured frost heave of non-sorted circles and inter-circles at several sites between the years 2001 to 2005. At some sites frost heave varied between $18-20 \mathrm{~cm}$ and at other sites it was typically less than $3 \mathrm{~cm}$ and very seldom reached $5 \mathrm{~cm}$. The issue with measuring subsidence is that methods to detect subsidence must be able to capture small and variable vertical surface displacements.

Measuring Earth's surface can be ambiguous due to a range of methods that have been developed for the definition of a surface. Therefore, a single best definition of what or where a surface is may not be possible for a given problem (Hobson, 1967). This causes an ambiguity in regards to where the surface elevation can be derived from (e.g., moss on top of sand). Due to this, the ambiguity of a surface definition and measurement of a specified scale must be determined for different surface characteristics.

Finally, vegetation is a confounding variable when measuring the surface. For contact methods, vegetation can be pressed under the device measuring the Earth's surface causing ambiguity in the data. Non-contact methods are confounded by vegetation too. Filtering removes non-ground objects, but distinguishing ground from non-ground can be a significant challenge in regions with high surface variability (Meng et al., 2009; Meng et al., 2010). The choice of filter parameters introduces some degree of arbitrariness depending on the platform, sensor, and environmental conditions (Aguilar et al., 2010). For ground-based LiDAR, Sharma et al. (2010) applied a vegetation removal method that resulted in an error up to $7.5 \mathrm{~mm}$ in the digital elevation model (DEM).

To detect the mean areal elevation results in having a method of measurement that can capture small surface displacements over a small spatial distance, having data to represent areas, detect small vertical surface displacements, and circumvent vegetation issues. This thesis will evaluate one contact method (surveying) and one non-contact method (terrestrial LiDAR) to determine the uncertainty of each method. 


\subsection{Research gaps}

In the past, point measurements of vertical movements have been made with contact methods (e.g., Mackay, 1976; Shiklomano et al., 2013; Beck et al., 2015). While, discrete points via contact methods often do not provide a high resolution sample of the surface, non-contact methods do (Jester \& Klik, 2005; Thomsen et al., 2015). A higher number of points thereby allows for a more detailed sample, which in turn means a higher accuracy for the areal elevation estimate, provided confounding points (e.g., vegetation) can be removed or avoided. This is a commonly accepted truth, however, comparison of point measurements and terrestrial laser scanning (TLS) in permafrost environments to prove this is lacking.

Jorgenson \& Grosse (2016) stated that interferometric synthetic aperture radar (InSAR), LiDAR, and Structure from Motion (SfM) are fundamental for a better understanding of permafrost and ground ice systems. However, there is little to no information on how well terrestrial LiDAR can be used in permafrost environments to capture vertical displacement (Bhardwaj et al., 2016).

Surface characteristics (i.e., vegetation and microtopography) impact elevation values because it causes ambiguity as to where the true surface is. Vegetation influences elevation errors because the bare ground surface may not be reached by the laser due to signal occlusion from vegetation. Microtopography influences how areal elevation measurements are determined. If points are collected in voids as opposed to on top of grains, the surface elevation will be reported as lower than if points were collected on top of the grains (Wheaton, et al., 2010;). Since surface characteristics influence the results of the data, there must be an associated uncertainty for each method and each different surface feature, which is not usually discussed.

To summarize, the key gaps that this thesis addresses are: the comparison of contact/non-contact methods, the comparison of differing surface characteristics, and surface ambiguity. 


\subsection{Research aim, objectives, and questions}

The aim of this thesis is to investigate how well the mean surface elevation of small plots in permafrost landscapes with different surface characteristics can be quantified. It uses terrestrial LiDAR and a total station as examples of non-contact and contact methods. This is accomplished by addressing three objectives.

The first objective is to quantify the difference between means and test statistically (at a $95 \%$ confidence level) if means from both methods are likely to come from the same surface (population). This addresses the research question: are the mean elevations derived from terrestrial LiDAR and a total station similar?

The second objective is to quantify the confidence intervals of the mean elevation for the two methods per plot experimentally. This addresses the research question: how much uncertainty is present in each method?

The third objective is to determine surface ambiguity to know what order of magnitude results from differing methods. This addresses the research question: what uncertainty is inherent in the ambiguous definition of a surface when deriving vertical movement from differing types of non-contact and contact survey method observations?

\subsection{Approach}

This thesis uses an empirical approach. The different field methods (TLS and a total station) were used on a man-made surface and 28 plots with different natural surface characteristics to determine the areal mean surface elevation. One way to estimate the mean surface elevation and its associated uncertainty is through different statistical resampling methods, such as bootstrapping (Brasington et al., 2000). Bootstrapping works by resampling the sample data and performing an inference about the sample, for example confidence intervals, which produces the range of uncertainty in the method. Typically, to detect the minimum vertical detection limit (of each method) one needs to propagate the potential uncertainties of two surveys from the $95 \%$ 
confidence interval estimate. However, due to the small vertical displacement that is caused by melting of excess ground ice in one year and the cost involved it was not feasible to return to all study plots every year. Consequently, a potential minimum vertical limit is discussed.

\subsection{Thesis structure}

The thesis is comprised of nine chapters. Following the introduction in this chapter is chapter two, which considers the background of permafrost and ground ice, surface ambiguity, and the different remote sensing techniques used for the detection of subsidence. Chapter three describes the study region. Chapter four describes the methods that were used. Chapter five describes the field experiments. Chapter six states the results that the experiments yielded. Chapter seven contains the interpretation of the experiments and their results. Chapter eight uses the results from chapter six and the interpretations from chapter seven to discuss the uncertainties and net findings into the context of published research. The final chapter, chapter nine, concludes the thesis by answering the questions that were sought out for in chapter one. 


\section{Chapter 2}

\section{Background}

\subsection{Introduction}

A study of the uncertainty involving TLS and a total station in a natural environment underlain by permafrost requires understanding the characteristics of frozen ground and the different surveying techniques used to quantify subsidence. This chapter reviews the distribution of permafrost, permafrost change, water and ground ice, heave and subsidence, the spatial and temporal variability of topography and subsidence, issues of scale, surface ambiguity, and finally, different contact and non-contact methods. It concludes with Table 2.1, which is a summary table of different surveying techniques, respective resolution, time, and selected references.

\subsection{Permafrost and the active layer}

\subsubsection{Distribution of permafrost}

The global permafrost region, excluding Antarctica, is about 17\% of Earth's exposed surface (Gruber, 2012). About 23\% of permafrost in the Northern Hemisphere lies in North America (Brown \& Haggerty, 1998).

The presence of permafrost is primarily a climatic phenomenon. Air temperature is the most dominant factor influencing the presence of permafrost at the global 
scale (Brown, 1966). This relationship allows for an interpolation and extrapolation approach for mapping of permafrost distribution based on air temperature. However, there are several issues with this approach that Heginbottom (2002) discussed. Permafrost maps have conventionally used zones, in which permafrost occurrence is spatially described as: continuous, discontinuous, sporadic, or isolated (Smith \& Riseborough, 2002). However, these zonal definitions are not universally agreed upon (Nelson, 1989; Heginbottom, 2002).

Within a zone, permafrost can be present or absent in areas with identical climates, demonstrating the importance of other biophysical factors (Shur \& Jorgenson, 2007). Local variations in vegetation, topography, snow cover, climate, and soil conditions contribute to produce a range of several degrees in mean annual ground temperature over a small region (Sturm et al., 2001; Smith \& Riseborough, 2002). Smith (1975) showed that microclimates produced local variations that differed up to $-4.2^{\circ} \mathrm{C}$ in the near-surface ground temperature at five nearby sites $50 \mathrm{~km}$ away from Inuvik, NWT.

\subsubsection{A three layer model}

A widely-used model of perennially frozen ground distinguishes three layers. From the top down there is the active layer, the transition zone, and finally permafrost (Figure 2.1).

The active layer is the layer above permafrost that seasonally freezes and thaws (French, 2007). It is important for the ecology and hydrology of permafrost environments because vegetation grow their roots into the ground; and in the summer, the active layer allows for a seasonal aquifer to form because the permafrost underneath acts as an aquitard to restrict the flow of water (Woo, 2008). The thickness of the active layer varies with disturbances to the surface, air temperature, snow cover, vegetation, aspect, soil water content, and ground materials (Mackay, 1970; Willams \& Smith, 1989). As such, the thickness of the active layer varies from year to year, but generally it is thin in the high Arctic and thickens as one moves to lower latitudes (French, 2007). 

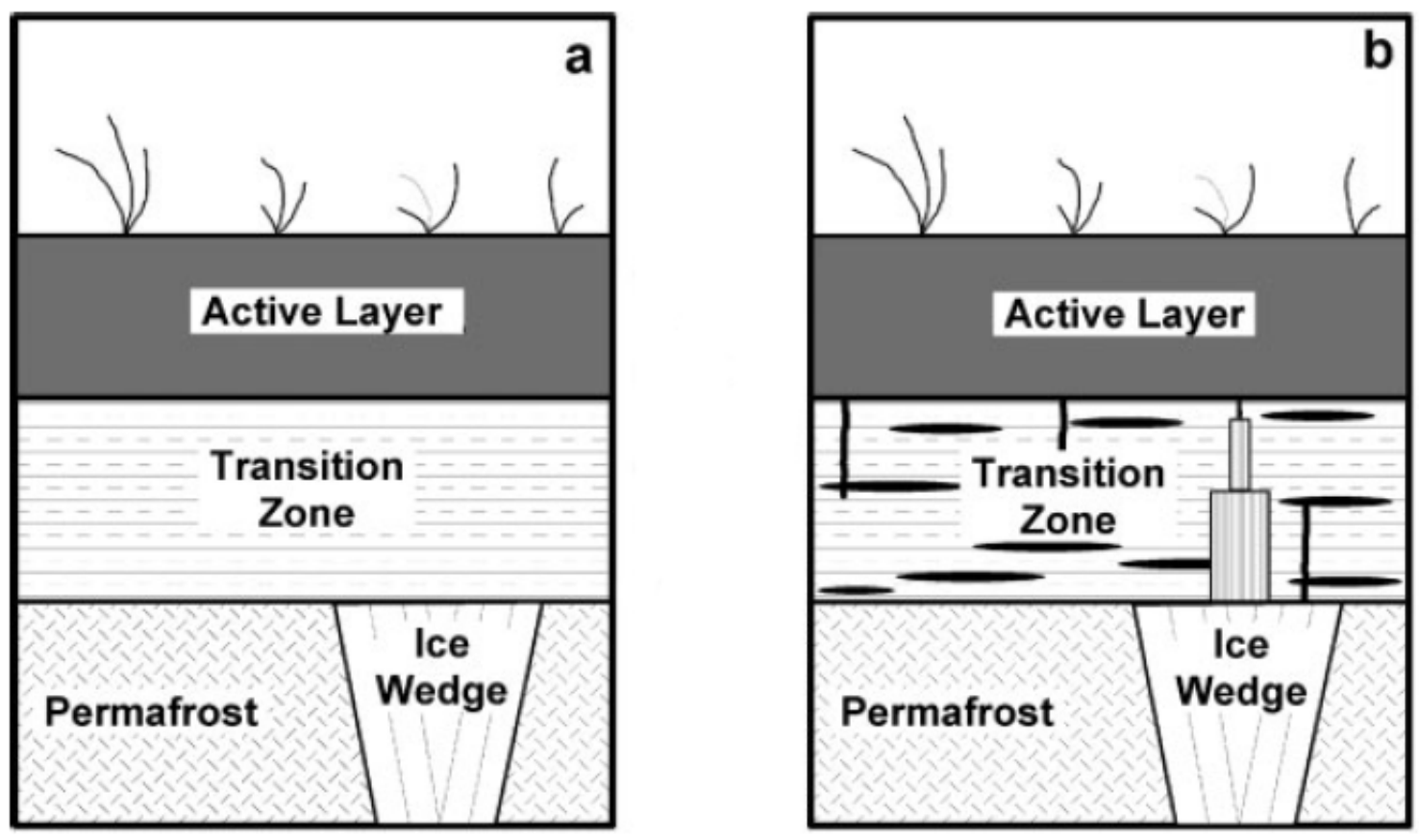

Figure 2.1: Three layer model showing the active layer, the transition zone, and permafrost (a), (b) shows ice enrichment over many centuries. The black ellipses are ice lenses, the vertical black lines are ice veins. Note that the there is growth of the ice wedge into the transition zone and that the layers are not to scale (Modified from Shur et al., 2005). 
The top of permafrost is often ice rich and contains more ice than deeper permafrost (Mackay, 1972, Burn 1988). This ice rich zone is known as the transition zone and the upper part of the transition zone is called the transient layer (Shur et al., 2005). The transient layer contains less ice than the lower region of the transition zone because it undergoes thaw more frequently (Shur et al., 2005). As such, the transient layer provides a thermal buffer that protects the deeper parts of the transition zone due to the high latent heat content (Shur et al., 2005). As air temperature continues to increase so does the thickness of the active layer, which may cause the ice rich zone of permafrost to thaw, resulting in subsidence (Mackay, 1970).

\subsubsection{Permafrost change}

An understanding of the thermal properties of the ground is essential to permafrost research because the ground materials influence how easily heat will flow through the ground and the amount of heat the ground can hold. Heat transfer through the ground is, for the most part, by conduction due to particle to particle contact (Willams \& Smith, 1989). As near surface temperature increases, heat is propagated into the ground, resulting in an increase in ground temperature, which may lead to a thicker active layer (French, 2007).

In North America, the thermal state of permafrost has changed at almost all sites of longer term records (Smith et al., 2010). Smith et al. (2010) gathered mean annual ground temperature between April 2007 and March 2009 for the Mackenzie Valley, NWT in both the continuous and discontinuous zones of permafrost. Their work showed that in both the continuous and discontinuous zones, the ground temperature increased. The magnitude of change was less in the discontinuous zone and this was attributed to phase change.

As ground temperature approaches $0^{\circ} \mathrm{C}$, soil profiles and time series increasingly become near-isothermal due to the release of latent heat. Further increases in ground temperature are small or non-existent for ice-rich permafrost for a long time because 
of that phase change (Smith et al., 2010). Nevertheless, even in cold permafrost $\left(<-2^{\circ} \mathrm{C}\right)$, warming can cause active layer thickening, which will result in the loss of excess ice (if present).

The future evolution of permafrost related to climate change and the detection of permafrost related events are of major concern (Jafarov et al 2012; Marmy et al., 2016; Vincent et al., 2017). Arctic and sub-arctic mean annual air temperature may increase by $1^{\circ} \mathrm{C}-11^{\circ} \mathrm{C}$ by 2100 depending on the climate model scenarios, however, a conservative amount of $5^{\circ} \mathrm{C}$ is expected (IPCC, 2013). In response to climate change, an increase in the active layer thickness is expected, however, some data from the Circumpolar Active Layer Monitoring (CALM) network have not shown an increasing active layer thickness (Shiklomanov et al, 2010). CALM is a program created in the 1990s to collect active layer thickness data, there exists over 200 sites worldwide that contribute to the program (Brown et al, 2000). The apparent stability of the active layer thickness may be attributed to the presence of the transition layer, which resists thaw because of the large amount of latent heat required to melt (Shiklomanov et al, 2013). Furthermore, to an observer measuring active layer thickness from the surface, thaw penetration into the ice-rich transition layer may not be apparent because of thaw consolidation and a net subsidence of the surface (Shiklomanov et al, 2013). As such, traditional methods for determining the active layer thickness (e.g., mechanical probing and temperature measurements from thermistor strings) does not explicitly account for thaw penetration into the transition layer associated with soil consolidation and net subsidence of the surface (Shiklomanov et al, 2013). Remote-sensing technology may be capable of providing integrated assessments of isotropic thaw subsidence over an area (Shiklomanov et al, 2013; Jorgenson \& Grosse, 2016).

\subsubsection{Water and ice in frozen soils}

A soil column with excess ice, exposed to an increase in ground temperature could result in a thaw of ice-rich ground and thereby cause a decrease in volume of the 
soil column. The melt water that is released from the soil column can build up considerably in the soil profile and then migrate through the soil elsewhere, thus causing the soil to consolidate under its own weight and further cause the surface to lower (Woo, 2008). It should be noted that the surface displacement caused by the transition of ice to water is much larger than the soil consolidating under its own weight (Morgenstern \& Nixon, 1971; Morgenstern \& Smith, 1973; Bommer et al., 2012).

When water starts to freeze in a soil pore, it does so furthest from the soil particle and with decreasing temperature, the interface of ice and the liquid layer adjacent to soil solids will gradually get closer to the soil particle (Williams and Smith, 1989). As water freezes, solutes are expelled, which depresses the freezing point in the remaining water. As the temperature continues to decrease, less liquid water will remain in the soil. Eventually, thin layers of unfrozen water remain around the soil particle because the concentration of solutes in the unfrozen water is high, which does not allow for the adsorption of ice to the soil particles (Woo, 2012).

The films of water are on the scale of nanometers (one billionth of a meter), meanwhile the pore dimensions often are on the scale of microns (one millionth of a meter) (Rempel et al., 2004). Since there are interconnecting spaces where unfrozen water exists and a difference in temperature, there is a potential that unfrozen water can migrate through the soil (Burt \& Williams, 1976). Woo (2012) proposes two mechanisms that allow for moisture to migrate through frozen soils: (1) movement of fluid through the film of interconnected unfrozen water on the surface of the soil particle or (2) associated with heat transfer and a phase change. Cryosuction is the concept of a freezing induced negative pressure in soil pores causing water to migrate through the soil pores to the freezing zone and to freeze there (Blanchard \& Frémond, 1982). The second mechanism works as the freezing front advances, latent heat is released by the freezing of water at the front. This heat is conducted through the ice lens toward the cold side. The heat then melts the ice on the cold side of the ice lens, thus creating water. With this process occurring across each lens and 
between lenses, the net effect is a transport of water (Woo, 2012).

Ground ice is a summary term for ice that is in the subsurface, either from being formed in the subsurface or from being buried (e.g., glacier ice), however, Mackay (1972) excluded buried ice from his definition because buried ice is uncommon in North America. There are numerous ways for ground ice formation, but those are not addressed in this thesis. What is important for this thesis is the presence of ice in the ground.

To describe ice conditions in unconsolidated materials, total moisture content and excess ice content are used. The typical usage of water or ice content refers to the mass of water divided by the mass of dry soil (dry gravimetric water content, Phillips et al., 2015). However, in ice rich soils the wet-basis gravimetric water content (mass of water per unit mass of field-moist soil) should be used because it eliminates the problem of extreme and difficult to interpret water value contents for ice-rich mineral soils (Phillips et al., 2015).

Excess ice is the volume of ice in the ground, which exceeds the total pore volume that the ground would have under natural unfrozen conditions (ACGR, 1988). Under a laboratory setting when permafrost samples are thawed, poured into beakers, and are allowed to settle, the volume of supernatant water can be recorded. This volume of supernatant water can be used to estimate the excess ice by the equation below

$$
E_{\mathrm{i}}=\frac{W_{\mathrm{v}} \times 1.09}{S_{\mathrm{v}}+W_{\mathrm{v}} \times 1.09} \times 100
$$

where $\mathrm{W}_{\mathrm{v}}$ is the volume of supernatant water, multiplied by 1.09 to estimate the equivalent volume of ice, and $\mathrm{S}_{\mathrm{v}}$ is the volume of saturated sediment (Kokelj and Burn, 2003). This method of collecting samples and calculating excess ice allows for a point measurement, but ground ice is likely to be spatially heterogeneous (as seen in Figure 2.1). As such, this methods does not capture the spatial variability of excess ice. 


\subsubsection{Frost heave and subsidence}

The process of frost heave is the migration of water through fine grained material to the freezing front of an ice lens which causes the ice lens to thicken. This can result in an excess of ice and displaces the ground surface upwards (Smith, 1984; Rempel et al., 2004). Frost heave is not only limited to soil. Murton et al. (2006) showed that unidirectional and bidirectional freezing caused ice segregation, which lead to fracturing and frost heave in bedrock.

A disturbance of the surface, whether man-made (e.g., French, 1974) or natural (e.g., Kokelj \& Jorgenson, 2013), may lead to ground subsidence (see Figure 2.2). Subsidence in permafrost environments is the downward displacement of the Earth's surface due to excess ice loss. Thawing of an unsaturated soil will release water, but not from excess ice, therefore, no subsidence develops (Mackay, 1970). There is only minor settling that occurs from soil particle readjustments (Mackay, 1970). However, thawing a soil with excess ice will cause subsidence, occurring when excess ice in permafrost thaws and drains away. 


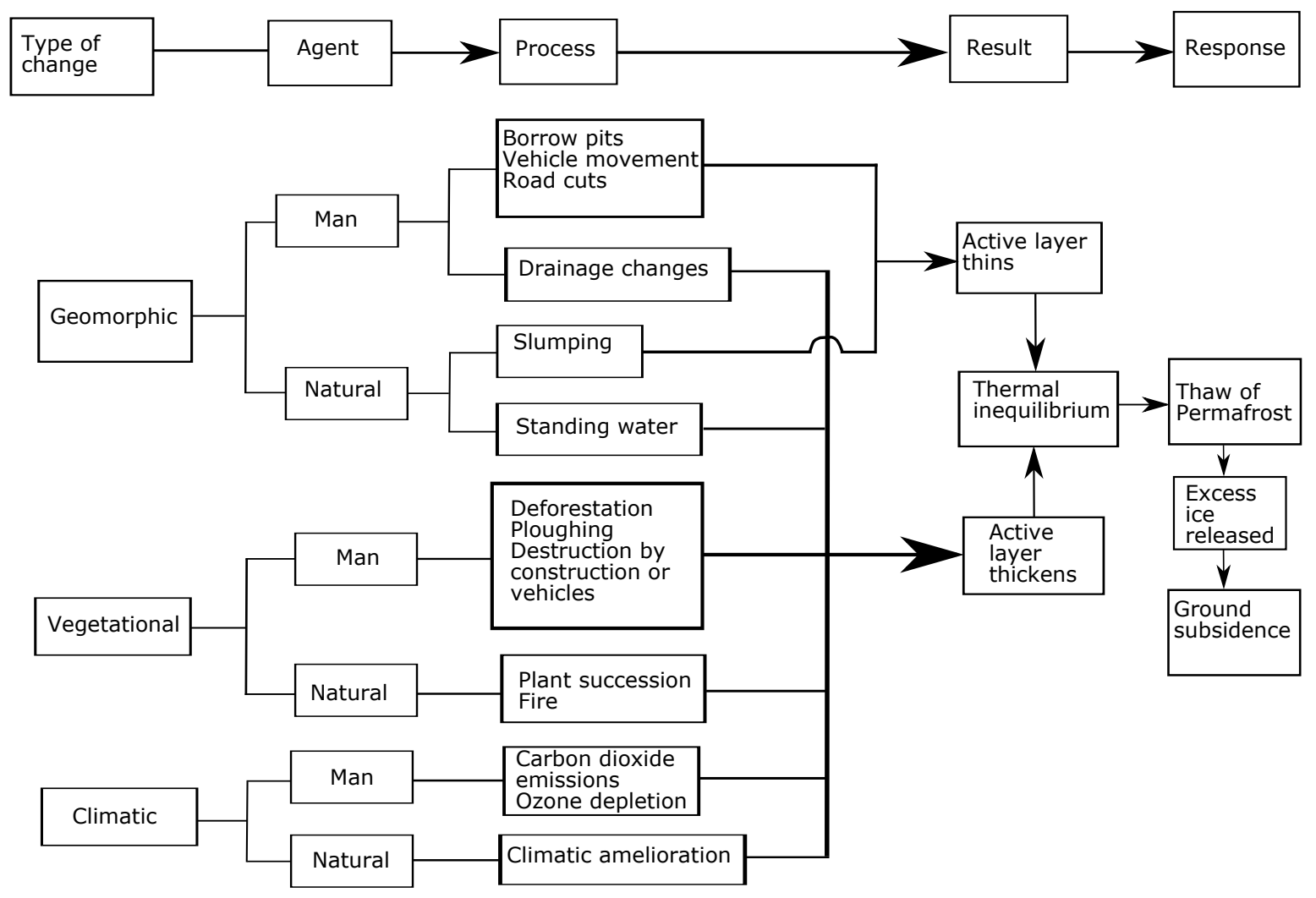

Figure 2.2: Types of change (geomorphic, vegetational, or climatic) that may cause subsidence (modified from French, 2007). 


\subsubsection{Spatial and temporal variability of subsidence and heave}

The distribution of ground ice is often spatially variable, which results in a heterogeneous landscape (National Research Council, 2014). Since ground ice is spatially uneven, subsidence and heave are also spatially uneven. Consequently, multiple elevation points are required in order to capture the spatial variability of subsidence and heave. With fine spatial resolution $(<5 \mathrm{~m})$ topographic surveying of subsidence and heave can be captured (Westermann et al., 2015).

The temporal variability of subsidence and heave has a seasonal trend and a long term trend. Within a year the surface elevation will increase and decrease due to the freeze-thaw cycle. During freeze back, any water in the active layer will freeze increasing the total volume of the ground that results in the ground to heave. During the thaw period, ice in the active layer will melt, decreasing the volume of the ground and the ground will subside, which results in a seasonal cyclic signal (Liu et al., 2015). Superimposed on the seasonal cycles, are the annual and long term changes of surface elevation. These surface changes usually occur in one direction over an extended period of time. Using a Global Navigation Satellite System (GNSS) can capture the small vertical displacements (Little et al., 2003), however, these campaigns are usually conducted annually, and therefore, do not allow one to measure the seasonal change, but only measure the annual and long term trends. However, some remote sensing platforms can detect the seasonal and yearly change (Liu et al., 2015).

\subsection{Surface: defining a scale of analysis}

Identifying elevation changes of the surface allows for estimating the loss of excess ice (National Research Council, 2014). However, a wide range of accepted methods exist for the definition of a surface, and therefore, a single best definition may not be evident for a given problem (Hobson, 1967). This causes an ambiguity of what is meant when the term surface is used. For example, if lichen is present on an esker does one remove it to measure the surface or is that not reasonable. If it is not 
reasonable then will the measurement be taken with the lichen on top of the esker? For this thesis, when the contact method is used it is placed below the vegetation canopy, but may ultimately end up on some vegetation making up the understory. When the non-contact method is used, it captures the vegetation of both the canopy and understory. Consequently, the vegetation must be filtered out of the data to determine the surface elevation. A caveat to filtering is that vegetation cannot be removed perfectly. It can only reduce the amount of vegetation present in the data.

In order to observe and study a phenomenon, scale is an important issue. The scale of analysis must match the scale of the phenomenon in order to have representative data of the phenomenon. This is because small scale issues may not be detected when a large scale is used and vice-versa. Additionally, spatial variations can simultaneously occur on scales of different orders of magnitude (Oliver \& Webster, 1986; Nelson et al., 1999). The phenomenon of subsidence due to the loss of excess ice is heterogeneous, which can cause relatively large features (e.g., collapsed pingo, which can range in size of $1000-10,000 \mathrm{~m}^{2}$ ) or relatively small features (e.g., thermokarst gullies, which can range in size from $0.1-1 \mathrm{~m}^{2}$; Jorgenson \& Osterkamp, 2005). Looking at the heterogeneous landscape as a mosaic of distinct facets and identifying the most important facets for the study allows one to capture the phenomenon. The important facet for this thesis is at a plot scale that measures $15 \mathrm{~m} \times 15 \mathrm{~m}$. This scale is used because it can capture the small scale vertical displacements and the heterogeneity of the environment. Consequently, a TLS and total station are used because they can detect the small spatial variability of the surface (Haubrock et al., 2009; Westermann et al., 2015).

\subsection{Surveying of heave or subsidence}

Field measurements of heave and subsidence use a wide variety of strategies and instruments (see Little et al., 2003) and this section provides a brief review. 


\subsubsection{Frost/thaw tubes}

Frost/thaw tubes have been used as an invasive method to monitor annual maxima of freezing and thawing within the soil. The typical frost gauge has a rigid outer tube, with a removable inner tube, installed vertically into the ground. As the inner tube is transparent and water filled, the freezing depth can be checked easily (Mackay, 1973a; Iwata et al., 2012). The thaw tube is able to measure vertical displacements annually and the accuracy is generally within $5 \%$ of the thaw depth in the ground (Mackay, 1973a; Nixon, 2000). The advantages of frost/thaw tubes are: providing an inexpensive method to record maximum thaw depth, providing an inexpensive method to measure active layer thickness, useful in areas where thaw is too deep, useful where the ground is too rocky to measure with a simple mechanical probe, and since the outer tube acts as a stable reference, measurement of heave and thaw subsidence is possible.

\subsubsection{Frost heave frame}

A frost heave frame is an example of a non-continuous method of recording vertical displacement. Smith (1987) used two frost heave frames that were designed to create short linear transects and permit measurement of vertical soil movements over several years. These frames are comprised of vertical rods, supported by a metal frame stabilized by cementing the uprights into the bedrock or subsoil. The rods are in contact with the soil, which moves vertically as the ground heaves or subsides. Smith's (1987) work in the Front Range of the Canadian Rocky Mountains over the period 1980 to 1983 indicated a diurnal frost heave activity of a maximum of 16.5 $\mathrm{mm}$ and a seasonal frost heave activity of a maximum of $4.5 \mathrm{~cm}$ over the transect. An advantage of the frost heave frame allows for several point measurements to be made along a transect and can be made for an areal coverage by having multiple transects spaced apart, however, such devices require a stable reference frame, which is often difficult to provide owing to the effects of heave and settlement on the frame itself. They are also impractical for heave and settlement measurements over extended 
geographical areas (Little et al., 2003).

\subsubsection{Optical leveling}

Another type of non-continuous method of recording vertical displacement is the use of the classical surveying method optical leveling. Mackay (1973b) used a Wild NA2 automatic engineer's level, invar rod, and supporting struts to have a closed survey of benchmarks that heaved and subsided due to the growth of several pingos. Mackay (1976) discovered that the vertical component of pingos alternately rose and subsided (in the decimeter range) in response to the rate of accumulation and loss of water beneath them. Although leveling provides accuracy to the $\mathrm{cm}$ level, it requires a line of sight to the benchmark, which prevents large areas from being studied, especially in the presence of tall vegetation.

\subsubsection{Total station}

A more technological advanced method of optical leveling is the use of a total station (both manual and robotic total stations exists). A total station is a machine that uses an electronic transit theodolite integrated with an electronic distance measurement to measure both vertical and horizontal angles and the slope distance from the instrument to a particular point (Ghilani \& Wolf, 2015). It can be used to survey features (e.g., a road) or be used to stakeout known and unknown points.

\subsubsection{Global navigation satellite systems}

During the 1970s, the global positioning system (GPS) emerged (Ghilani \& Wolf, 2012). The principle of GPS is it acquires a position through triangulation between an antenna receiver and several satellites (Ghilani \& Wolf, 2012). DGPS is a method that uses code-based positioning to improve the positioning or timing performance of GPS using one or more reference stations at known locations, each equipped with at least one GPS receiver (Kaplan \& Hegarty, 2005). This improvement reduces errors from meters (from simple hand-held GPS) to centimeters for both the horizontal 
and vertical scale (Kaplan \& Hegarty, 2005). Little et al. (2003) used DGPS to monitor frost heave and thaw settlement in tundra environments within a couple of centimeters for the vertical component. Their results showed that post-processed DGPS measured a mean value of a vertical heave of $1 \mathrm{~cm}$ and a mean subsidence value of $4 \mathrm{~cm}$ during 2001-2002 at Prudhoe Bay, Alaska. However, their study did not include any uncertainty of their measurements, which may produce misleading information on the usefulness of DGPS to measure heave and subsidence.

Real-time kinematic (RTK) works by using carrier-based ranging for its underlying position information, which can provide range values that are orders of magnitude more precise than code-based positioning (Kaplan \& Hegarty, 2005). It works by determining the number of carrier cycles between the receiver and satellite and then multiplying the wavelength of the carrier signal. If several frequencies are used to determine the position, the error of atmospheric delays and signals are minimized (Kaplan \& Hegarty, 2005). This technique allows for a more rapid acquisition of data than traditional surveying methods. Lambiel \& Delaloye (2004) concluded that RTK GPS is an efficient tool for studying the dynamics of active rock glaciers and moraine deposits with an accuracy of $2-3 \mathrm{~cm}$. They also state that the temporal evolution of surface movements can be determined, however, a sufficient number of points is absolutely necessary to get a good appreciation of the movements.

Nevertheless, any of the methods of manual surveying requires a lot of time to set up and collect data. For this reason, if a high level of detail of the surface is required, then more efforts are necessary to overcome the restrictions in spatial coverage imposed by practical constraints (e.g., sampling the study site). As such, remote sensing may provide some help in reducing the efforts of manual surveying because of the higher acquisition rate of data. 


\subsection{Remote sensing of heave or subsidence}

\subsubsection{Comparing remote sensing techniques}

Many modern remote sensing techniques have a high spatial and temporal resolution (Kääb, 2008). Several remote sensing platforms exist (e.g., spaceborne, airborne, and ground based) and each platform has different advantages and drawbacks, which must be considered for the study of interest.

Kääb (2008) states the applications of remote sensing to permafrost problems are governed by: spatial resolution, spatial coverage, temporal resolution, timing of data acquisition, portion of the electromagnetic spectrum, and interferometric or ranging capabilities, which governs the usefulness of data.

Jorgansson and Grosse (2016) state that InSAR, LiDAR, and SfM are the most optimistic remote sensing techniques to better understand ground ice and permafrost dynamics. As such, these remote sensing techniques are compared to determine the usefulness of the data to be used at the plot scale (Table 2.1).

\subsubsection{InSAR}

Radar (radio detection and ranging) is an active remote sensing technique that sends a signal to a target and then receives a return signal to deduce information about the target. The signal is in the microwave spectrum so it can pass through clouds. The return signal depends on the orientation, roughness, and the dielectric characteristics of the surface material (Bürgmann et al., 2000). Radar has the capability to penetrate the ground, snow, and vegetation to varying degrees, depending on the liquid water content, structure, and texture of the soil (Nolan \& Fatland, 2003). Synthetic Aperture Radar (SAR) combines signal processing techniques with satellite orbit information to produce a radar image with improved resolution.

Interferometric synthetic aperture radar (InSAR) uses interferometry, which exploits phase differences between pairs of differing SAR images. InSAR works based on a phase shift between two pixels acquired over the same area at a different 
time (Massonnet \& Feigl, 1998). The resulting difference is an interferogram, which expresses the amount the surface has deformed in slant range on a pixel to pixel basis. Interferograms can be interpreted to vertical accuracies in the millimeter to centimeter range and a spatial resolution of about a square meter with TerraSAR-X to of tens of meters with ALOS-PALSAR (Gabriel et al., 1989; Short et al., 2011; Iwahana et al., 2016).

The revisit times of satellites are predetermined and are difficult to adjust, limiting the capabilities of use. Due to the predetermined times, it may not be possible to study an area of interest adequately. However, the ability to compute an interferogram may be compromised due to loss of coherence. With a loss of coherence a decrease in accuracy is produced or no data is generated for those pixels. Coherence ranges from zero to one, where zero is a mismatch and one is a perfect match (Liu et al., 2015). Loss of coherence can result from surface moisture change, vegetation change, snow and snowmelt, and surface changes (Short et al., 2011).

The usage of InSAR in permafrost environments can be problematic. Short et al. (2011) suggested values of $1 \mathrm{~cm}$ or less than $1.5 \mathrm{~cm}$ as approximate margins of error for TerraSAR-X and RADARSAT-2 and PALSAR, respectively. In another study, Short et al. (2013) used RADARSAT-2 InSAR and compared the results with thaw tube data. In well drained areas, there was good quantitative agreement with seasonal ground settlement measurements, potentially as good as $4 \mathrm{~mm}$ and certainly within $1 \mathrm{~cm}$. When in areas where the ground was saturated the InSAR method underestimate the true settlement of the ground by several centimeters. In another study by Liu et al. (2015), they used InSAR to model the loss of excess ice on the Arctic lowland coast about $14 \mathrm{~km}$ south of Deadhorse on the North Slope of Alaska. They had field measurements of the active layer via mechanical probing and ground penetrating radar (GPR). The excess ice model derived from the InSAR data showed a greater seasonal subsidence than the subsidence inferred from the GPR data. For both studies the InSAR model did not agree with field measurements, especially when the ground was saturated. 


\subsubsection{LiDAR}

LiDAR works by emitting light pulses in the visible light to infrared spectrum from fixed wing aircraft or helicopter for airborne LiDAR or on a tripod for ground based LiDAR (Heritage \& Large, 2009). There are three main types of distance measurements utilised by LiDAR systems: triangulation, time-of-flight and phase-based (Smith, 2015). Triangulation-based measurements are usually done for distances smaller than $5 \mathrm{~m}$ (Vosselman \& Maas, 2010); as such, this method will not be discussed.

Time of flight works by measuring time delays of returned signals (Vosselman \& Maas, 2010). Emitted light pulses are sent out in a given medium and interact with and reflect off an object. The return signals come back with a time delay, which can be converted into a distance to the point with the equation 2.2 (Vosselman \& Maas, 2010).

$$
d=c t / 2
$$

where $\mathrm{d}$ is distance, $\mathrm{c}$ is the speed of light in a given medium, and $\mathrm{t}$ is time. The division by two is because the laser pulse travels to and from the device so dividing by two gives the distance from the device to the target.

Phase-based measurements exploit a difference in the phase between transmitted and received signal. The device emits a laser pulse that is amplitude modulated, which interacts with the surface and is reflected back to the scanner. The phase shift in the modulation between the returned pulse is compared with the emitted pulse. The difference is converted to a time delay that is then converted into a distance from the laser to the point (Vosselman \& Maas, 2010).

The revisit time for LiDAR applications is determined by the researcher. Although the revisit time is flexible, LiDAR is affected by four main factors that influence scan quality: (1) atmospheric conditions, (2) instrumental error, (3) surface properties, and (4) the geometry between the device and measured object (Kaasalainen et al., 2011; Soudarissanane et al., 2011). To correct for atmospheric conditions, 
temperature, humidity, and atmospheric pressure are adjusted on the device before use. Instrumental error is a given and is reported in the white papers or manual of the device and is calculated in a laboratory setting producing sub-millimeter errors. Surface properties concerns the anisotropy of the light reflection that depends on the reflectivity and the roughness of the surface material with respect to the wavelength of the scanner. Finally, geometry deals with the placement of the device relative to the location and orientation of the scanned surface. Geometry determines the local incidence angle, the local range and the local point density of the surface. In general it is assumed that the lower the incident angle is and the closer the scanner is the higher the accuracy, however, it is hard to achieve in the natural environment (Kaasalainen et al., 2011; Soudarissanane et al., 2011).

Airborne LiDAR studies routinely quote vertical accuracies of $15 \mathrm{~cm}$, however, it is agreed such accuracy is only achievable under the most ideal circumstances (Hodgson \& Bresnahan, 2004; Aguilar et al., 2010). A few empirical studies have been conducted to date and suggest vertical accuracies of $26 \mathrm{~cm}$ to $153 \mathrm{~cm}$ for large scale mapping applications (Hodgson \& Bresnahan, 2004). Terrestrial LiDAR has a vertical accuracy in the millimeter range or better, however, that is usually only achieved in a laboratory setting (e.g., Cournoyer, 2015). When taken into a field setting the accuracy of the desired products especially after vegetation filtering usually decreases into the centimeter to sub-meter scale (Lichti et al., 2000). The spatial resolution of TLS is usually higher than ALS. Consequently, TLS is usually used for a smaller area of study, whereas airborne LiDAR is used for larger areas of study (Haubrock et al., 2009; Westermann et al., 2015; Lato et al., 2015).

Bhardwaj et al. (2016) conducted an extensive literature review and pointed out that there is small number of studies using laser scanning for the cryosphere, but the proportion of laser scanning studies mostly use ALS. The usage of TLS was more used to study mountain permafrost such as rockfalls and the movements of rock glaciers (Deline et al., 2008; Avian et al., 2009). 


\subsubsection{Photogrammetry}

Photogrammetry is the use of photography in surveying and mapping to measure distances between objects and produce 3-D images (Ghilani \& Wolf, 2012). There are several different platforms that use photogrammetry (e.g., aerial photography, terrestrial and close-range photogrammetry) (Ghilani \& Wolf, 2012). Since the only photogrammetry method mentioned by Jorgansson and Grosse (2016) to study permafrost environments was Structure from Motion (SfM) this is the method that is discussed in this section.

SfM is a method used to measure distances between objects and produce 3-D images from the platforms. SfM is a photogrammetric technique for estimating three-dimensional structures from two-dimensional images using a sensor and ground control points (Ullman, 1979; Nouwakpo \& Huang, 2012; Nouwakpo et al., 2016). After photos have been taken (e.g., from a unmanned aerial vehicle (UAV)), they are uploaded into a SfM software. Smith et al. (2015) outlined a typical SfM workflow: (1) feature detection, (2) keypoint correspondence, (3) identification of geometrically consistent matches, (4) structure from motion (5) scaling and georeferencing, (6) refinement of parameter values and (7) multi-view stereo image matching. The result is a point cloud that has the estimated values of the structures with an accuracy in the millimeter to centimeter range.

The usage of SfM in permafrost environments is in an early phase. Kääb et al. (2014) used SfM on patterned ground of sorted circles. They found in the fine domain, surface material moves radially outward at horizontal rates of up to $2 \mathrm{~cm}$ per year. The error estimates for vertical precision of the models are of the order of $\pm 6 \mathrm{~mm}$, which is small, but it should be noted that there was no vegetation on the surface.

\subsubsection{Processing of remotely sensed elevation data}

In order to detect the surface when a surface cover is present a process known as filtering usually needs to be done. Filtering removes unwanted data (e.g., surface 
cover) and leaves the useful data (the surface). Several different ways exist to filter depending on the platform and sensor that is chosen (e.g., Evans \& Hudak, 2007; Rodriguez-Caballero et al., 2016). Filtering can be done on the basis of lowest elevations, surface steepness, surface elevation difference, surface homogeneity, segmentation and cluster-based, morphological, and interpolation based (Meng et al., 2009; Meng et al., 2010 Rodriguez-Caballero et al., 2016). This is not an exhaustive list, but just some of the various methods to filter. Each method of filtering comes at a cost and may not actually remove all of the unwanted data or removes some of the useful data.

The lowest elevation filter works by selecting the minimum point in a selected grid cell because it is assumed that it is the ground surface and applying it to the entire cell, thus removing the surface cover. Morphological filters work with object's shape or shape measurement and experiments on LiDAR data have shown that a morphological filter has the ability to remove non-ground objects, such as buildings and trees (Meng et al., 2010). Interpolation filtering works by comparing the elevation of points with its estimated values through different interpolation methods (e.g., linear interpolation). However, this method is difficult to use when applied to surfaces with a rough terrain and/or steep ground slope (Meng et al., 2010).

Both LiDAR and SfM produce point clouds, which can be interpreted in different ways to detect a vertical displacement of Earth's surface. One way is to compare point clouds with point clouds to obtain data of the surface, such as the $\mathrm{M} 3 \mathrm{C} 2$ method (Lague et al., 2013). This method's error range was found to be from $6 \mathrm{~mm}$ to $6 \mathrm{~cm}$ (Lague et al., 2013). Another way is to aggregate and/or interpolate the points into grids known as digital elevation models (DEMs). DEMs are useful to characterize and interpret surficial features, such as: permafrost landforms, surface displacement, and mass movement (Westermann et al., 2015). DEMs assign elevation values for pixels of a designated size. Surface elevation change over time is determined from vertical differences between repeated DEMs. 
Table 2.1: Selected surveying methods to compare usefulness of the data.

\begin{tabular}{|c|c|c|c|c|c|c|c|}
\hline Method & $\begin{array}{l}\text { Spatial } \\
\text { Coverage }\end{array}$ & $\begin{array}{l}\text { Spatial } \\
\text { Resolution }\end{array}$ & $\begin{array}{l}\text { Vertical } \\
\text { Resolution }\end{array}$ & $\begin{array}{l}\text { Vertical Accuracy in } \\
\text { Permafrost Environments }\end{array}$ & $\begin{array}{l}\text { Time Required } \\
\text { to Collect Data }\end{array}$ & $\begin{array}{l}\text { Time Required } \\
\text { to Process Data }\end{array}$ & Selected References \\
\hline Total Station & $\begin{array}{l}\text { Meters to } \\
\text { hundreds of meters }\end{array}$ & Centimeters & $\begin{array}{l}\text { Millimeters } \\
\text { to centimeters }\end{array}$ & $\begin{array}{l}\text { Millimeters } \\
\text { to centimeters }\end{array}$ & Variable & Less than a day & \multirow{4}{*}{$\begin{array}{l}\text { Mackay, } 1976 \\
\text { Little et al., } 2003 \\
\text { Short et al., } 2011 \\
\text { Liu et al., } 2015 \\
\text { Hubbard et al., } 2013 \\
\text { Jones et al., } 2013 \\
\text { Deline et al., } 2008 \\
\text { Avian et al., } 2009\end{array}$} \\
\hline InSAR & Kilometers & $\begin{array}{l}\text { Meters to tens } \\
\text { of meters }\end{array}$ & $\begin{array}{l}\text { Millimeters } \\
\text { to centimeters }\end{array}$ & Centimeters & Days & Days & \\
\hline Airborne LiDAR & $\begin{array}{l}\text { Decameter } \\
\text { to kilometers }\end{array}$ & $\begin{array}{l}\text { Decimeters } \\
\text { to meters }\end{array}$ & Decimeters & Decimeters & Hours & Days & \\
\hline Terrestrial LiDAR & $\begin{array}{l}\text { Meters to } \\
\text { hundreds of meters }\end{array}$ & Millimeters & $\begin{array}{l}\text { Millimeters } \\
\text { to centimeters }\end{array}$ & Decimeters & Hours & Days & \\
\hline SfM & Decameter to kilometers & Millimeters & $\begin{array}{l}\text { Millimeters } \\
\text { to centimeters }\end{array}$ & Centimeters & Minutes to hours & Days & Kaab et al., 2014 \\
\hline
\end{tabular}




\section{Chapter 3}

\section{Study region}

\subsection{Introduction}

In July 2015, field data was collected in the Slave Geological Province, between Great Slave Lake and the Coronation Gulf, in the Northwest Territories, Canada (Northwest Territories Geological Survey, 2015). This chapter describes the location, physical characteristics, and vegetation of the study region.

\subsection{Location}

The study region is located north of the tree line and northeast of Lac de Gras, about $320 \mathrm{~km}$ northeast of Yellowknife, NWT (Figure 3.1). The study region is located on the property of the Ekati Diamond Mine. This was and continues to be an active mine that mainly mines for diamonds. The plots (shown on Figure 3.1) were assumed to be far enough away from the active mines as not to interfere with the results. 


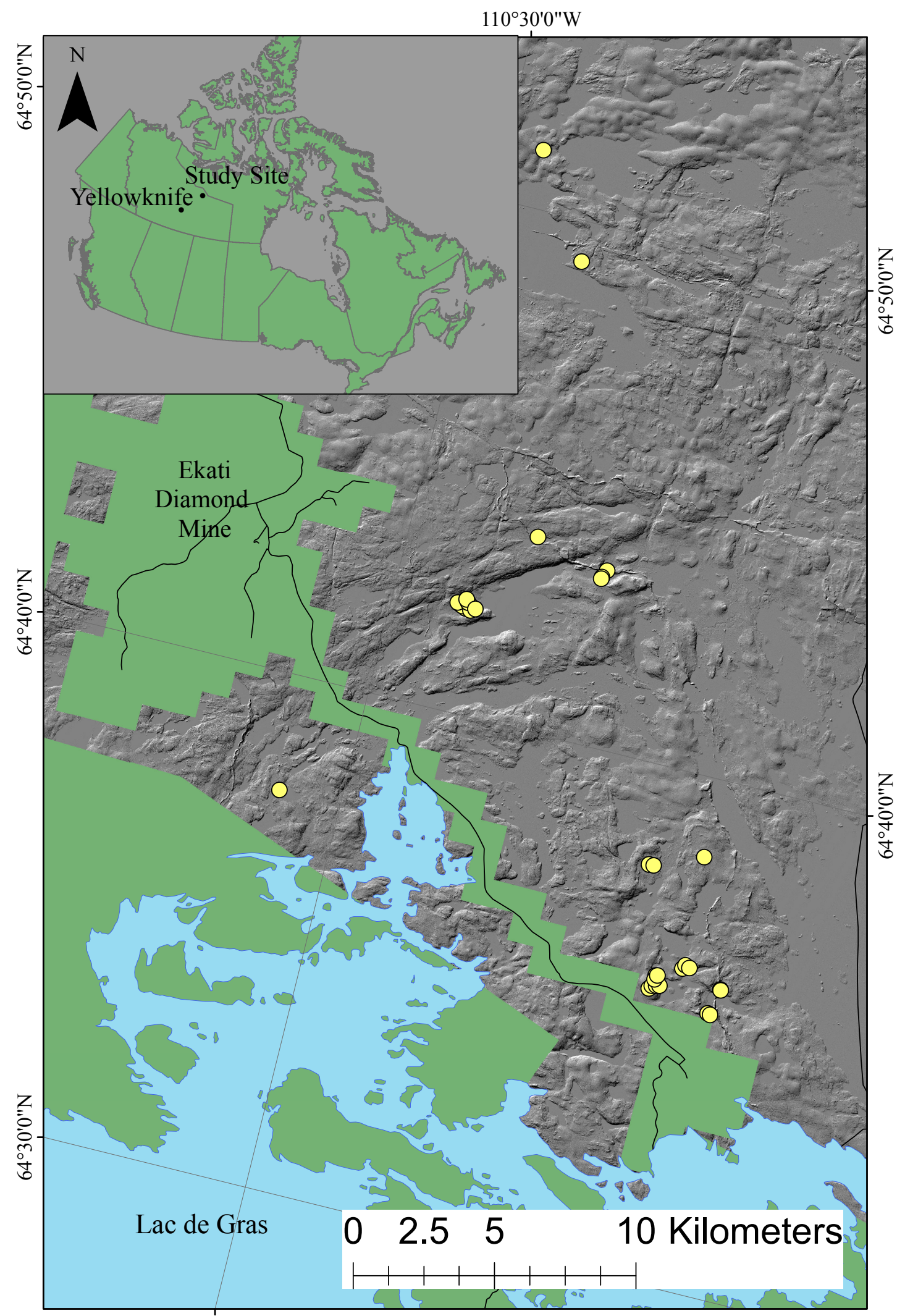

$110^{\circ} 30^{\prime} 0^{\prime \prime} \mathrm{W}$

Figure 3.1: A map showing the study region of the Lac de Gras area. The grey hillshade is based on a DEM derived from airborne LiDAR provided by Dominion Diamond Mines. The green part are the land where no airborne LiDAR data was collected. The yellow dots are the location of the study plots. 


\subsection{Surficial geology}

The glacial features and sediments of the region are related to the Late Wisconsinan Glaciation. The study region became deglaciated and vegetated 9620-8530 years ago (Dredge et al., 1994; Dredge et al., 1999). The most extensive deposit in the region is till, with some widespread glaciofluvial deposits (Dredge et al., 1994). The glaciofluvial features are indicative of warm-based ice conditions, a factor which accounts for a relatively small thickness of permafrost (Dredge et al., 1999). Dredge et al. (1994) divided till into three units based on thickness and surface morphology: veneer, blanket, and hummocky. Till veneers are generally less than two meters thick, contain exposures of bedrock and conform to the underlying bedrock morphology. They are generally loose and their surfaces are characterized by high concentrations of cobbles and boulders. Till blankets are generally greater than two meters thick and drape the underlying bedrock. They tend to be relatively compact and contain fewer boulders than veneers. Hummocky till deposits are greater than five meters thick and form hummocky topography with relief up to thirty meters, which is widespread in the Lac de Gras region (Dredge et al., 1999).

\subsection{Climate}

The climate of the Ekati Diamond Mine is continental to maritime-arctic (Dredge et al., 1999). Since the opening of the mine in 1998, climate data has been collected, however, 1999 was the first year where a complete data set was obtained. Air temperatures are highest in the month of July and lowest in January (Figure 3.2) with a mean annual air temperature (MAAT) of $-8.7^{\circ} \mathrm{C}$ in $1999-2016$. July to September are the months where the most precipitation falls, with August receiving the majority (Figure 3.2). On average there is $283.9 \mathrm{~mm}$ of precipitation per year. 


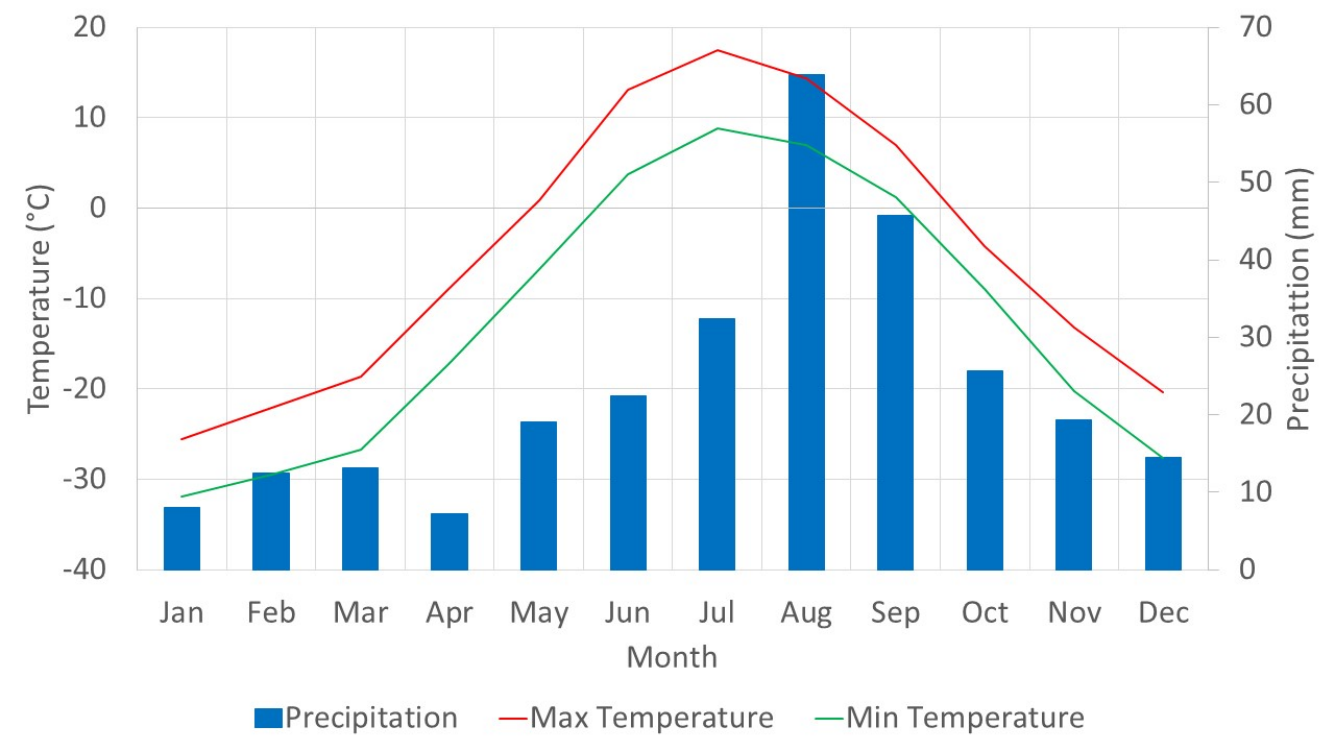

Figure 3.2: A climograph for Ekati Airport (1999-2016) (Environment and Climate Change Canada, 2016), where maximum/minimum temperature are represented by the lines and the precipitation is represented by the bar graph. 


\subsection{Vegetation}

The sub-arctic vegetation is characterized by shrubs, herbs, mosses, and lichens. Bare ground is generally a minor feature and restricted to bedrock outcrops, active frost boils, and glaciofluvial surfaces (Bliss, 1978). The main vegetation in the study area is characterized by continuous shrub tundra, of which northern Labrador tea (Ledum decumbens) and dwarf birch (Betula pumila) are the common shrubs in this region (Karunaratne, 2011). The bog cranberry (Vaccinium vitis-idaea) and dwarf bog rosemary (Andromeda polifolia) are the dominant short shrubs found in the region (Karunaratne, 2011).

In the upland areas, the soil surface is covered by a thin layer of lichen and mosses, due to the well-drained soil conditions ( $\mathrm{Hu}$ et al., 2003). In contrast, the lowland areas have poorly drained soil, which causes the typical Arctic wetland type, consisting of coarse grasses, sedges, mosses, and peat (Hu et al., 2003). The thickest deposits of peat are associated with ice-wedge polygons and sedge meadows, found in depressions underlain by fine-grained sediments that impede drainage (Karunaratne, 2011). Vegetation can be quite lush along drainage courses, willows (Salix spp.) can be found in wet areas where they can be as tall as three meters in height (Hu et al., 2003; Karunaratne, 2011).

\subsection{Active layer and permafrost}

The Lac de Gras Region is located in the zone of continuous permafrost with varying excess ice contents depending on the terrain unit (Subedi, 2017). The active layer depths depend on vegetation cover, subsurface material type, and moisture conditions. They typically range from about $15 \mathrm{~cm}$ in areas supporting a thick organic mat to more than $120 \mathrm{~cm}$ in areas where vegetation cover is thin (Dredge et al., 1999). At Diavik Diamond Mine, approximately, $25 \mathrm{~km}$ south of Ekati, permafrost can reach depths of $250 \mathrm{~m}$ and the mean annual ground temperature at $20 \mathrm{~m}$ below the surface is between $-3{ }^{\circ} \mathrm{C}$ and $-6{ }^{\circ} \mathrm{C}(\mathrm{Hu}$ et al., 2003). 


\section{Chapter 4}

\section{Methods}

\subsection{Study design}

This study used TLS over various surface cover and surface features near the Lac de Gras region. The Lac de Gras region has a typical tundra environment with various surface and subsurface types (section 3.2), including exposed bedrock allowing for anchoring of local benchmarks. A total of 28 study sites in various terrain units were measured. At each site, a detailed checklist was followed to ensure data was collected in a consistent manner (see Appendix A.1) and site specific characteristics were collected (Table 4.2).

The majority of permafrost studies that have used TLS have been for slope failures due to permafrost degradation or mass movements where little to no vegetation was present (Deline et al., 2008; Avian et al., 2009). In this study a TLS and a total station were used to determine uncertainties in detection of subsidence in lowland permafrost environments where vegetation was present.

\subsubsection{Selection of sites}

The selection of sites was based on the airborne LiDAR and imagery dataset provided by the Dominion Diamond Ekati Corporation. LiDAR data was collected in twelve flights between July 23rd and August 11th 2013 at an average flying height of 700 
m above ground level and a forward speed of $230 \mathrm{~km} / \mathrm{h}$. A Riegl Q560 device was used and a laser pulsed at a rate of $123 \mathrm{kHz}$ resulting in an average computed laser point spacing of $0.80 \mathrm{~m}$ and an average point density of 1.6 points per square meter. LiDAR point clouds were classified to different features and bare earth and full feature grids were made available at $1 \mathrm{~m}$ grid resolution. With the available data, sites with different characteristics were chosen ahead of the field campaign. The site selection reflected the aim of the study to sample a variety of surface cover and surface feature to determine the repeatability of a non-contact and contact method. A close proximity (approximately $1 \mathrm{~km}$ ) to bedrock was needed to install multiple local benchmarks. Each site location is stated in decimal degrees (in WGS 84) and can be found in the appendix in Table A.1.

\subsubsection{Grouping of plots}

Surface features, vegetation, and vegetation height were important characteristics when determining surface elevation, active layer thickness, and permafrost temperature (Nelson et al., 1998; Minke et al., 2009; Fan et al., 2014). For that reason, the study plots were grouped based on surface features and vegetation. The surface features of the plots included: blockfields, sand (eskers), hummocks, ice-wedge polygons, and mud boils. Vegetation includes: bearberries, dwarf birch, Labrador tea, lichen, and sedges. Tables $4.1 \mathrm{a}$ and $4.1 \mathrm{~b}$ provide the number of plots in each category.

Grouped plots based on similar surface features and vegetation allowed to understand how much uncertainty that arose in the non-contact and contact methods. Twelve groups that had the same surface features and vegetation were formed (Table 4.2). In Figure 4.1, examples of those groups based on surface features and vegetation are shown. 
Table 4.1: The number of plots associated with the dominant vegetation. It should be noted that the plots are not a full representation of the region.

\begin{tabular}{ll}
\hline Dominant Surface Vegetation & Number of Plots \\
\hline Bearberries & 1 \\
Dwarf birch & 16 \\
Dwarf birch/Labrador Tea & 2 \\
Labrador Tea & 3 \\
Lichen & 1 \\
Lichen/Dwarf birch & 2 \\
Sedges & 5 \\
\hline
\end{tabular}

Table 4.2: The various types of surface features found within the study region.

\begin{tabular}{ll}
\hline Surface features & Number of Plots \\
\hline Blockfield & 5 \\
Esker & 5 \\
Hummock & 5 \\
Ice wedge with hummocks & 6 \\
Mud boil & 7 \\
\hline
\end{tabular}


Table 4.3: The grouping of plots based on surface features and vegetation. The maximum height of vegetation (all vegetation, not just dominant) was collected by hand with a measuring tape.

\begin{tabular}{|c|c|c|c|c|}
\hline Group Number & Site & Surface features & Dominant vegetation & Max vegetation height $(\mathrm{m})$ \\
\hline \multirow[t]{4}{*}{1} & NGO-DD-2030 & Blockfield & Dwarf birch & 0.45 \\
\hline & NGO-DD-2033 & Blockfield & Dwarf birch & 0.45 \\
\hline & NGO-DD-2034 & Blockfield & Dwarf birch & 1.30 \\
\hline & NGO-DD-2035 & Blockfield & Dwarf birch & NA \\
\hline 2 & NGO-DD-2032 & Blockfield & Labrador Tea & 0.40 \\
\hline 3 & NGO-DD-2023 & Sand (esker) & Bearberries & 0.15 \\
\hline 4 & NGO-DD-2026 & Sand (esker) & Labrador Tea & 0.35 \\
\hline 5 & NGO-DD-2020 & Sand (esker) & Lichen & 0.15 \\
\hline \multirow[t]{2}{*}{6} & NGO-DD-2008/2028 & Sand (esker) & Lichen/Dwarf birch & 0.50 \\
\hline & NGO-DD-2029 & Sand (esker) & Lichen/Dwarf birch & 0.40 \\
\hline \multirow[t]{3}{*}{7} & NGO-DD-2013 & Hummock & Dwarf birch & 0.80 \\
\hline & NGO-DD-2015 & Hummock & Dwarf birch & 0.40 \\
\hline & NGO-DD-2016 & Hummock & Dwarf birch & 0.55 \\
\hline \multirow[t]{2}{*}{8} & NGO-DD-1010 & Hummock & Sedges & 0.20 \\
\hline & NGO-DD-2019 & Hummock & Sedges & 0.20 \\
\hline \multirow[t]{3}{*}{9} & NGO-RC-165 & Ice wedge with hummocks & Dwarf birch & 0.70 \\
\hline & NGO-RC-166 & Ice wedge with hummocks & Dwarf birch & 0.40 \\
\hline & NGO-RC-168 & Ice wedge with hummocks & Dwarf birch & 0.70 \\
\hline \multirow[t]{3}{*}{10} & NGO-DD-1005 & Ice wedge with hummocks & Sedges & 0.25 \\
\hline & NGO-DD-2011 & Ice wedge with hummocks & Sedges & 0.30 \\
\hline & NGO-RC-164 & Ice wedge with hummocks & Sedges & 0.40 \\
\hline \multirow[t]{5}{*}{11} & NGO-DD-1004 & Mud boil & Dwarf birch & 0.80 \\
\hline & NGO-DD-2004 & Mud boil & Dwarf birch & 0.40 \\
\hline & NGO-DD-2005 & Mud boil & Dwarf birch & 0.45 \\
\hline & NGO-DD-2007 & Mud boil & Dwarf birch & 0.45 \\
\hline & NGO-DD-2009 & Mud boil & Dwarf birch & 0.75 \\
\hline \multirow[t]{2}{*}{12} & NGO-RC-170 & Mud boil & Dwarf birch/Labrador Tea & 0.70 \\
\hline & NGO-RC-171 & Mud boil & Dwarf birch/Labrador Tea & 0.80 \\
\hline
\end{tabular}




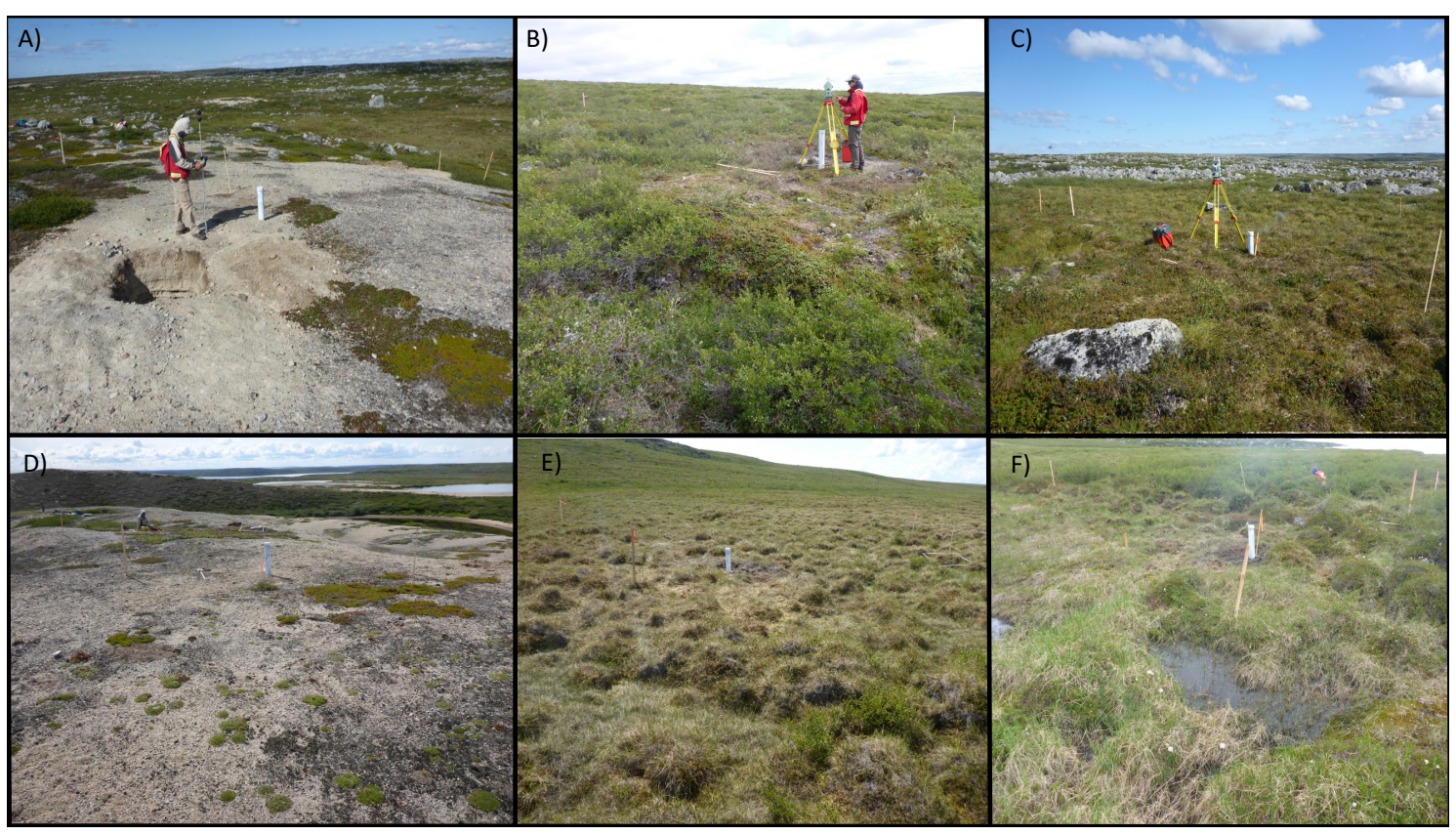

Figure 4.1: Examples of surface features and vegetation. (A) Bearberries on top of an esker, (B) dwarf birch on top of a mud boil, (C) Labrador tea surrounded by a blockfield, (D) lichen on an esker, (E) sedges on hummocks, and (F) sedges and ice-wedge polygons. 


\subsection{Instruments and materials used}

The instruments and materials used for this thesis were: a Leica Nova MS50 MultiStation, GNSS RTK system (Leica Viva CS15 and CS10 Field Controller), a survey pole, two tripods, several different targets including four Leica round prisms (GPR 113), a Leica mini prism (GMP 101), and a Leica $360^{\circ}$ prism (GRZ4), expansion bolts, hammer drill, a measuring tape (for delinating the study plot), and a compass.

The Leica Nova MS50 is a combined terrestrial laser scanner and a total station that features an electro-optical distance measurement system based on the wave form digitizing technology (WFD). WFD is a specific type of a time of flight measurement system which sends out a signal and detects and stores a digital signal vector (Leica Nova MS50 white paper, 2013). The advantages of the WFD technology are the fast distance measurements, small laser dot size, and high measurement accuracy. The accuracy is $1 \mathrm{~mm}+1.5 \mathrm{ppm}$ onto a prism (according to ISO 17123-4) and $2 \mathrm{~mm}+$ 2 ppm for measurements onto any surface (Leica Nova MS50 white paper, 2013).

The GNSS RTK system has an accuracy that is dependent upon various factors including the number of satellites tracked, constellation geometry, observation time, ephemeris accuracy, ionospheric disturbance, multipath and resolved ambiguities. Therefore, the accuracy varies, however, Leica Geosystems states a vertical of accuracy for static surveys to be $10 \mathrm{~mm}+0.5 \mathrm{ppm}$ and $20 \mathrm{~mm}+1 \mathrm{ppm}$ for kinematic surveys (Leica CS10/CS15 \& GS sensors user manual). Since the MS50 has a higher accuracy than the GNSS RTK system a local grid was implemented in order to have a smaller uncertainty in the vertical measurement (Section 4.3.3).

\subsection{Survey methods}

\subsubsection{Plot preparation}

Upon arrival at the study site a plot with a length and width of approximately 15 meters was created and situated northwards. The plot was delineated with four wooden slats to mark the corners. The Leica Nova MS50 was set up in the middle of 
the plot, the atmospheric conditions (temperature, pressure, humidity) were entered to the MS50 (to correct for the atmospheric errors), and a north orientation was set by using a compass that was corrected for declination (Figure 4.2). Simultaneously, a Global Navigation Satellite System (GNSS) Real-Time Kinematic (RTK) mobile base station was set up on a tripod away from the plot. A $360^{\circ}$ scan was set up from inside the plot and took about an hour to complete. While this occurred, local benchmarks were installed.

\subsubsection{Local benchmarks}

Study sites relatively near to bedrock (within 1-2 km) were selected for the purpose of installing multiple local benchmarks, most of the time there were four benchmarks that were installed, however, in a few cases three benchmarks were installed due to the lack of bedrock. A hammer (Hilti) drill was used to drill into bedrock using a 3/8" drill bit. Then an air bulb was used to blow out the rock debris that was created by drilling. A 3/8" expansion bolt was then hammered into the hole and an adapter was screwed onto the expansion bolt so a reflector/prism (e.g., Leica round prism, GPR 113) could be placed on the adapter without moving (Figure 4.3). A larger hole (5/8") was drilled near the benchmark as a reference hole (Figure 4.3). This reference hole was made as a fall-back solution in case the bolt got damaged. If the benchmark was tampered with then the hole could be used, but someone would have to hold the prism in place. The holes and local benchmarks were measured with the Leica MS50 (Figure 4.3) in a local coordinate system as well as the Leica GNSS RTK (Viva GS14) rover to retrieve geographic coordinates. The local coordinates of the benchmarks served as reference points for when the station was moved so it remains comparable in the local grid without the additional error of GNSS navigation. As such, the GPS coordinates were only used to determine where the four corners of the plot were and not used to georeference the data. 


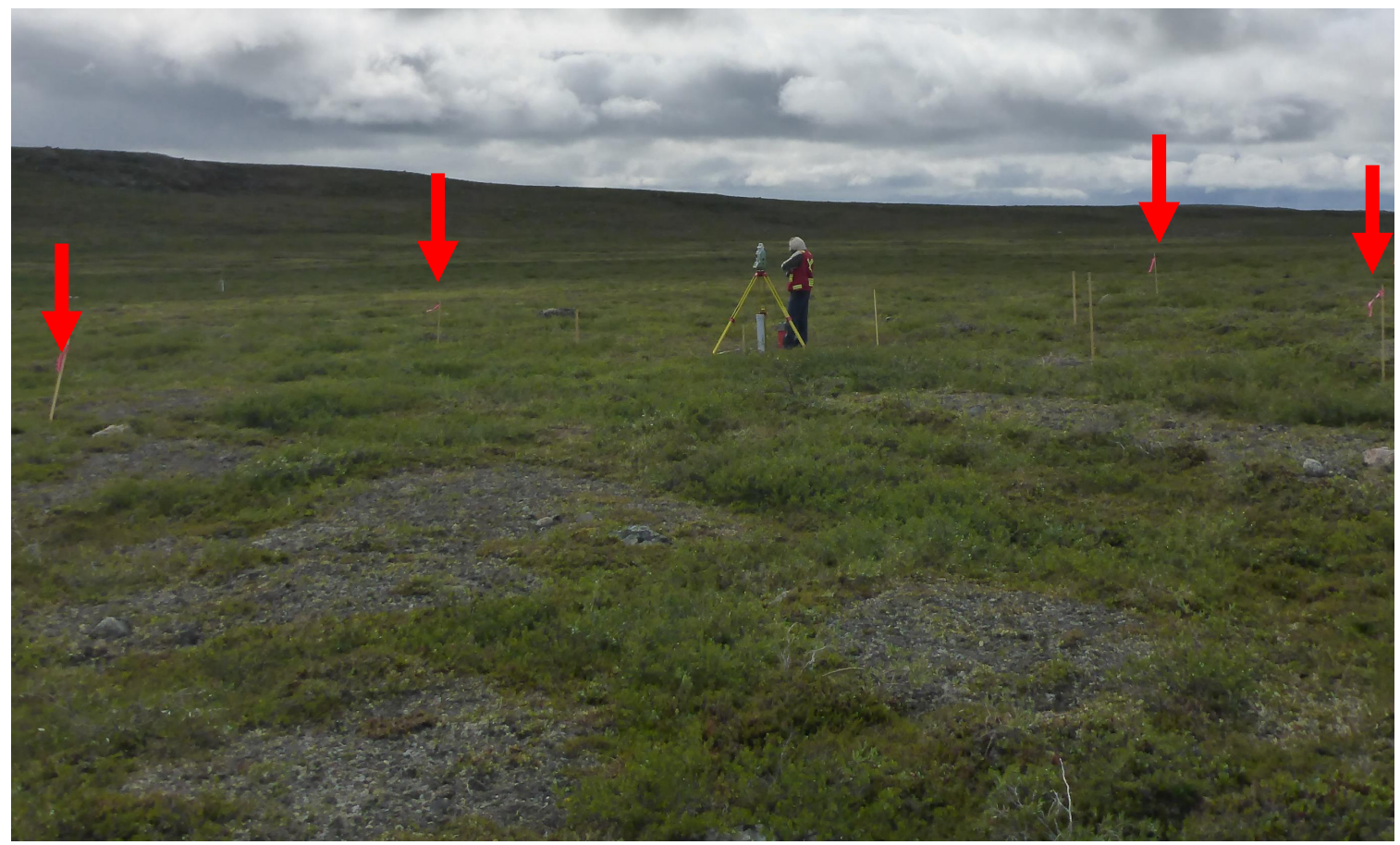

Figure 4.2: A typical set up of a plot. The red arrows show the corners of the plot. The MS50 (the TLS and total station) is situated in the middle of the plot. 


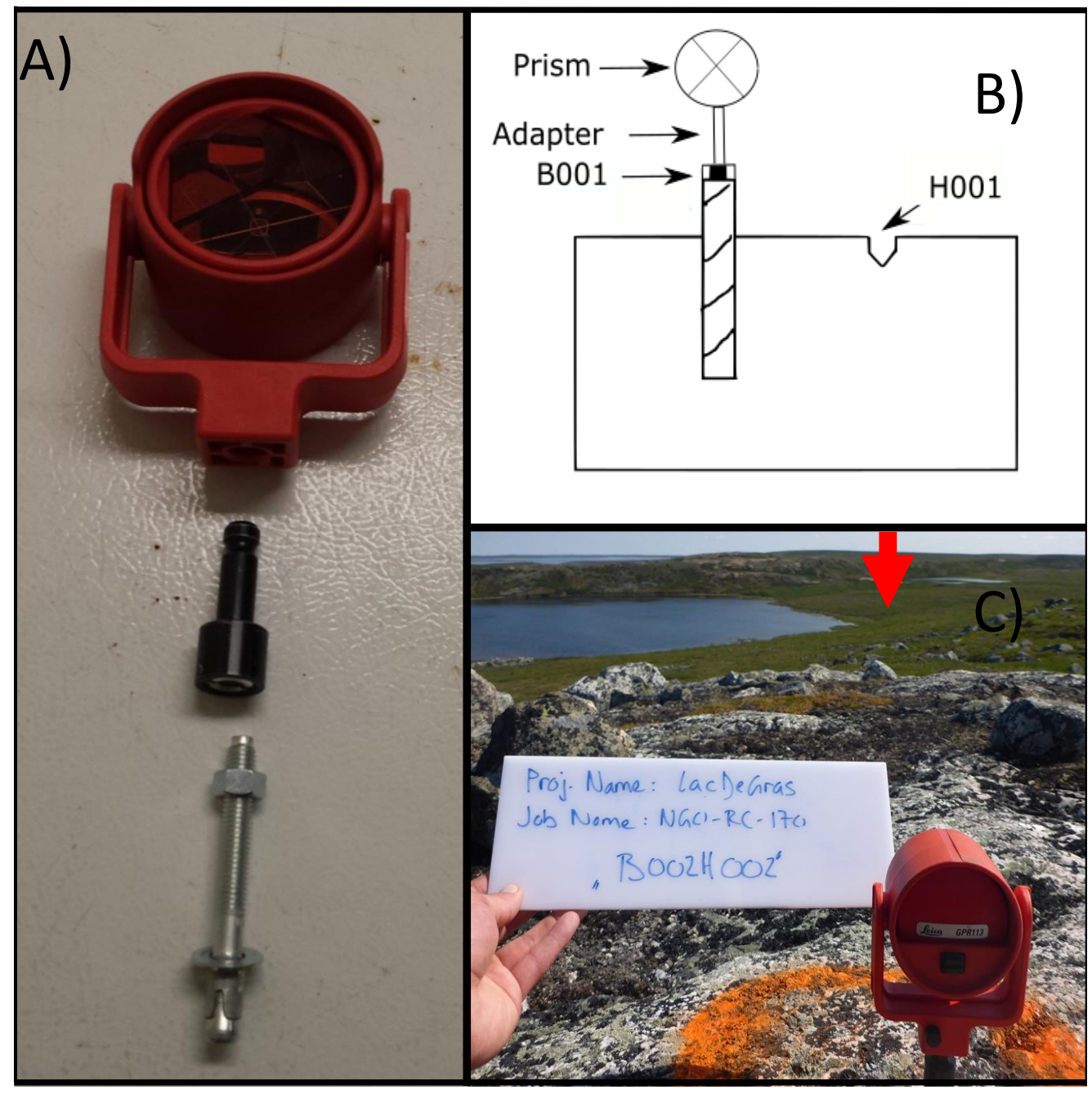

Figure 4.3: This figure shows the benchmark set up. (A) The components of a local benchmark. The Leica round prism attached to the adapter, which screwed onto the expansion bolt anchored into bedrock, which allowed for a permanent position of the benchmark and provided a fixed location for the re-occupation of a prism for future studies. In (B) a sketch of the cross section of bedrock, a local benchmark, and a hole beside the local benchmark are visible. B001 and H001 are the naming convections, where B represents benchmark and $\mathrm{H}$ represents hole. In (C) an installed local benchmark in bedrock with an orange spray-painted circle around it for ease of finding the benchmark are visible. The red arrow (to the left of the $\mathrm{C}$ ) indicates the position of the MS50. 


\subsubsection{Local grid}

After the local benchmarks were installed, a local Cartesian grid was created with the MS50. The origin of the local grid was centred in middle of the plot and used artificial coordinates $($ Easting $=1000 \mathrm{~m}$, Northing $=2000$, Elevation $=100 \mathrm{~m}$ ). The MS50 would then measure the local benchmarks and calculate their position relative to the origin.

Measurements in the local grid allowed for smaller errors in the vertical direction than with the use of a GNSS device. The local grid also allowed the Leica Nova MS50 to be moved to different positions to scan the plot from different views, all while it remained in the same coordinate system. This was done by a method known as resection. Resection is a method to determine an unknown point by measuring angles and distances in relation to known points (the local benchmarks). This was completed by the use of the resection function on the MS50. After a resection was completed the MS50 would return statistics on the overall quality of the resection. Each resection produced a different overall quality. The absolute maximum error of all resections was $1.3 \mathrm{~cm}$ for the vertical direction, with an average maximum error of $0.7 \mathrm{~cm}$. For a more extensive list of maximum vertical error from resections per plot see Table A.2 in the appendix.

\subsubsection{Scanning}

After the local grid was created, the MS50 scanned the plot from the inside (scan name S001C001), which made the point cloud look like a donut. The resolution was determined in-situ, which allowed for denser scans if time permitted. Typically, the scan with the MS50 inside the plot was set with a resolution of $5 \mathrm{~cm}$ for both the vertical and horizontal component. After the donut scan was completed the MS50 was removed from the center of the plot to the outside of the plot and then scanned the plot. The resolution for scans done outside of the plot was set to $2 \mathrm{~cm}$ for the vertical and horizontal component. The area scanned was larger than the plot to ensure the entire plot was scanned from each orientation. On average a scan that 
has about 250,000 points for the plot takes about 15-20 minutes to complete. When one scan was completed, the scanner was moved to a different side of the plot to capture a different view. A resection to the benchmarks was performed each time the MS50 was moved and then another scan was completed in the same local coordinate system.

\subsubsection{Point surveys}

After the scanning was completed, point surveys were conducted. The mode of the MS50 was changed from a TLS to a total station and the survey pole was used. Since the pole would sit on the surface and the bottom of the pole was manufactured to be pointed, it would sink into the surface. Consequently, three different attachments were created to be used in an experiment to investigate surface ambiguity and the resulting differences between the attachments (Section 5.3). The three attachments are as follows: a medium attachment, a wide attachment, and a needle attachment (Figure 4.5). From the experiment, one attachment (the medium attachment) was chosen to survey the plots and for the analysis.

A Leica $360^{\circ}$ prism was attached to the top of the survey pole and the medium attachment was placed on the bottom of the survey pole. The pole with the prism attached, sat (by its own weight) on the surface or surface cover. Then the MS50 would shoot a laser pulse to the prism to measure the elevation of the survey point (Fig 4.4). The person with the survey pole would walk inside the plot and take 50 point elevations to best represent the plot. It would take about 30 minutes to obtain 50 arbitrarily sampled manual points across the plot. 


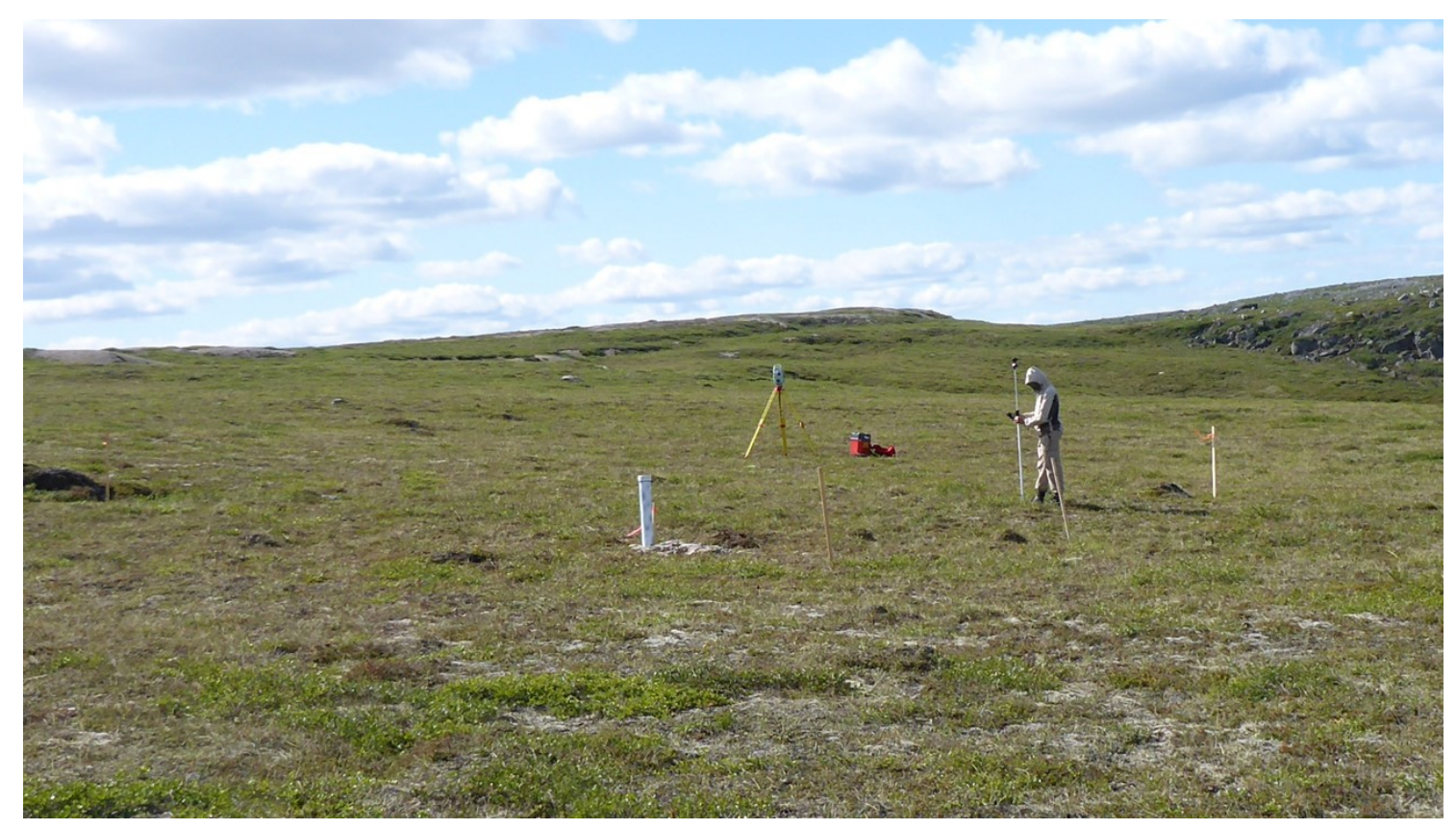

Figure 4.4: A typical collection of points surveys. A person moved around the plot while the MS50 followed the prism on the pole and obtains point data of the surface. 


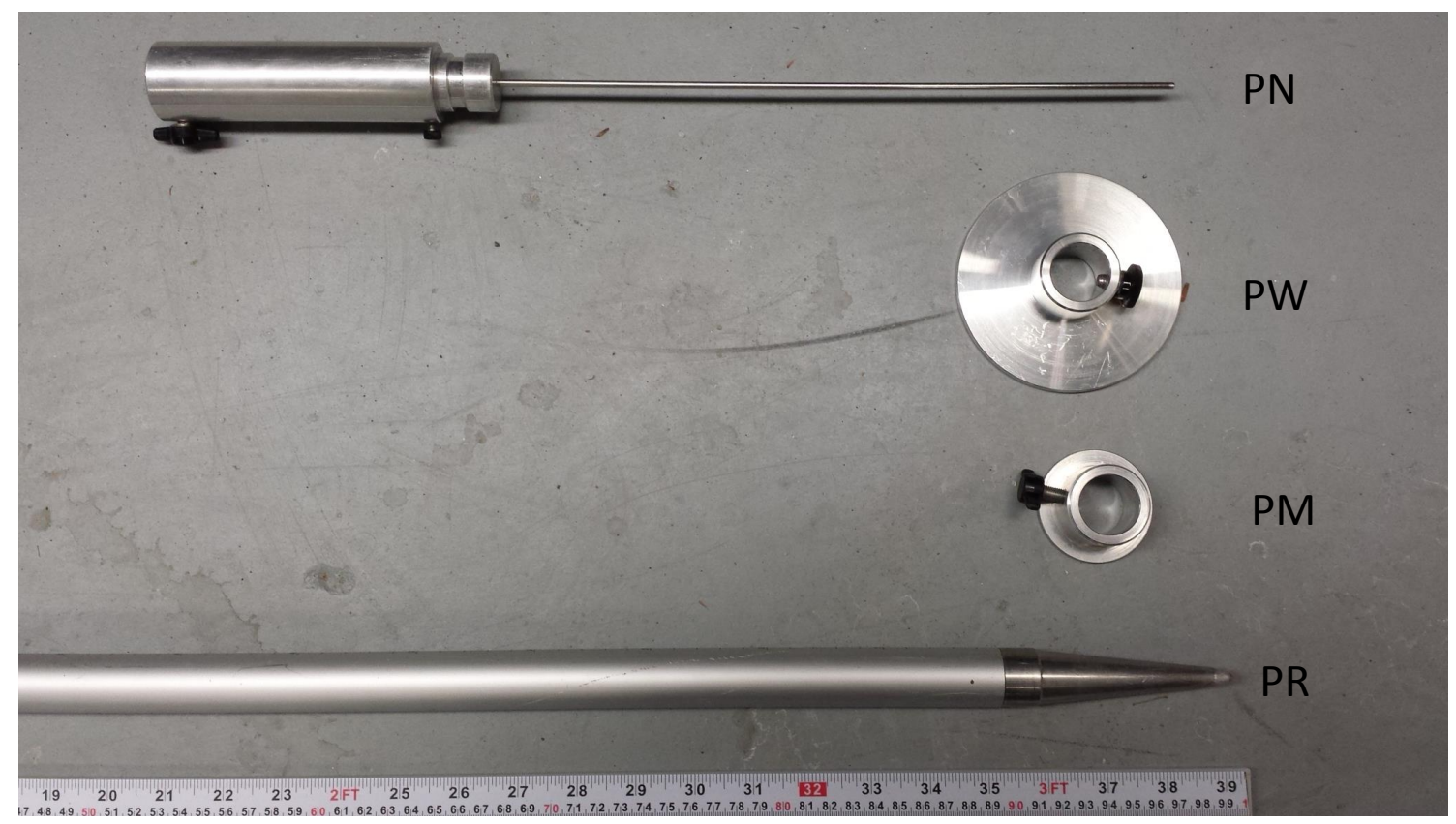

Figure 4.5: Each attachment gives a different representation of a surface. The needle attachment $(\mathrm{PN})$, the wide attachment $(\mathrm{PW})$, the medium attachment $(\mathrm{PM})$ and the regular bottom of the pole $(\mathrm{PR})$ are shown. A ruler was used for scale. The notations for the listed attachments are PN for needle point, PW for wide point, PM for medium point, and PR for regular point. 


\subsection{Processing}

\subsubsection{Exporting scans}

MS50 data was exported as a proprietary .dbx file (scan data) and an .xml file (survey data). The .dbx file was imported in the Leica Infinity software. Leica Infinity is proprietary software that is a geospatial office suite made for professional surveyors. The scans were exported as a las format with specific naming conventions. The naming convention of the scans is as follows: S00XC00Y, where X and Y are both integers. The S stands for station and C represents the point cloud scan. An example would be S001C001. This would mean it was at first station point and the first scan that was done from that station. After all the scans were exported they underwent processing into a raster. It should be noted that all scans that were taken from inside the plot were labelled as S001C001. When scans have a different X value it meant the scan was taken from outside of the plot.

\subsubsection{Point clouds to grids}

A set of dedicated tools were developed in Python software to make the grid-based processing of scans effective and reproducible. This program was developed by Dr. Stephan Gruber and allows the reading of the native .xml file and .las files.

The Python code parses the .xml file and reads the scans individually. It then takes the las file (point cloud) and then overlaid a grid of $1 \mathrm{~m} \times 1 \mathrm{~m}$ resolution per .las file (Figure 4.6). For combined/merged scans, the code layered all of the las files over each other then overlaid a grid of $1 \mathrm{~m} \times 1 \mathrm{~m}$. The resolution of the grid can be modified, but for this research it was set to a $1 \mathrm{~m} \times 1 \mathrm{~m}$. A minimum number of points in each $1 \mathrm{~m} \times 1 \mathrm{~m}$ cell of must be present for statistics to be returned, if the minimum number of points per grid are not met then no data is presented. For this research the minimum number of elevation points per cell was set at 50 . 


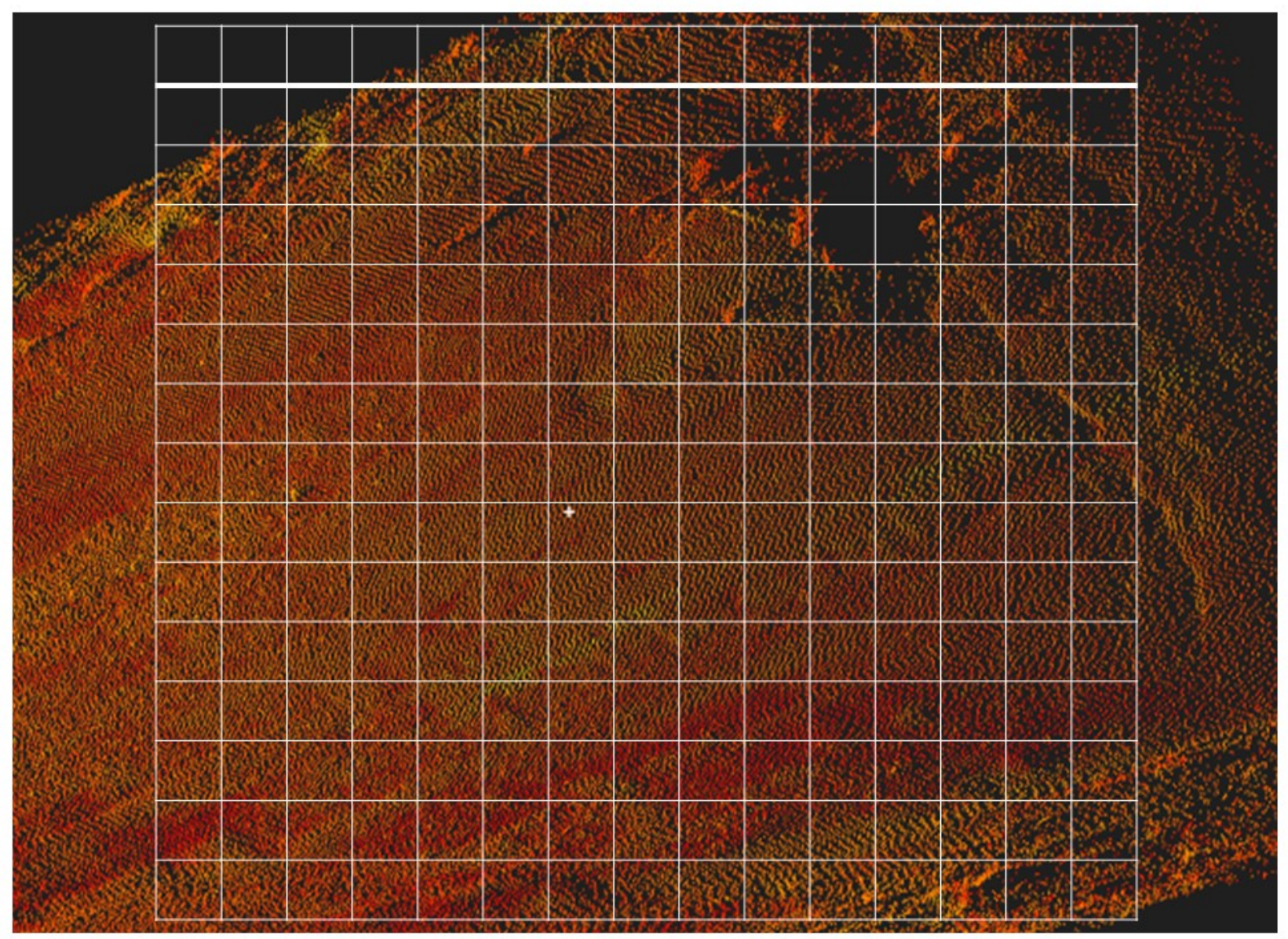

Figure 4.6: Here a point cloud from the MS50 is shown. It then was processed by the Python code to overlay a $15 \mathrm{~m} \times 15 \mathrm{~m}$. In the upper left hand corner there is less than 50 points in the $1 \mathrm{~m} \times 1 \mathrm{~m}$ cell, therefore, no data was returned for the cell. In the middle of the grid there was more than 50 points in the cell, which resulted in taking the lowest elevation point of that of the point cloud and applied it to the cell. 
Considering that each cell contained a mix of vegetation and surface elevation, filtering the data must be considered. The filtering method that was selected was the local-lowest-point filter which has been used by several researchers (e.g., Wang et al., 2009; Coveney \& Fotheringham, 2011; and Fan et al., 2014). It was chosen because of the ease of use and it is a method that works well with little variation in elevation (Fan et al., 2014). In this method, the local minimum elevation point per cell is applied because it is assumed to be the bare surface. The only parameter affecting the selection of the lowest point per cell is the resolution of the grid. There are no set standards for determining the resolution. However, a coarser resolution is likely to capture a point closer to the bare ground, and hence reduces the overall vegetation-induced elevation error. However, too coarse of a spatial resolution may not capture the average elevation of an undulating surface.

After each scan and combined scan per plot was processed, the custom Python code would produce American Standard Code for Information Interchange (ASCII) files of the data. These ASCII files were then imported into the programming language $\mathrm{R}$ for raster processing and analyses. RStudio is a free and open-source integrated development environment for $\mathrm{R}$, a programming language for statistical computing and graphics.

\subsubsection{Raster and total station processing}

The custom $\mathrm{R}$ code reads the ASCII grids from the Python code by using the Raster package in RStudio. Since the original scans were larger than the plots the rasters were cropped to the plot outline, which resulted in about 225 grid cells per plot. The minimum elevation in each grid cell with sufficient data was regarded as one measurement and processed with the bootstrap method, using the Boot package in RStudio to compute the confidence interval for the mean bare surface elevation of the entire plot. This was done because when calculating normal confidence intervals there are assumptions that must be made (e.g., data must be normally distributed), and that cannot be ascertained for the collected data. To avoid transformations of 
the non-normally distributed data to normally distributed data the non-parametric bootstrap method was used. Additionally, the bootstrap method created an equal number of re-sampled data for both methods. Furthermore, the bootstrap method is more accurate than the use of standard intervals obtained by sample variance and assumptions of normality (DiCiccio \& Efron, 1996).

The Boot package works as a computer-based method by re-sampling data with replacement $\mathrm{N}$ number of times, in this case 1000 times, to approximate the mean of the population. The Boot package took the filtered TLS data and drew 1000 values with replacement. It then calculated an estimated mean from the re-sampled data. This process was repeated 1000 times, which generated a sampling distribution of 1000 means. The re-sampled distribution of data produced by the Boot package did not produce the same distribution of the original data that was collected in the field. Re-sampling of data essentially takes advantage of the central limit theorem, which states that if a sufficiently large number of random samples are taken then the distribution from repeated sampling will approach normality. This results in the re-sampled data being normally distributed, and simultaneously produces a similar result (e.g., mean) to the actual data (Efron, 1979; Efron \& Tibshirani, 1986). Finally, the boot package then assigned measures of accuracy to the statistical estimates of the data (e.g., standard error of the mean) (Efron, 1979; Efron \& Tibshirani, 1986; Efron \& Tibshirani, 1993; Canty \& Ripley, 2017). After the data underwent the bootstrap method the result was a normal distribution of the average surface elevation. This data was then plotted as a beanplot in RStudio using the Beanplot package to display the distribution. Since the re-sampled data was parametric, the normal approximation in the boot package was used to calculate the confidence intervals. This method worked by taking the mean from the re-sampled data and then plus/minus the standard error (of the set of data) multiplied by 1.96 (for a confidence value of $95 \%$ ) to give both the minimum and maximum confidence intervals for the 95\% level, from the "boot.ci" command in RStudio. This method was then repeated using the total station data. 
After the means and the 95\% confidence intervals were calculated for both the TLS data and total station data the means were statistically compared by using a t-test to determine if the means were statistically different. The assumptions for the t-test were to have normally distributed data and with equal variances (homoscedastic). To test for normality, the data underwent three tests. The first test was to observed the distribution of data to determine if it resembled a typical parametric distribution, which the data in this thesis followed. However, there were times that visually it did not appear this way (Figure 6.3). The next test that was performed was a quantile-quantile (QQ) plot. If the data on a QQ plot was a linear line then it suggests the data is normal, which the data in this thesis followed. Finally, a Shapiro-Wilk test was used to determine if the data came from a normally distributed population. The null hypothesis of the Shapiro-Wilk test is that the population of the data is normally distributed. The data from this thesis resulted in having a p-value of greater than 0.05 for both the TLS and total station method, as such the null hypothesis was accepted. The next step was to determine if the t-test assumptions were met for equal variance. The "var.test" command was used in RStudio to determine if the variances were equal or not. It resulted in the variances of the TLS data and the total station data to not be equal. As a result, the data did not follow with the second assumption, as such, a modified t-test where the variances were not equal was used. This test is known as the Welch's t-test. A Welch's t-test corrects for the problem of unequal variances by estimating variances and adjusting the degrees of freedom (Welch, 1947; Yuen, 1974). In RStudio the "t.test" command was used and the variance was set to false, which meant the data did not have equal variances. The null hypothesis for a Welch's t-test is the results of the compared data are similar. When the p-values were calculated comparing the TLS to the total station with the medium attachment all of the p-values were less than 0.05 , which meant that the null hypothesis must be rejected and the alternative hypothesis must be accepted. Finally, Figure 4.6 shows a flow chart of the procedures of processing data after the field data has been obtained. 


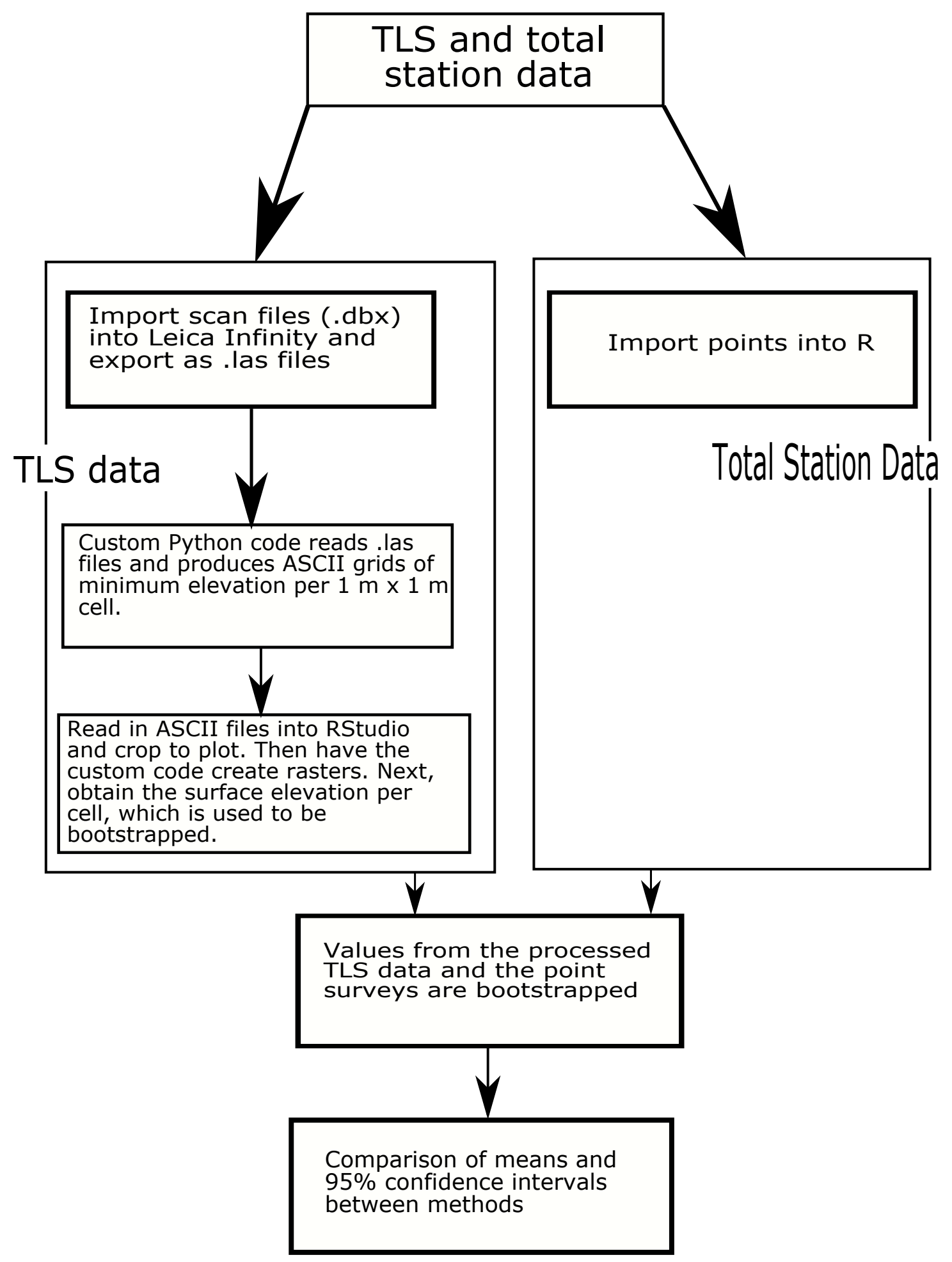

Figure 4.7: Workflow to process TLS and total station measurements. At the top the TLS and total station data was collected. On the right hand side shows a simplified work flow of how TLS data was processed. On the right hand side the total station points are shown. Since the total station points did not have to undergo any filtering their points were processed with the filtered TLS data, bootstrapped, and then were compared. 


\subsubsection{Potential minimum vertical detection limit}

To estimate the detection limit of an elevation difference from each method, one needs to propagate the potential uncertainties of two surveys (of the same method) from the 95\% confidence interval estimate (Wheaton et al., 2010). The formula is below:

$$
\Delta L=\sqrt{L_{1}^{2}+L_{2}^{2}}
$$

where $\Delta \mathrm{L}$ is the propagated uncertainty of the two surveys, $\mathrm{L}_{1}$ is uncertainty from the first measurement, and $\mathrm{L}_{2}$ is the uncertainty from the second measurement. Since there is no data for a second survey, but the $95 \%$ confidence intervals of combined points clouds for separate dates assumed to be somewhat similar (see section 6.2) the same confidence interval from $\mathrm{L}_{1}$ are used as $\mathrm{L}_{2}$ to produce a potential minimum vertical change detection limit. Furthermore, because the combined scans have similar confidence intervals they were compared to the total station's confidence intervals for simplicity. 


\section{Chapter 5}

\section{Experiments conducted to test method uncertainty and surface}

ambiguity

\subsection{Introduction}

Permafrost environments pose a challenge to TLS and usage of total station. With modern methods and instruments, surveying a smooth surface (e.g., a road) can be measured with millimeter accuracy. However, in natural environments, the surface is not clearly defined because when vegetation is present it can interfere with the instruments. In addition to surficial characteristics the spatial scale is important. The scale must be determined in order to capture the phenomenon. This short chapter introduces different field experiments that were conducted to test the uncertainty of the MS50 on man-made and natural environments and the ambiguity of the surface to derive elevation.

\subsection{Man-made environment: laser scanning a highway}

On June 25, 2015, a small portion of Highway 3 (about $20 \mathrm{~km}$ west of Yellowknife, Figure 5.1) was scanned several times from different locations. All the scans were 
done on the same day because one would not expect the surface elevation of the highway to change in that short period of time. On August 28, 2015 and August 11, 2016, the highway was re-scanned to determine it was possible to detect and quantify the amount of change in surface elevation. It should be noted that manual survey points were not taken on the highway due to safety concerns.

This experiment was conducted to address two concerns. One, to determine the overall uncertainty of the TLS on a relatively smooth man-made surface, in this case a highway; and two, if detecting subsidence in a short time was possible for this method on a man-made surface. 


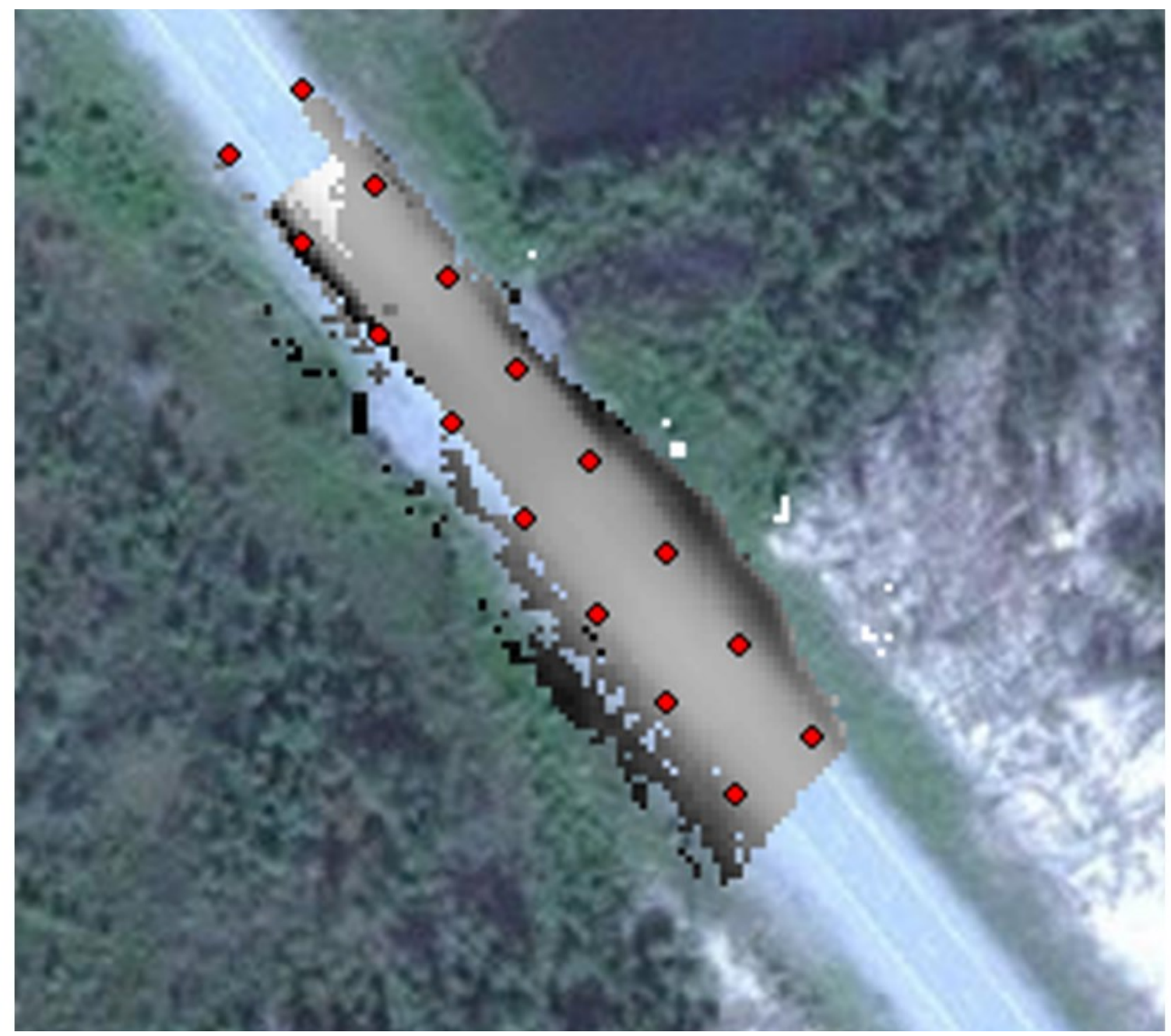

Figure 5.1: The portion of Highway 3 about $20 \mathrm{~km}$ west of Yellowknife that was surveyed. The grayscale represents the scans of Highway 3, with red dots outlining the edge of the road. 


\subsection{Surface ambiguity of natural tundra surfaces}

On July 1, 2015, at the Harry Winston camp in the NWT (64 ${ }^{\circ} 11^{\prime} 34^{\prime \prime}$ N $110^{\circ} 32^{\prime} 20^{\prime \prime}$ W), fifty repeated point measurements, with all of the different attachments for the survey pole and scans were taken of various surface covers on a flat top esker (Figure 5.2). There was bare sand, low vegetation, and taller vegetation. On July 21, 2016, in Yellowknife, NWT (62 $\left.27^{\prime} 23^{\prime \prime} \mathrm{N}, 114^{\circ} 22^{\prime} 40^{\prime \prime} \mathrm{W}\right)$ repeated point measurements (with all the different attachments of the survey pole) and scans were taken of a flat organic soil surface with no vegetation with an area approximately $9 \mathrm{~m}^{2}$ (Figure 5.3). These tests were conducted to determine how well repeat measurements of elevation could be compared when differing methods and instruments were used. This experiment also demonstrates how well the surface can be defined. 


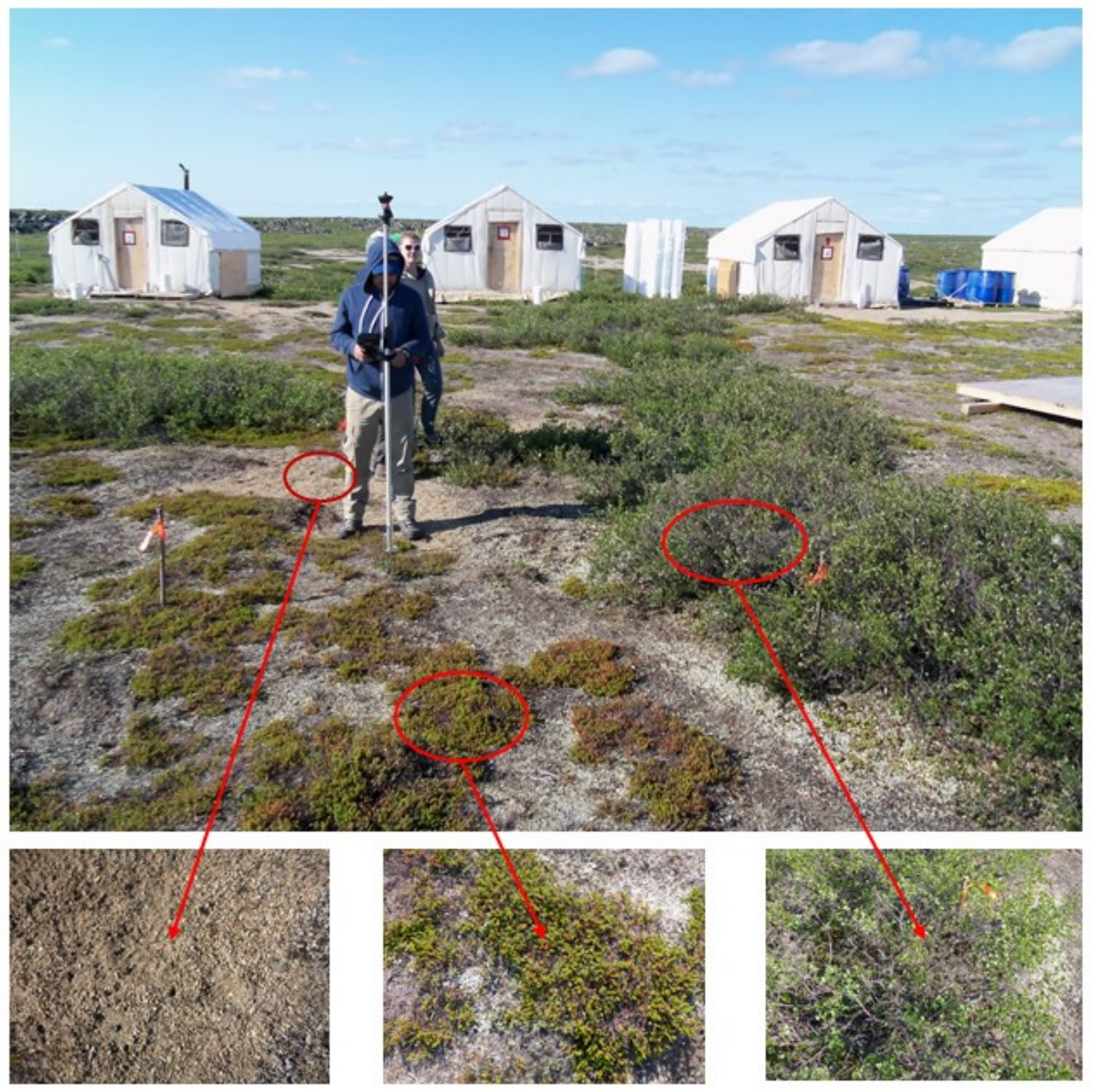

Figure 5.2: Experiment of different surface conditions in a $3 \mathrm{~m}$ by $3 \mathrm{~m}$ area. Three red circles show the different conditions. The left image shows a bare surface, the middle image shows short vegetation on the surface, and the right image shows tall vegetation. 

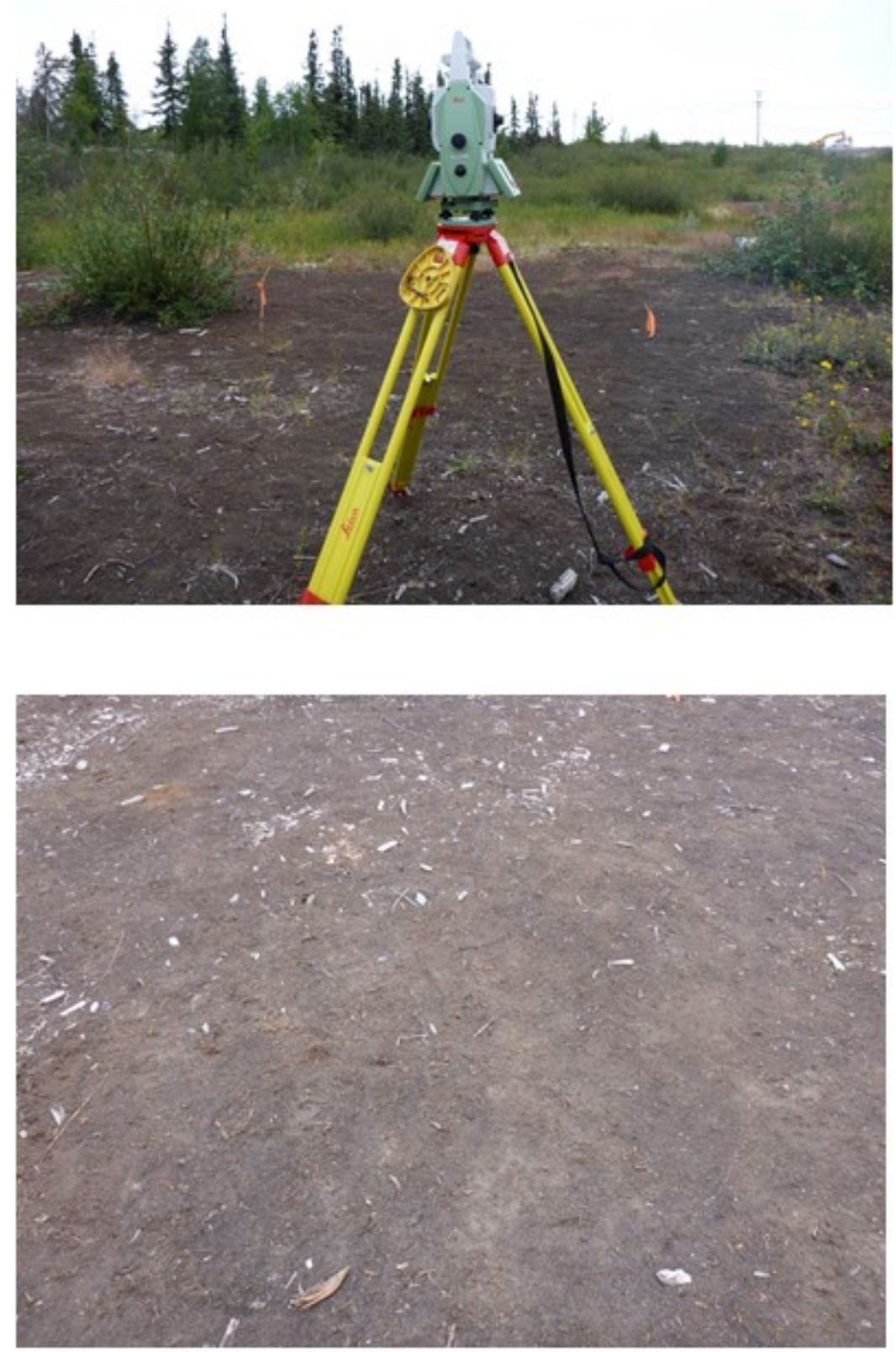

Figure 5.3: Experimental site in Yellowknife with an organic surface. 


\subsection{Tundra plots near Lac de Gras}

For the month of July 2015, 28 plots (Figure 3.1) with various terrain units and different vegetation near Lac de Gras were measured for surface elevation using TLS and a total station (see Table A.1 for the geographical coordinates for each plot). All the measurements were conducted on the same day because the surface elevation was not expect to change in that short period of time. At each site, a detailed checklist was followed to ensure data was collected in a consistent manner (see Appendix A.1). This experiment was conducted to determine the overall uncertainty of the TLS and a total station on a natural tundra environment. 


\section{Chapter 6}

\section{Results}

\subsection{Introduction}

The results section is broken up into three sections distinguished by the purpose of each experiment. The first section (section 6.2) shows the results of deriving the surface elevation of a man-made surface. The second section (section 6.3) presents the results of the surface ambiguity of natural surfaces. Finally, the third section (section 6.4) reveals the results of deriving the surface elevation of a natural tundra environment. It should be noted that the resections error values are not incorporated into these results. More on this in section 7.5.

\subsection{Laser scanning a relatively smooth man-made surface}

An area of approximately $1220 \mathrm{~m}^{2}$ of Highway 3 was scanned. From the area scanned, a subsect of approximately $232 \mathrm{~m}^{2}$ was designated as the plot to be similar in area as the plots in the Lac de Gras region. The associated metrics for Highway 3 are shown in Table 6.1. The mean and confidence intervals for repeated scans on one day were plotted in Figure 6.1. It should be noted that all the means are statistically different at a $95 \%$ confidence level. 
Table 6.1: Scans and the associated data of the plot from Highway 3. The uncertainty is the range of the maximum confidence interval (CI) minus the minimum CI.

\begin{tabular}{lllllll}
\hline Scan name & $\begin{array}{l}\text { Date } \\
(\mathrm{mm} / \mathrm{dd} / \text { yyyy })\end{array}$ & Mean $(\mathrm{m})$ & $\begin{array}{l}\text { Max CI } \\
(\mathrm{m})\end{array}$ & $\begin{array}{l}\text { Min CI } \\
(\mathrm{m})\end{array}$ & $\begin{array}{l}\text { Uncertainty } \\
(\mathrm{m})\end{array}$ & $\begin{array}{l}\text { Potential min } \\
\text { detection limit } \\
(\mathrm{cm})\end{array}$ \\
\hline S001C001 & $06 / 25 / 2015$ & 178.278 & 178.285 & 178.271 & 0.014 & 2.0 \\
S002C001 & $06 / 25 / 2015$ & 178.272 & 178.284 & 178.260 & 0.025 & 3.5 \\
S007C001 & $06 / 25 / 2015$ & 178.286 & 178.296 & 178.275 & 0.021 & 3.0 \\
Combined & $06 / 25 / 2015$ & 178.274 & 178.282 & 178.266 & 0.016 & 2.3 \\
& & & & & & \\
S008C001 & $08 / 28 / 2015$ & 178.260 & 178.268 & 178.252 & 0.016 & 2.3 \\
S009C001 & $08 / 28 / 2015$ & 178.268 & 178.276 & 178.260 & 0.016 & 2.3 \\
Combined & $08 / 28 / 2015$ & 178.259 & 178.267 & 178.251 & 0.016 & 2.3 \\
& & & & & & \\
S020C001 & $08 / 11 / 2016$ & 178.243 & 178.253 & 178.234 & 0.019 & 2.7 \\
S021C001 & $08 / 11 / 2016$ & 178.232 & 178.241 & 178.224 & 0.018 & 2.5 \\
S023C001 & $08 / 11 / 2016$ & 178.239 & 178.247 & 178.230 & 0.017 & 2.4 \\
Combined & $08 / 11 / 2016$ & 178.243 & 178.252 & 178.234 & 0.017 & 2.4 \\
\hline
\end{tabular}



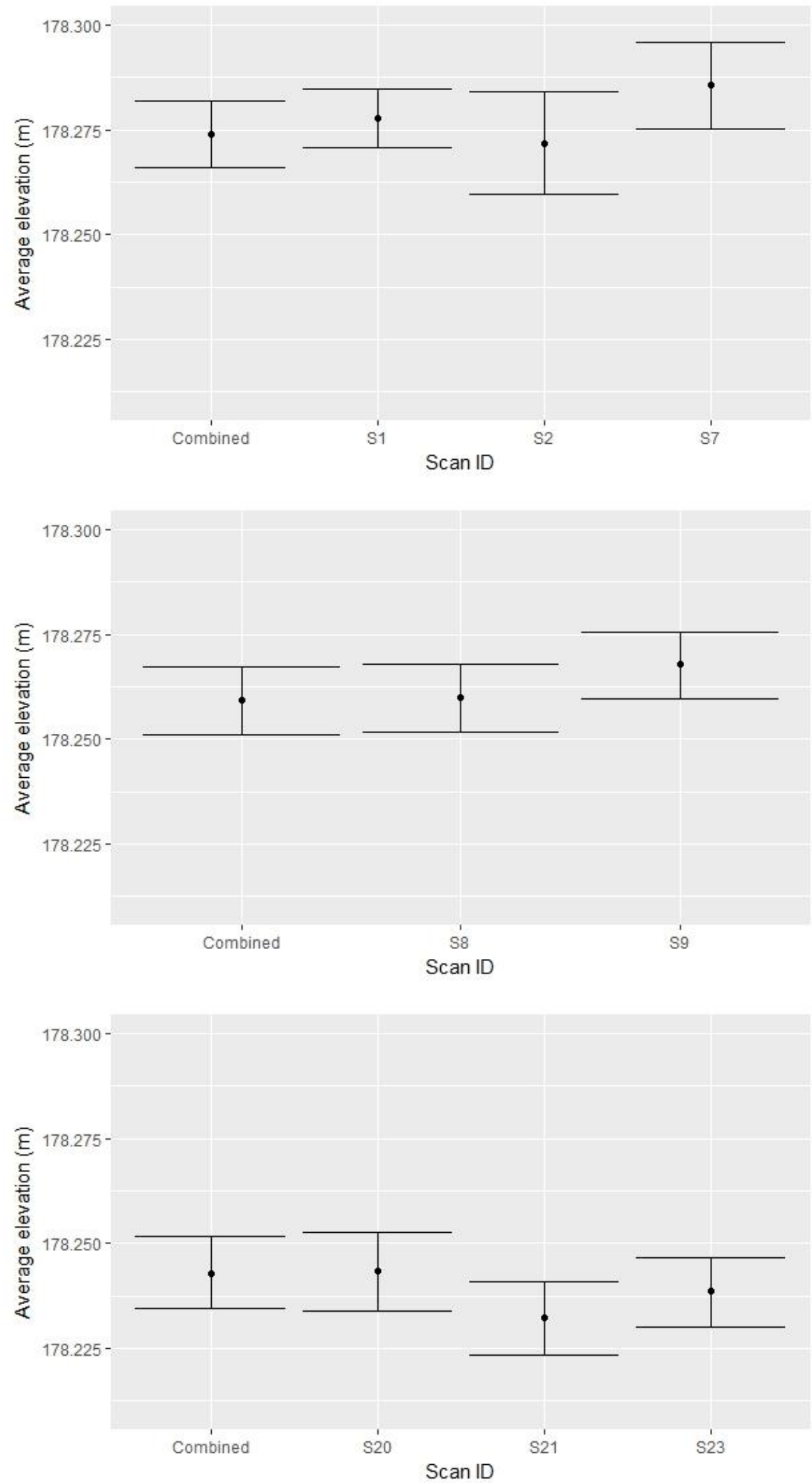

Figure 6.1: The 95\% confidence intervals for the various date of scans. June 2015 is at the top, followed by August 2015 below, and at the bottom is August 2016. Note, the scan names have been shorted and all the y-axes have been set to be the same range so they can be visually compared. 


\subsection{Surface ambiguity of natural tundra surfaces}

Different methods and attachments to detect the surface are shown in Figure 6.2. The needle and regular attachments are pointed, which allowed the penetration of the surface, resulting in a lower mean surface elevation than other attachments. The wide and medium attachments had a greater surfaced area at the bottom of the pole. This allowed for less of a penetration of the surface, if any, but it did allow for vegetation to be caught underneath the attachment. Since the area of this experiment is smaller than the plots the resulting numbers cannot be directly compared.

The values for the TLS data were not filtered, as such, it can be observed that non-filtered LiDAR data has a mean surface elevation value greater than the contact methods, especially when tall vegetation is present. This is depicted in Figure 6.2, which resulted in a mean surface elevation about $20 \mathrm{~cm}$ taller than the contact methods. However, the confidence intervals (Figure 6.4) shows that the non-contact method always has the smallest ranged compared to the contact methods. When comparing confidence interval ranges of different surfaces the bare sand produces the smallest range, then the short vegetation, next is the organic, and finally the tall vegetation produces the largest confidence interval range. 
Table 6.2: Metrics collected from the surface ambiguity experiment. The means are statistically different at a 95\% confidence level (all p-values were less than $2.2 \times$ $10^{-16}$ ) when compared to the medium attachment (PM) within one surface type.

\begin{tabular}{llllll}
\hline ID & Mean $(\mathrm{m})$ & $\begin{array}{l}\text { Deviation of the mean } \\
\text { in reference of PM }(\mathrm{cm})\end{array}$ & Min CI $(\mathrm{m})$ & Max CI $(\mathrm{m})$ & $\begin{array}{l}\text { Uncertainty } \\
(\mathrm{cm})\end{array}$ \\
\hline Org PM & 98.741 & 0.00 & 98.727 & 98.755 & 2.80 \\
Org PN & 98.689 & -5.22 & 98.672 & 98.706 & 3.46 \\
Org PR & 98.705 & -3.63 & 98.689 & 98.721 & 3.22 \\
Org PW & 98.748 & 0.62 & 98.733 & 98.762 & 2.87 \\
Org TLS & 98.735 & -0.64 & 98.735 & 98.735 & 0.09 \\
& & & & & \\
Sand PM & 98.244 & 0.00 & 98.243 & 98.246 & 0.31 \\
Sand PN & 98.186 & -5.87 & 98.182 & 98.189 & 0.74 \\
Sand PR & 98.212 & -3.28 & 98.211 & 98.213 & 0.18 \\
Sand PW & 98.242 & -0.26 & 98.240 & 98.243 & 0.30 \\
Sand TLS & 98.245 & 0.09 & 98.245 & 98.245 & 0.01 \\
& & & & \\
Short PM & 98.310 & 0.00 & 98.304 & 98.315 & 1.08 \\
Short PN & 98.212 & -9.72 & 98.205 & 98.219 & 1.45 \\
Short PR & 98.285 & -2.50 & 98.279 & 98.290 & 1.16 \\
Short PW & 98.308 & -0.17 & 98.301 & 98.314 & 1.30 \\
Short TLS & 98.297 & -1.30 & 98.296 & 98.297 & 0.02 \\
Tall PM & 98.219 & 0.00 & & & \\
Tall PN & 98.087 & -13.17 & 98.195 & 98.242 & 4.64 \\
Tall PR & 98.176 & -4.35 & 98.061 & 98.115 & 5.45 \\
Tall PW & 98.249 & 3.02 & 98.155 & 98.196 & 4.14 \\
Tall TLS & 98.445 & 22.62 & 98.231 & 98.269 & 3.80 \\
\hline
\end{tabular}


Organic

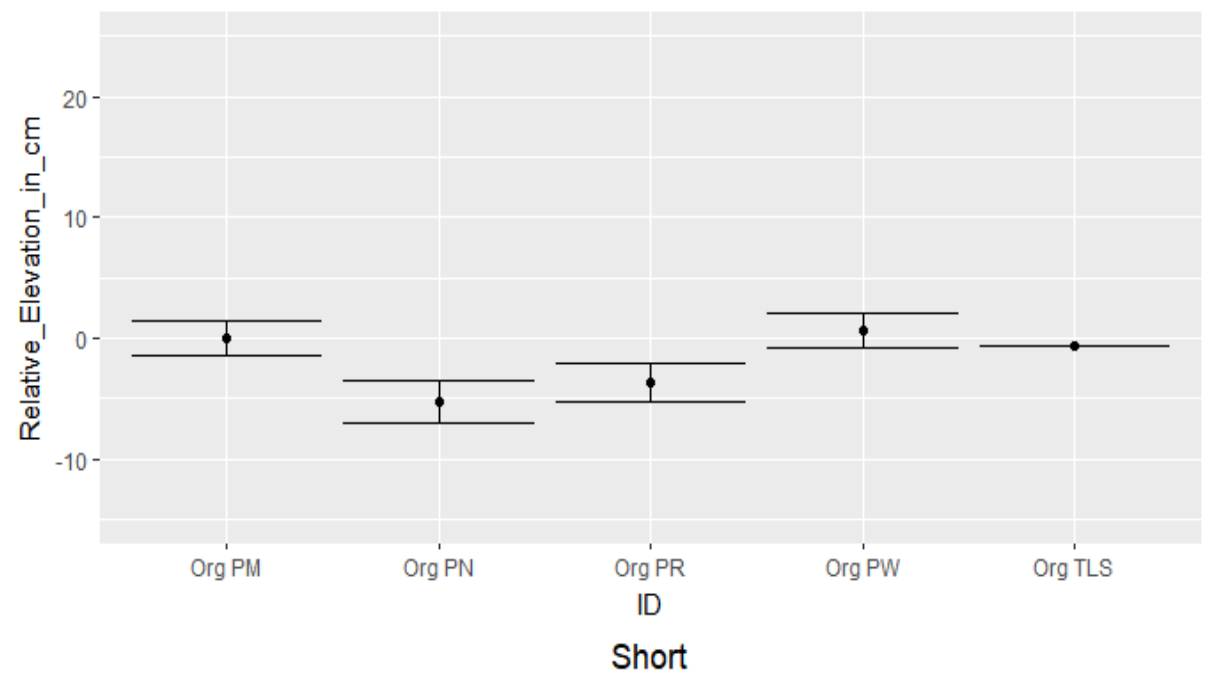

8

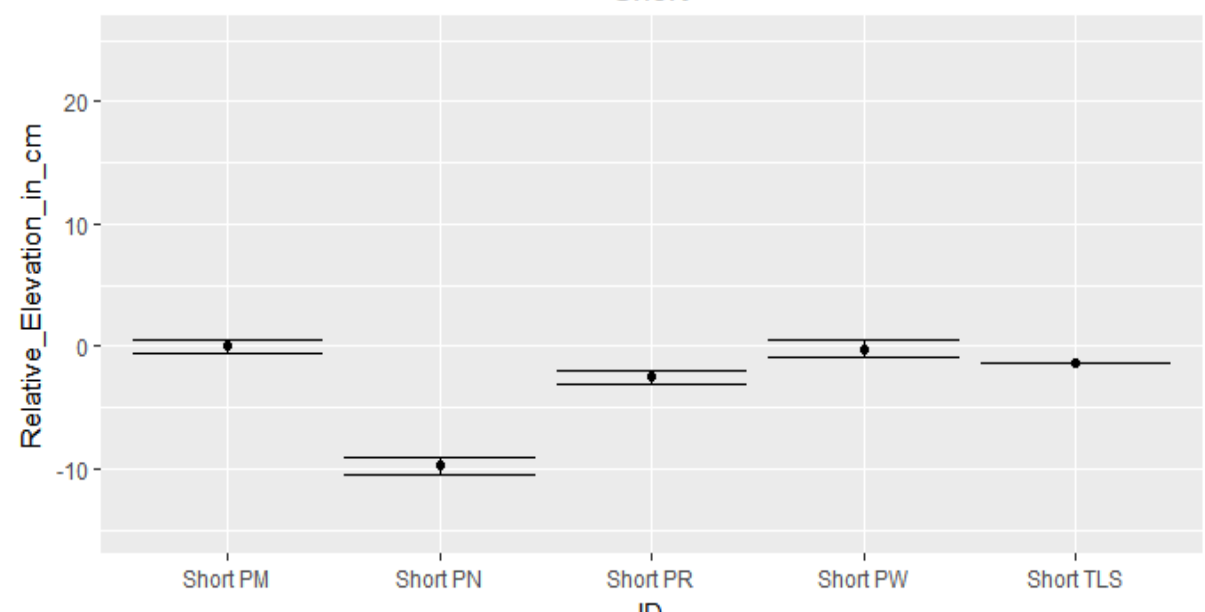

ID
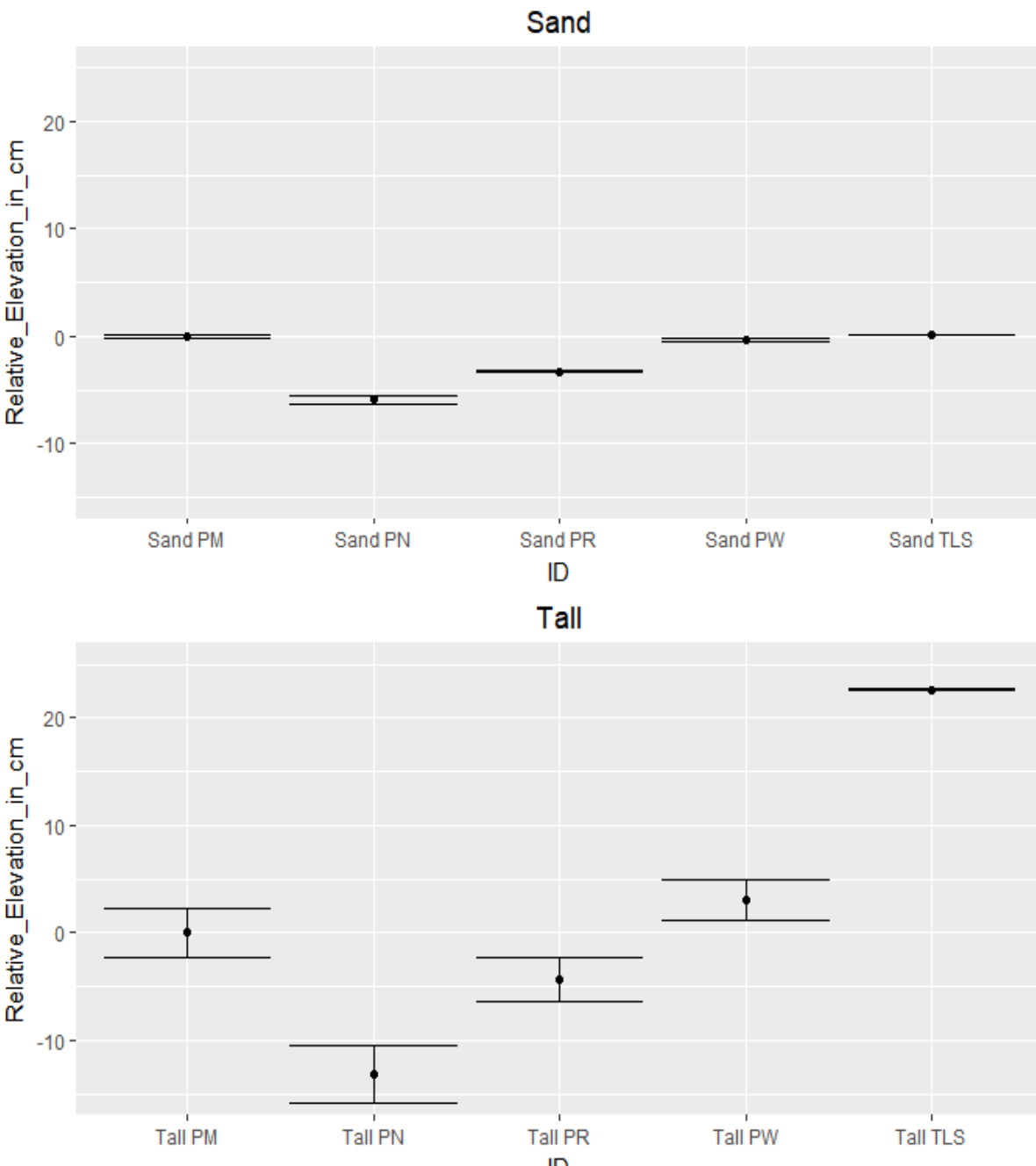

Figure 6.2: Plot of deviation of the mean (shown as a point) in reference to PM in centimeters versus the relative $95 \%$ confidence intervals (shown as bars). The y-axis are the same on each plot so they can be visually compared. 


\subsection{Tundra plots near Lac de Gras}

In this section, an arbitrarily chosen example of one plot (NGO-DD-2015) was shown in great detail to illustrate the distribution of the beanplots of both methods and the 95\% confidence intervals. Plot NGO-DD-2015 contained hummocks and dwarf birch for the surface features. Figure 6.3 shows a beanplot of the total station method and scans from the MS50. The elevation of these observations are inconsequential in absolute terms since the Lac de Gras region has an elevation around $400 \mathrm{~m}$ above sea level. Therefore, the elevations of the plots were made to be relative to the PM measurement.

In figure 6.4 the $95 \%$ confidence intervals are shown for the total station and TLS method. The confidence interval for the total station method was $98.358 \mathrm{~m}$ to 98.424 $\mathrm{m}$, with a range of $0.066 \mathrm{~m}$. The confidence interval for the TLS method was 98.380 $\mathrm{m}$ to $98.410 \mathrm{~m}$ with a range of $0.030 \mathrm{~m}$. To determine the potential minimum vertical detection, equation 4.1 was used. The result was an uncertainty of $9.3 \mathrm{~cm}$ and $4.2 \mathrm{~cm}$ for the total station and TLS method respectively. A summary table (Table 6.3) is presented at the end of this section. In figure 6.5, a plot of the difference of relative mean areal elevation for the PM versus the TLS method is shown. Generally, the contact method produced a higher mean areal elevation. 


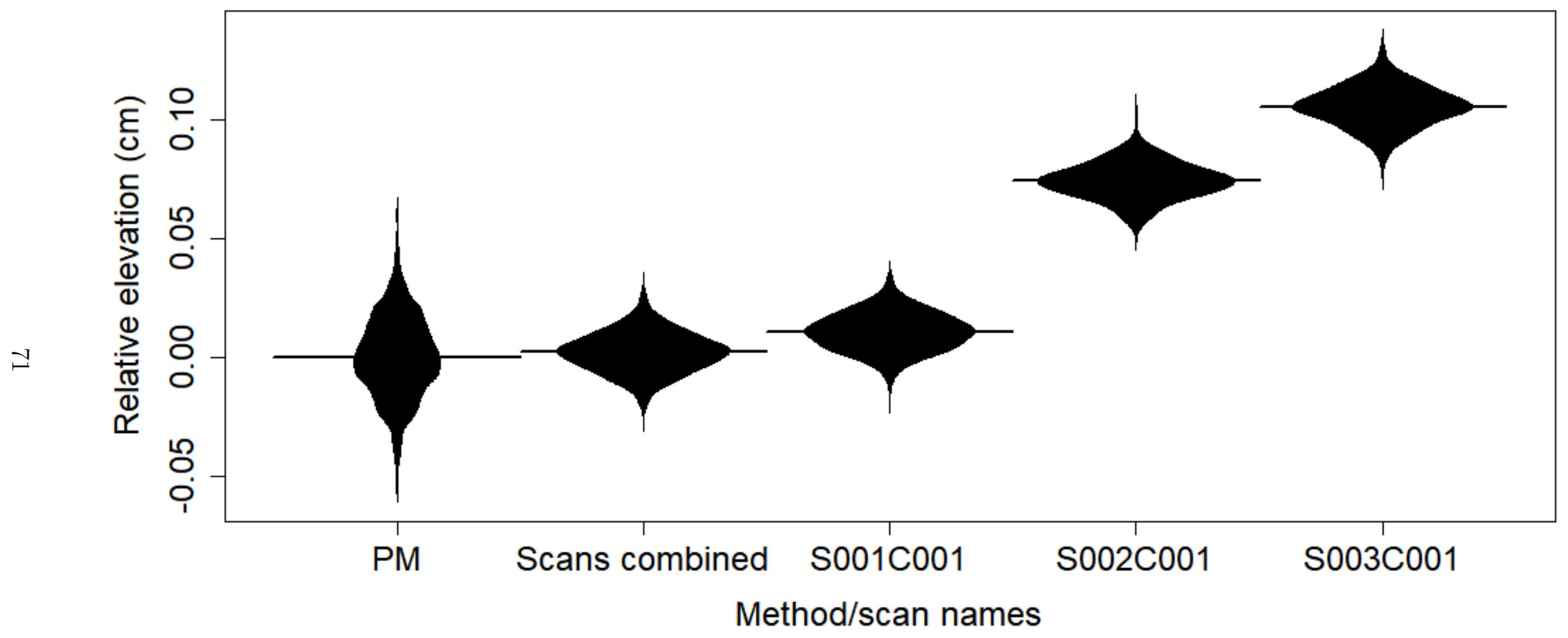

Figure 6.3: Beanplots of the total station and TLS method (that have been filtered based on lowest elevation point per grid cell) versus the relative elevation of PM. In each bean there are a 1000 samples because the bootstrap was set to 1000 replicates. The mean elevation is shown as a horizontal black line. 


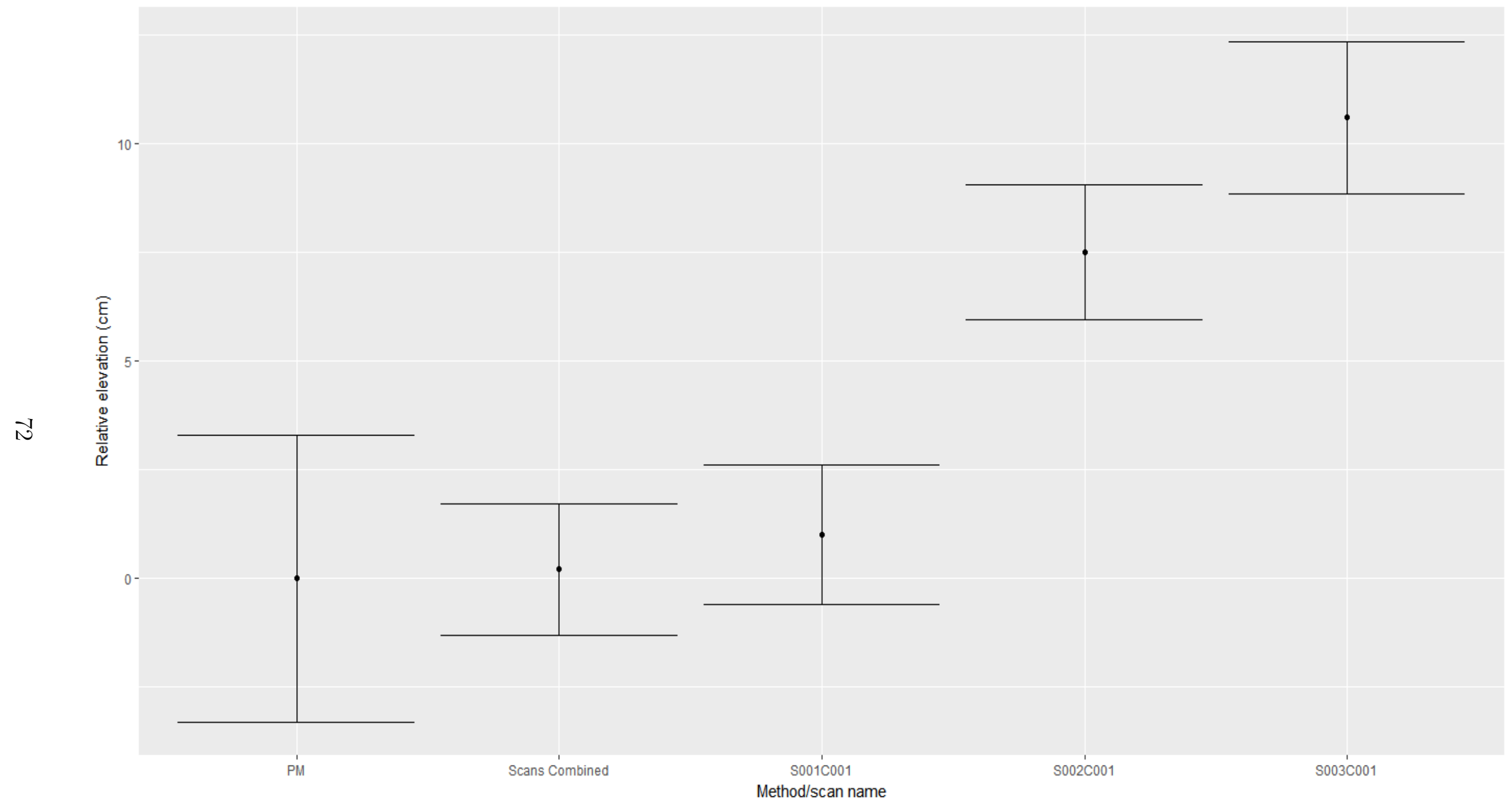

Figure 6.4: Plots of mean (shown as points) elevations $(\mathrm{m})$ versus the $95 \%$ confidence intervals (shown as bars) of the different methods. 
Table 6.3: Each plot with its associated key data. All plots are significantly different (at a $95 \%$ level, p-value of less than $2.2 \times 10^{-16}$ ) between the PM mean and TLS mean.

\begin{tabular}{|c|c|c|c|c|c|c|c|c|c|c|c|}
\hline $\begin{array}{l}\text { Group } \\
\text { number }\end{array}$ & Site & $\begin{array}{l}\text { Surface } \\
\text { feature }\end{array}$ & $\begin{array}{l}\text { Dominant } \\
\text { surface vegetation }\end{array}$ & $\begin{array}{l}\text { Max } \\
\text { vegetation } \\
\text { height }(\mathrm{m})\end{array}$ & $\begin{array}{l}\mathrm{PM} \\
\text { mean }(\mathrm{m})\end{array}$ & $\begin{array}{l}\text { Difference between } \\
\text { methods }(\mathrm{cm})\end{array}$ & $\begin{array}{l}\text { PM uncertainty } \\
\text { (m) }\end{array}$ & $\begin{array}{l}\text { PM potential } \\
\text { min vertical } \\
\text { detection }(\mathrm{cm})\end{array}$ & TLS mean $(\mathrm{m})$ & $\begin{array}{l}\text { TLS uncertainty } \\
\text { (m) }\end{array}$ & $\begin{array}{l}\text { TLS potential } \\
\text { min vertical } \\
\text { detection }(\mathrm{cm})\end{array}$ \\
\hline 1 & NGO-DD-2030 & Blockfield & Dwarf birch & 0.45 & 98.451 & 15.9 & 0.215 & 30.4 & 98.292 & 0.1 & 14.1 \\
\hline 1 & NGO-DD-2033 & Blockfield & Dwarf birch & 0.45 & 109.825 & 3.8 & 0.138 & 19.5 & 109.787 & 0.02 & 2.8 \\
\hline 1 & NGO-DD-2034 & Blockfield & Dwarf birch & 1.3 & 98.385 & 25.6 & 0.253 & 35.8 & 98.129 & 0.16 & 22.6 \\
\hline 1 & NGO-DD-2035 & Blockfield & Dwarf birch & Not available & 101.38 & 47.2 & 0.245 & 34.6 & 100.908 & 0.1 & 14.1 \\
\hline 2 & NGO-DD-2032 & Blockfield & Labrador Tea & 0.4 & 98.435 & 9.4 & 0.127 & 18 & 98.341 & 0.05 & 7.1 \\
\hline 3 & NGO-DD-2023 & Esker & Bearberries & 0.15 & 98.296 & 12.4 & 0.168 & 23.8 & 98.172 & 0.08 & 11.3 \\
\hline 4 & NGO-DD-2026 & Esker & Labrador Tea & 0.35 & 98.411 & 4.1 & 0.193 & 27.3 & 98.37 & 0.08 & 11.3 \\
\hline 5 & NGO-DD-2020 & Esker & Lichen & 0.15 & 98.075 & -6.8 & 0.212 & 30 & 98.143 & 0.09 & 12.7 \\
\hline 6 & NGO-DD-2008/2028 & Esker & Lichen/Dwarf birch & 0.5 & 98.533 & 0.9 & 0.027 & 3.8 & 98.524 & 0.02 & 2.8 \\
\hline 6 & NGO-DD-2029 & Esker & Lichen/Dwarf birch & 0.4 & 98.334 & 3 & 0.074 & 10.5 & 98.304 & 0.03 & 4.2 \\
\hline 7 & NGO-DD-2013 & Hummock & Dwarf birch & 0.8 & 102.251 & 2.8 & 0.066 & 9.3 & 102.223 & 0.01 & 1.4 \\
\hline 7 & NGO-DD-2015 & Hummock & Dwarf birch & 0.4 & 98.39 & -0.2 & 0.066 & 9.3 & 98.392 & 0.03 & 4.2 \\
\hline 7 & NGO-DD-2016 & Hummock & Dwarf birch & 0.55 & 98.482 & 11.1 & 0.176 & 24.9 & 98.371 & 0.06 & 8.5 \\
\hline 8 & NGO-DD-1010 & Hummock & Sedges & 0.2 & 91.534 & 3.2 & 0.041 & 5.8 & 91.502 & 0.02 & 2.8 \\
\hline 8 & NGO-DD-2019 & Hummock & Sedges & 0.2 & 93.478 & -2.9 & 0.077 & 10.9 & 93.507 & 0.03 & 4.2 \\
\hline 9 & NGO-RC-165 & $\begin{array}{l}\text { Ice wedge } \\
\text { with hummocks }\end{array}$ & Dwarf birch & 0.7 & 98.182 & -1.8 & 0.117 & 16.5 & 98.2 & 0.06 & 8.5 \\
\hline 9 & NGO-RC-166 & $\begin{array}{l}\text { Ice wedge } \\
\text { with hummocks }\end{array}$ & Dwar fbirch & 0.4 & 98.155 & 1.8 & 0.114 & 16.1 & 98.137 & 0.06 & 8.5 \\
\hline 9 & NGO-RC-168 & $\begin{array}{l}\text { Ice wedge } \\
\text { with hummocks }\end{array}$ & Dwarf birch & 0.7 & 98.364 & -0.6 & 0.05 & 7.1 & 98.37 & 0.02 & 2.8 \\
\hline 10 & NGO-DD-1005 & $\begin{array}{l}\text { Ice wedge } \\
\text { with hummocks }\end{array}$ & Sedges & 0.25 & 98.611 & 50.3 & 0.324 & 45.8 & 98.108 & 0.05 & 7.1 \\
\hline 10 & NGO-DD-2011 & $\begin{array}{l}\text { Ice wedge } \\
\text { with hummocks }\end{array}$ & Sedges & 0.3 & 98.439 & 3 & 0.058 & 8.2 & 98.409 & 0.02 & 2.8 \\
\hline 10 & NGO-RC-164 & $\begin{array}{l}\text { Ice wedge } \\
\text { with hummocks }\end{array}$ & Sedges & 0.4 & 98.35 & 14.2 & 0.105 & 14.8 & 98.208 & 0.07 & 9.9 \\
\hline 11 & NGO-DD-1004 & Mud boil & Dwarf birch & 0.8 & 98.612 & 33.1 & 0.333 & 47.1 & 98.281 & 0.12 & 17 \\
\hline 11 & NGO-DD-2004 & Mud boil & Dwarf birch & 0.4 & 98.415 & 4.5 & 0.025 & 3.5 & 98.37 & 0.02 & 2.8 \\
\hline 11 & NGO-DD-2005 & Mud boil & Dwarf birch & 0.45 & 98.307 & 10.9 & 0.229 & 32.4 & 98.198 & 0.12 & 17 \\
\hline 11 & NGO-DD-2007 & Mud boil & Dwarf birch & 0.45 & 97.762 & -43.6 & 0.272 & 38.5 & 98.198 & 0.17 & 24 \\
\hline 11 & NGO-DD-2009 & Mud boil & Dwarf birch & 0.75 & 98.276 & 7.8 & 0.276 & 39 & 98.198 & 0.11 & 15.6 \\
\hline 12 & NGO-RC-170 & Mud boil & Dwarf birch/Labrador Tea & 0.7 & 98.387 & 2.9 & 0.149 & 21.1 & 98.358 & 0.08 & 11.3 \\
\hline 12 & NGO-RC-171 & Mud boil & Dwarf birch/Labrador Tea & 0.8 & 102.003 & -1.8 & 0.104 & 14.7 & 102.021 & 0.02 & 2.8 \\
\hline
\end{tabular}




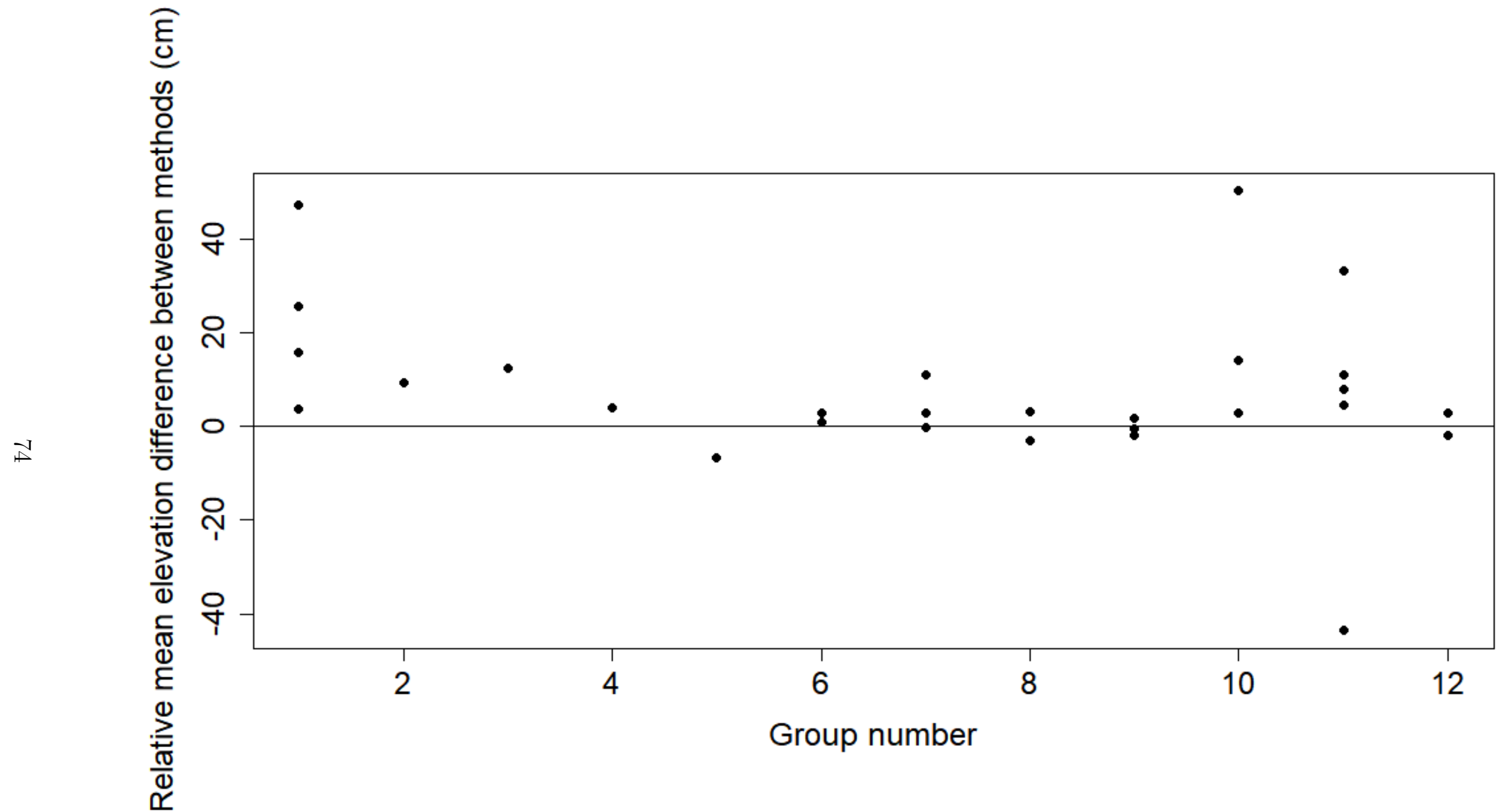

Figure 6.5: Plot of the difference of relative mean areal elevation for the PM versus the TLS method based on group numbers. When the value of a point is greater than zero it means the contact method (PM) resulted in a greater relative mean areal elevation than the non-contact method (TLS). When the value of a point is less than zero it means the contact method (PM) resulted in a lower relative mean areal elevation than the non-contact method (TLS). A horizontal line at an elevation value of zero was constructed to quickly identify the number of points greater than or less than zero. 


\section{Chapter 7}

\section{Interpretation}

\subsection{Introduction}

The interpreted results are separated into four sections distinguished by the purpose of each experiment and phenomena of data.

\subsection{Laser scanning a relatively smooth man-made surface}

Figure 6.1 shows that some of the confidence intervals overlap with each other, which suggests that it is likely the same surface (population) that was sampled, however, they were statistically different (t-test at 95\%). Furthermore, the confidence intervals for the combined scans for separate dates were somewhat similar (Table 6.1). Consequently, results on the minimum detection limit were based on the confidence limit of the combined scans.

To determine the minimum detection limit of Highway 3, equation 4.1 was used. The uncertainty that was present in each measurement was generally around $2 \mathrm{~cm}$ (Table 6.1). It was determined that the propagated uncertainty between August 2015 and August 2016 was $0.023 \mathrm{~m}$ or $2.3 \mathrm{~cm}$ and the areal mean difference between the two scans was $-1.6 \mathrm{~cm}$ (Table 6.1 ). Since the uncertainty was larger than the 
mean difference, no subsidence can be detected. From June 2015 to August 2015 the propagated uncertainty was also $2.3 \mathrm{~cm}$, which was larger than the mean difference so no vertical displacement can confidently be detected. However, from June 2015 to August 2016 a downward vertical displacement of $3.1 \mathrm{~cm}$ was detected, which was larger than the propagated uncertainty $(2.3 \mathrm{~cm})$.

\subsection{Surface ambiguity of natural tundra surfaces}

When an organic surface with no vegetation was surveyed, the uncertainty for TLS was $0.1 \mathrm{~cm}$. The experiment showed that when the PR and PN attachments were used the elevations were lower than the PW and PM and TLS method. This suggests that the pointed end of the survey pole would penetrate the ground under the weight of the prism that was on top of the pole. The penetration of the ground was not consistent, which resulted in a larger uncertainty for the PR and PN attachments (Table 6.2). In Table 6.2 similar results can be said about a bare sandy surface. The pointed end of the survey pole would penetrate the ground, but to a lesser extent. However, both methods and all of the attachments for the survey pole produced uncertainties less than $1 \mathrm{~cm}$ (Table 6.2).

When short vegetation (i.e., lichen) was present on a sandy surface the uncertainty increased by about $1 \mathrm{~cm}$ (Table 6.2, Figure 6.2). Again the pointed end of the survey pole penetrated the ground causing a range of the means to be approximately 10 $\mathrm{cm}$ (Figure 6.2). This time the PM and PW attachments did not sit directly on top of the surface and caused an increase in the mean elevation by about $1 \mathrm{~cm}$. Surprisingly, the mean elevation derived from TLS was about $1 \mathrm{~cm}$ below the PM and PW methods. This suggests that the laser penetrated the lichen to reach the ground surface or it found some gaps in the lichen.

Tall vegetation (i.e., dwarf birch) produced about three times the amount of uncertainty than the short vegetation (Table 6.2). A Welch's t-test that compared the total station with the medium attachment versus the other attachments and TLS was conducted for the experiment that had a small area with relatively the 
same vegetation (section 5.3 and 6.3). The data in Figure 6.2 showed that when the TLS was compared to the total station method with the medium attachment they were significantly different, which means both methods measured a different surface (population). Additionally, when the total station with the medium attachment (PM) was compared with each other attachments (PN, PR, and PW) one at a time, the results showed that the other attachments were significantly different from the medium attachment. Again, this means when compared to the medium attachment, all the other attachments measured a different surface. The mean elevation of PW is higher than PM, which suggests that PW was caught up in the understory of the vegetation, meanwhile, the PM with a smaller diameter made it further in the understory or sat on top of the surface. The TLS method produced an elevated mean surface due to the increased height and density of the vegetation. It appears that many of the points were that of vegetation and not of the surface (Figure 6.2).

This experiment reveals that in a relatively small area $(3 \mathrm{~m}$ by $3 \mathrm{~m})$ the contact method depicts an ambiguous mean surface elevation between different attachments for the same surface (Figure 6.2), and thus cannot be used as the absolute truth to determine the mean surface elevation. Additionally, the non-contact method depicts an ambiguous mean surface elevation and that tall vegetation highly influences the results from a TLS. Furthermore, this experiment reveals that bare sand with no vegetation produces uncertainties below $1 \mathrm{~cm}$, however, when vegetation, especially tall, dense vegetation is added to the surface the uncertainty increases by four or fives times (Table 6.2). The composition of organic matter allows for the compression of the surface, as such, the uncertainty with contact methods is greater than with non-contact methods by about $3 \mathrm{~cm}$.

\subsection{Tundra plots near Lac de Gras}

The results of this experiment show that the mean surface elevations of the TLS method and total station method are all significantly different in each plot (Table $6.3)$. 
When comparing the TLS method to the total station method, the TLS method has a lower uncertainty, which ranges from $1 \mathrm{~cm}$ to $17 \mathrm{~cm}$. Meanwhile, the total station's uncertainty ranges from $2.5 \mathrm{~cm}$ to $33.3 \mathrm{~cm}$. However, grouping reveals the reason behind these ranges. When the data for both methods are grouped based on surface features and vegetation, the distributions of uncertainty appears to be different. In all of the groups, the total station method has a larger range of uncertainty than the TLS method (Table 6.3). When comparing groups, groups 1, 7, 10, and 11 have a large range of uncertainty for the total station method. This is most likely due to the fact that these plots contain tall dwarf birch and/or contains ice-wedge polygons. Groups that contain dwarf birch has a larger uncertainty than groups that did not contain dwarf birch (Table 6.3). When groups containing low-lying vegetation (less than or equal to $0.2 \mathrm{~m}$ ) the uncertainty range was small (Table 6.3). The surface features influence the uncertainty as well. For example, blockfields and mud boils have a high median and a large range of uncertainty meanwhile terrain that was solely hummocks had low and a narrow range of uncertainty (Table 6.3). Blockfields contain a large uncertainty due to the presence of large boulder in and around the plot. This allows for measurements to be made on top of the boulders as well as in the voids. Mud boils also, have a large uncertainty because of the organic matter. Recall section 7.3, when organic surfaces were measured with the total station, the uncertainty was large because the structure of organic matter was highly compressible. The TLS method does have a smaller uncertainty compared to the total station method as expected with an organic surface, however, it is larger than expected, this is the result of different surface vegetation acting as a confounding variable.

The potential minimum detection limit ranges from $1.4 \mathrm{~cm}$ to $24.0 \mathrm{~cm}$ and 3.5 $\mathrm{cm}$ to $47.1 \mathrm{~cm}$ for the TLS and total station methods, respectively (Table 6.3). The potential minimum detection limit has a low range for groups 6 and 8, meanwhile, groups $1,7,9,10$ and 11 have a large potential minimum detection limit. If the uncertainty range is large, the potential minimum detection limit is also large. 
This experiment shows that compounding different surficial characteristics with different surface features results in larger uncertainties than what was expected from the experiment in section 7.2. It also shows that when dwarf birch (tall dense vegetation) is present and/or the surface features is a blockfield or an ice-wedge polygon then larger uncertainties are expected. When low-lying or sparse vegetation was on top of the sand or hummocks a smaller uncertainty is expected. Furthermore, this experiment shows that generally the non-contact method produced an areal mean surface elevation that was lower than the areal mean surface elevation for the contact method (Figure 6.5). This could be due to the fact that the understory of the vegetation was compressed beneath the survey pole resulting in a increased elevation. Meanwhile, the non-contact method had filtered out the vegetation.

\subsection{Other phenomena}

In this section there are three phenomena of data that are discussed. First, in Figure 6.3 it appears that the bootstrap method did not make the data normally distributed for the total station method. However, when a normality test (Shapiro-Wilk) was conducted a p-value of 0.96 was given, which means the data was likely to be normally distributed. Additionally, the quantile-quantile (QQ) plot is typical of normally distributed data (Figure 7.1).

Second, the confidence intervals and mean areal elevation of the combined scans and scan S001C001 produce similar results (Figures 6.1, 6.2, 6.3, 6.4; Tables 6.2 and 6.3). This could be due to the angle of incidence of the laser from the scanner. In scan S001C001 the scanner is placed in the center of the plot, which produced less of a glancing incidence angle compared to when the scanner was placed out of the plot. With an angle closer to perpendicular of the surface, the laser beam would allow for a bird's eye view, which would measure the bottoms of the troughs and crests. However, when the scanner is placed outside of a plot the incidence angle glances the surface. As such, it cannot measure the bottom of the troughs, which produced elevated surfaces (Figure 6.3). When all the scans were combined it produced a 
result where the most point lowest points could been viewed, which resulted in a slightly lower elevation than just scan S001C001.

Finally, the error of resections were not used in propagating the uncertainty. They were not used because originally, they were very small (average was $0.7 \mathrm{~cm}$ ) and were assumed not to impact the results. However, when the maximum resection error of $1.3 \mathrm{~cm}$ was applied to all of the results using formula 4.1 the additional error for Highway 3 was between $0.4-0.7 \mathrm{~cm}$ and for the tundra surfaces it ranged between $0.5-0.9 \mathrm{~cm}$. An interesting result of the added error was if the uncertainty was more than $10 \mathrm{~cm}$ the added error of the resection was negligible. However, if the uncertainty of the method was less than $10 \mathrm{~cm}$ then it impacted the results and the closer the uncertainty of the method to $0 \mathrm{~cm}$ the greater the impact. In the case of the tundra the maximum error was an additional $0.9 \mathrm{~cm}$. This estimate is applying the maximum resection error and assigning it to all of the data, which means the added uncertainty of the resections are overestimated. 


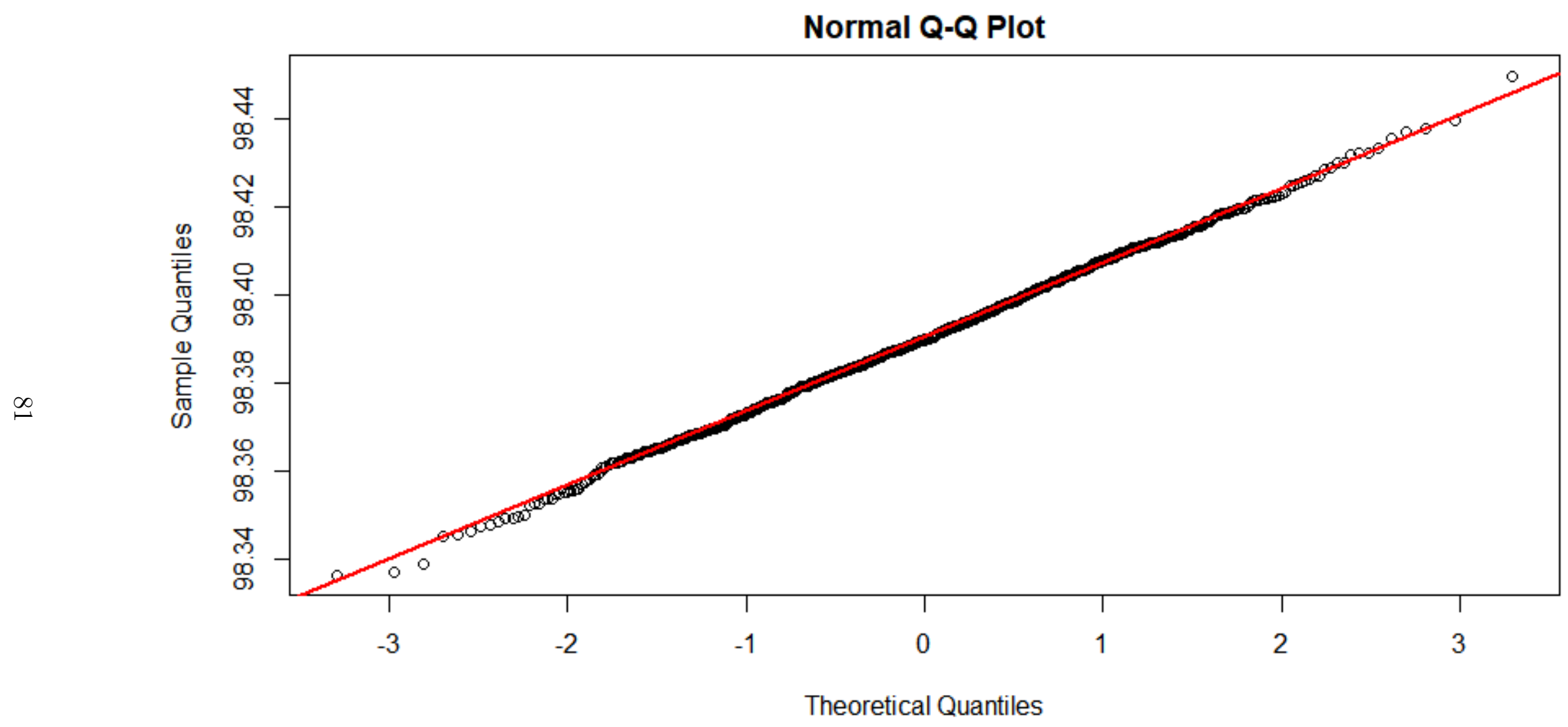

Figure 7.1: QQ plot of the beanplot of PM from Figure 6.3. Most of the data is on the red reference line, as such, normality is assumed. 


\subsection{Summary of experiments}

Highway 3, a man-made surface with no surface cover, results in an uncertainty of approximately $2 \mathrm{~cm}$ when scanned. Moving to a small area, with simple natural surfaces, the uncertainties are less than $1 \mathrm{~cm}$ for bare sand, approximately $1-2 \mathrm{~cm}$ for low-lying vegetation, approximately $3-4 \mathrm{~cm}$ for organic surfaces, and approximately $5 \mathrm{~cm}$ when tall vegetation is introduced for both methods. When a larger area, with natural tundra surfaces, and a combination of different surficial features and various surface characteristics are surveyed, the uncertainties of both methods increase higher than what is expected with the simple natural surface characteristics. 


\section{Chapter 8}

\section{Discussion}

\subsection{Introduction}

In this section the results and their interpretation are discussed in light of existing literature. There is a lack of literature existing in the realms of TLS and permafrost data to detect vertical movement (Bhardwaj et al., 2016), as such, data will be discussed in various environments and not just in permafrost environments.

\subsection{Laser scanning a relatively smooth man-made surface}

A study examining the effect of pavement degradation using a TLS, Akgul et al. (2017) found that their TLS method can be used effectively in measuring vertical movement of $1 \mathrm{~cm}$ in the pavement. In this thesis, vertical displacement was only detected after $2.3 \mathrm{~cm}$ when discussing a man-made feature. This difference can be attributed to the methods used and to the composition of materials used to create the road, resulting in slightly different surface features. The surface features of roads include small voids that the TLS can detect and if the roads from two different studies were made with different materials, larger distance between the voids compared to the top of the grains may exist, which could result in a larger uncertainty (Wheaton 
et al., 2010).

\subsection{Surface ambiguity of natural surfaces}

Surface ambiguity of natural tundra surfaces varies depending on the surface features and surface cover. A study conducted by Kääb et al. (2014) used SfM as a non-contact method to detect changes in the vertical and horizontal direction of sorted circles. They found that the uncertainty measurements for the vertical axis are in the range of $\pm 6 \mathrm{~mm}$, which is well below the actual relative displacements revealed for large parts of their study. In a different study by Kociuba et al. (2014) they used TLS to create a DEM of an alluvial fan. The stated uncertainty did not exceed $\pm 9 \mathrm{~mm}$. In this thesis, the experiment that involved the bare sand, produced an uncertainty of less than $1 \mathrm{~mm}$ for the TLS method and less than $1 \mathrm{~cm}$ for the total station method, respectively (Table 6.2). As such, the TLS method allowed for less uncertainty than the total station method. This means that TLS method is more useful than the total station method to detect vertical displacements.

When low-lying vegetation was scanned, the errors increased compared to when there was no surface cover. Guarnieri et al. (2009) wanted to understand the effects of vegetation on DEMs. They found that vegetation error from a marsh can be reduced by combining their filtering technique (with a cell size of $1 \mathrm{~m}^{2}$ ) and using the point cloud based on object reflectance (intensity). The results showed that the average estimation error to be about $1 \mathrm{~cm}$, but ranged from $0.5 \mathrm{~cm}-2.0 \mathrm{~cm}$. A study by Gruszczynski et al. (2017) compared UAV photogrammetry with TLS in terrain covered in short grass. Their work with the TLS produced an accuracy of $1 \mathrm{~cm}$, which is comparable with the research conducted by Guarnieri et al. (2009). The results of this experiment are comparable to the other two research because the contact method has an uncertainty of about $1 \mathrm{~cm}$. The non-contact method has a lower uncertainty, but that can be attributed to the vegetation type and height. The work done by the other studies had vegetation slightly taller and denser than the lichen that was scanned for this study. 
Gruszczynski et al. (2017) had also scanned tall grass (approximately 30-40 cm in height). They found that the error had a median value of $7 \mathrm{~cm}$. This value is about $2 \mathrm{~cm}$ higher than what this study showed. However, this is still a comparable number. It should be noted that some of the discussed studies may have overlap on the methods used, however, none of the studies used exactly the same parameters, but the overall result of uncertainty remains similar regardless of the environment it is in.

\subsection{Tundra plots near Lac de Gras}

Shiklomanov et al. (2013) introduced the term of isotropic thaw subsidence to distinguish between the slow, widespread, relatively homogeneous, and low-magnitude thaw-induced lowering of the land surface compared to the the more geographically restricted, irregular, and relatively large-magnitude subsidence usually associated with thermokarst terrain. The slow rates stated are in the range of $1-2 \mathrm{~cm} /$ year. This thesis shows that TLS has the potential to detect vertical displacements that are greater than $1.4 \mathrm{~cm}$ depending on the surface characteristics, but typically these methods work better with larger vertical displacements.

When plots contain tall dwarf birch and/or ice-wedge polygons they have a large range of uncertainty (Figure 6.7). This is due to tall, dense, vegetation and thawing of ice wedges creating complex surface features and strong, meter-scale contrasts in vegetation, ground-ice content, and thaw-settlement potential (Fan et al., 2014; Frost et al., 2018). Hummocky terrain with an absence of ice-wedge polygons, produce relatively the same undulating surface. Generally, the tops of the hummocks to the bottom of the troughs average between 40-60 cm (Tarnocai \& Zoltai, 1978). This could be why group 8 with sedges has a lower detection limit than group 7 , which has dwarf birch instead.

Overduin \& Kane (2006) used heave rods and ultrasonic distance sensors between the fall of 2001 and spring of 2005 to detect areal subsidence of frost boils near Galbraith Lake, Alaska. They found the mean subsidence of the frost boils to be 
about $5 \mathrm{~cm}$ per year. In this thesis when the contact method was used with mud boils, the potential minimum vertical detection limit was about $28 \mathrm{~cm}$. When the non-contact method was used, the average potential minimum vertical detection limit was approximately $13 \mathrm{~cm}$. Using $5 \mathrm{~cm}$ per year as a reference to how much frost boils subside, this implies that using the methods stated in this thesis it would take an average of three to six years between field campaigns to detect subsidence of mud boils using the non-contact and contact method, respectively.

Areal surface elevation changes in permafrost environments are difficult to detect. However, remote sensing methods are becoming more useful to detect subsidence. Short et al. (2011) compared TerraSAR-X, RADARSAT-2, and ALOS-PALSAR interferometry for monitoring permafrost environments. They detected subsidence of $20 \mathrm{~cm}$ to $30 \mathrm{~cm} /$ year spanning the years 2007 to 2010 of the north-east coast of Herschel Island. However, they state that comparing InSAR to the ground truth is difficult to accomplish and thus might not ever have the exact same agreement, so other studies have to be used to obtain ground truth data. For example, Burn \& Zhang (2009) calculated the excess ice content of soils on Herschel Island. It varied from $22 \%$ to $63 \%$ with an average of $47 \%$. They also calculated that a $10 \mathrm{~cm}$ deepening of the active layer could melt excess ice and cause subsidence between $0.5 \mathrm{~cm}$ to $17 \mathrm{~cm}$. At this magnitude, InSAR works especially the L-band that is associated with ALOS-PALSAR. Using the method discussed in this thesis the use of the TLS has the potential to detect subsidence with a $10 \mathrm{~cm}$ deepening of the active layer, thus allowing for a quicker detection of subsidence than with InSAR.

Liu et al. (2015) used L-band SAR and a model to detect $2.7 \mathrm{~cm}$ of subsidence with an uncertainty of $0.7 \mathrm{~cm}$ over an area of $0.45 \mathrm{~km}^{2}$. Their study site's vegetation primarily consisted of low sedges and mosses and a surface features associated by ice-core frost mounds and depressions. This resulted in a loss of excess ice that was claimed to be $1.2 \pm 0.3 \times 10^{7} \mathrm{~m}^{3} / \mathrm{yr}$, but upon contacting the author it was revealed to be $1.2 \pm 0.3 \times 10^{4} \mathrm{~m}^{3} / \mathrm{yr}$ of excess ice lost (personal communications, 2016). There is a possibility that the TLS method used in this thesis could detect 
subsidence, however, the area of Liu et al. (2015) study is $450000 \mathrm{~m}^{2}$, meanwhile, this thesis used a plot of approximately $225 \mathrm{~m}^{2}$. As such, this method could not capture the magnitude of subsidence for the area.

\subsection{Usage of methods in the field}

The excess ice content near Lac de Gras ranges from 0 to $98 \%$ depending on the soil type, organic matter, and surface/subsurface features (Subedi, 2017). The results from this thesis for the potential minimum vertical detection range from $1.4 \mathrm{~cm}$ to $17.0 \mathrm{~cm}$ for the non-contact method and $3.5 \mathrm{~cm}$ to $47.1 \mathrm{~cm}$ for the contact method. In permafrost literature, subsidence rates vary, but are typically low. Fortier et al. (2011) found a maximum subsidence rate of $4.72 \mathrm{~cm}$ per year on the road leading to Umiujaq's airport in northern Quebec. Short et al. (2011) estimated permafrost subsidence rates to be less than $5 \mathrm{~cm}$ per year on the northern shore of Herschel Island of the Yukon in Canada. Shiklomanov et al. (2013) measured isotropic thaw subsidence rates to between $0.81 \mathrm{~cm} 1.72 \mathrm{~cm}$ per year at two different study sites in northern Alaska. Finally, Liu et al. (2015) estimated permafrost subsidence rates of $2.7 \mathrm{~cm}$ per year near Deadhorse, Alaska. The average amount of subsidence rate is about $3 \mathrm{~cm}$ per year. If a $3 \mathrm{~cm}$ per year subsidence was used for the region then if the right conditions are met the non-contact method would be able to detect subsidence after one year, however, it is unlikely that the contact method could.

It seems at best that current remote sensing methods can detect vertical displacement in the centimeter to decimeter range when scanning permafrost environments. Lato et al. (2015) did a study that used ALS, TLS, and photogrammetry to determine the validity of use in mountainous environments. Their work concluded that all are viable choices, however, they all result in very similar data, thus photogrammetry offers the most affordable equipment solution. Since photogrammetry produces point clouds too both photogrammetry and TLS systems could be used in permafrost enviroments since the filtering of the point cloud is key. However, photogrammetric methods are much cheaper and less bulky than a TLS, and as a result should be 
used over a TLS.

\subsection{Limitations of the study}

Limitations of this study come from the parameters that were used. They consisted of: approximately 50 manual contact points per plot, a plot size of $15 \mathrm{~m} \times 15 \mathrm{~m}$, the size of each cell of $1 \mathrm{~m} \times 1 \mathrm{~m}, 50$ points per cell, and the minimum point per cell applied to the cell as the filter method. This limits the conclusions that can be obtained from this study because maybe approximately 50 manual contact points per plot does not fully represent the plot, as such, the comparison between TLS and the total station method would be different. The size of the plot was arbitrarily chosen. To combined scans together georeferencing is key. Fan et al. (2015) showed that georeferencing, which is mainly includes DGPS introduces larger errors than with a total station, as a result, a total station was used in this method. This procedure used the resection method to reduce the errors from centimeter that typically come from DGPS (when georeferencing) to millimeters on average (Table A.2). The size of each cell was $1 \mathrm{~m} \times 1 \mathrm{~m}$, and could have been smaller, however, Fan et al. (2014) states that in general, a larger search window is likely to capture a point closer to the bare ground, and hence reduces the overall vegetation-induced elevation error, however, a larger grid size will increase the sampling error and lead to data of a coarser spatial resolution. There are so many different filtering methods out there that may prove better than the method chosen (e.g., Meng et al., 2010; Lague et al., 2013; Che \& Olsen, 2017) and time did not permit to test all of them out. As such, these parameters were not optimized and future studies should test them in order to minimize uncertainties in both methods.

Additionally, the derived values for uncertainty and potential minimum detection limits contains the error from the resections and from the transformation from a $3 \mathrm{D}$ object (point clouds) to a $2.5 \mathrm{D}$ object (DEM). Futhermore, the accuracy of the instruments stated by the manufacturer should be limited when operating in the field due to the differing results. The Leica Nova MS50's whitepapers state at accuracy 
of $2 \mathrm{~mm}+2 \mathrm{ppm}$ for measurements onto any surface, however, in the field the uncertainty of measurements is in the centimeter range. 


\section{Chapter 9}

\section{Conclusion}

The aim of this thesis was to investigate how well the mean surface elevation of small plots in permafrost landscapes with different surface characteristics can be quantified. The following conclusions can be drawn from this study:

(i) The areal mean elevations derived from TLS and a total station in 28 tundra plots are all statistically different at a 95\% confidence level.

(ii) The uncertainty that is apparent in TLS Highway 3 just outside of Yellowknife, NWT is approximately $1.9 \mathrm{~cm}$. This results in a minimum vertical detection threshold of $2.3 \mathrm{~cm}$. The use of a TLS on natural tundra surfaces has an uncertainty that is generally greater than that of a man-made surface. It ranges from $1.4 \mathrm{~cm}$ to $24 \mathrm{~cm}$ depending on the surface conditions. The use of a total station on natural tundra surfaces has an uncertainty range of $3.5 \mathrm{~cm}$ to $47.1 \mathrm{~cm}$.

(iii) When natural surface characteristics are introduced, the uncertainty that is inherent in the ambiguous definition of a surface when deriving vertical movement increases. When a flat organic surface with no vegetation was surveyed, the uncertainty for the total station method was approximately $3 \mathrm{~cm}$ greater than with the TLS. When bare sand was surveyed the uncertainty for both methods was less than $1 \mathrm{~cm}$. When vegetation was added to bare sand the uncertainty increases four to fives times that of bare sand. These uncertainties associated with simple permafrost landscape appear to be similar across different landscapes. When complex tundra surfaces are surveyed, the ambiguity increases because of the confounding 
variables, which increases uncertainty. As a result the potential minimum detection limits are $1.4 \mathrm{~cm}-24.0 \mathrm{~cm}$ and $3.5 \mathrm{~cm}-47.1 \mathrm{~cm}$ of TLS and TS respectively on natural tundra surfaces. 


\section{References}

ACGR. 1988. Glossary of permafrost and related ground-ice terms. Permafrost Subcommittee, Associate Committee on Geotechnical Research. National Research Council of Canada, Ottawa. 156.

Aguilar, F. J., Mills, J. P., Delgado, J., Aguilar, M. A., Negreiros, J. G., \& Perez, J. L. 2010. Modelling vertical error in LiDAR-derived digital elevation models. Journal of Photogrammetry and Remote Sensing, 65, 103-110.

Akgul, M., Yurtseven, H., Akburak, S., Demir, M., Cigizoglu, H. K., Ozturk, T., Eksi, M., \& Akay, A. O. 2017. Short term monitoring of forest road pavement degradation using terrestrial laser scanning. Measurement, 103, 283-293.

Avian, M., Kellerer-Pirklbauer, A., \& Bauer, A. 2009. LiDAR for monitoring mass movements in permafrost environments at the cirque Hinteres Langtal, Austria, between 2000 and 2008. Natural Hazards and Earth System Sciences, 9, 1087-1094.

Bauer, A., Paar, G., \& Kaufmann, V. 2003. Terrestrial laser scanning for rock glacier monitoring. In Eighth International Conference on Permafrost, 55-60.

Beck, I., Ludwig, R., Bernier, M., Strozzi, T., \& Boike, J. 2015. Vertical movements of frost mounds in subarctic permafrost regions analyzed using geodetic survey and satellite interferometry, Earth Surface Dynamics, 3, 409-421.

Bennett, H. E. \& Porteus, J. O. 1961. Relation between surface roughness and specular reflectance at normal incidence. Journal of the Optical Society of America, 51, 123-129.

Bhardwaj, A., Sam, L., Bhardwaj, A., \& Martín-Torres, F. J. 2016. LiDAR remote 
sensing of the cryosphere: present applications and future prospects. Remote Sensing of Environment, 177, 125-143.

Blanchard, D. \& Frémond, M. 1982. Cryogenic suction in soils. Proceedings of the Third International Symposium on Ground Freezing, 233-238.

Bliss, L. C. 1978. Vegetation and revegetation within permafrost terrain. In Proceedings of the 3rd International Conference on Permafrost, 31-50.

Blunden, J., \& Arndt, D. S. 2017. State of the climate in 2016. Bulletin of the American Meteorological Society, 98, Si-S277.

Bommer, C., Fitze, P., \& Schneider, H. 2012. Thaw-consolidation effects on the stability of alpine talus slopes in permafrost. Permafrost and Periglacial Processes, 23, 267-276.

Brasington, J., Rumsby, B. T., \& McVey, R. A. 2000. Monitoring and modelling morphological change in a braided gravel-bed river using high resolution GPS-based survey. Earth Surface Processes and Landforms, 25, 973-990.

Brown, J., Hinkel, K. M., \& Nelson, F. E. 2000. The circumpolar active layer monitoring (CALM) program: Research designs and initial results. Polar Geography, 24, 166-258.

Brown, J. \& Haggerty, C. 1998. Permafrost database now available, EOS 79, 634-636.

Brown, R. 1966. Relation between mean annual air and ground temperatures in the permafrost region of Canada. In Proceedings of the Permafrost International Conference, 241-246.

Bucksch, A. Linndenbergh, R., \& van Ree, J. 2007. Error budget of terrestrial laserscanning: influence of the intensity remission on the scan quality. In Proceedings GeoSibera, 1-13.

Burn, C. R., \& Zhang, Y. 2009. Permafrost and climate change at Herschel Island (Qikiqtaruq), Yukon Territory, Canada. Journal of Geophysical Research, $114,3-16$.

Burn, C. R. 1988. The development of near-surface ground ice during the Holocene 
at sites near Mayo, Yukon Territory, Canada. Journal of Quaternary Science, $3,31-38$.

Burn, C. R. 1997. Cryostratigraphy, paleogeography, and climate change during the early Holocene warm interval, western Arctic coast, Canada. Canadian Journal of Earth Sciences, 34, 912-925.

Bürgmann, R., Rosen, P., A., \& Fielding, E. J. 2000. Synthetic aperture radar interferometry to measure Earth's surface topography and its deformation. Annual Review of Earth and Planetary Sciences, 28, 169-209.

Burt, T. P. \& Willams, P. J. 1976. Hydraulic conductivity in frozen soils. Earth Surface Processes, 1, 349-360.

Canty, A. \& Ripley, B. 2017. R Package 'boot'.

Che, E \& Olsen, J. 2017. Fast ground filtering for TLS data via scanline density analysis. Journal of Photogrammetry and Remote Sensing, 129, 226-240.

Clark, J. \& Robson, S. 2004. Accuracy of measurements made with a Cyrax 2500 laser scanner against surfaces of known colour. Survey Review, 37, 626-638.

Cournoyer, L. 2015. Evaluation of the repeatability and of the accuracy of the Leica Nova MS50 Multi-Station owned by Carleton University (NRC Report Number LS-2015-0007), Ottawa. 1-18.

Coveney, S. \& Fotheringham, A. S. 2011. Terrestrial laser scan error in the presence of dense ground vegetation. The Photogrammetric Record. 26, 307-324.

Deline, P., Jaillet, S., Rabatel, A., \& Ravanel, L. 2008. Ground-based LiDAR data on permafrost-related rock fall activity in the Mont-Blanc massif. Proceedings of the 9th International Conference on Permafrost, 349-354.

DiCiccio, T \& Efron, B. 1996. Bootstrap confidence intervals. Statistical Science, 11, 189-228.

Dredge, L. A., Ward, B. C., \& Kerr, D. E. 1994. Glacial geology and implications for drift prospecting in the Lac de Gras, Winter lake, and Aylmer lake map areas, central Slave Province. Geological Survey of Canada, 33-38.

Dredge, L. A., Kerr, D. E., \& Wolfe, S. A. 1999. Surficial materials and related 
ground ice conditions, Slave Province, N.W.T., Canada. Canadian Journal of Earth Sciences, 36, 1227-1238.

Dyke, A. S. 2004. An outline of North American deglaciation with emphasis on central and northern Canada. Developments in Quaternary Science, 2, $373-424$.

Efron, B. 1979. Bootstrap methods: another look at the jackknife. Annals of Statistics, 7, 1-26.

Efron, B. \& Tibshirani, R. 1986. Bootstrap methods for standard errors, confidence intervals, and other measures of statistical accuracy. Statistical Science, 1, $54-77$.

Efron, B. and Tibshirani, R. 1993. An introduction to the bootstrap. Chapman \& Hall.

Environment and Climate Change Canada. 2017. Current weather in Ekati (Lac de Gras). https://ekati.weatherstats.ca/download.html.[Date accessed: July 17 2017].

Evans, J. S. \& Hudak, A. T. 2007. A multiscale curvature algorithm for classifying discrete return LiDAR in forested environments. IEEE Transactions on Geoscience and Remote Sensing, 45, 1029-1038.

Fan, L., Powrie, W., Smethurst, J., Atkinson, P. M., \& Einstein, H. 2014. The effect of short ground vegetation on terrestrial laser scans at a local scale. Journal of Photogrammetry and Remote Sensing, 95, 42-52.

Fan, L., Smethurst, J. A., Atkinson, P. M., \& Powrie, W. 2015. Error in target-based georeferencing and registration in terrestrial laser scanning. Computers and Geosciences, 83, 54-64.

Fortier, R., LeBlanc, A. M., \& Yu, W. 2011. Impacts of permafrost degradation on a road embankment at Umiujaq in Nunavik (Quebec), Canada. Canadian Geotechnical Journal, 48, 720-740.

Frampton, A., Painter, S. L., Destouni, G. 2013. Permafrost degradation and subsurface-flow changes caused by surface warming trends. Hydrogeology 
Journal, 21, 271-280.

French, H. M. 1974. Man-induced thermokarst, Sachs Harbour airstrip, Banks Island, Northwest Territories. Canadian Journal of Earth Sciences, 12, $132-144$.

French, H. M. 2007. The periglacial environment: third edition. John Wiley and Sons, England.

Frost, G. V., Christopherson, T., Jorgenson, M. T., Liljedahl, A. K., Macander, M. J., Walker, D. A., \& Wells, A. F. 2018. Regional patterns and asynchronous onset of ice-wedge degradation since the mid-20th century in Arctic Alaska. Remote Sensing, 10, 1-15.

Gabriel, A. K., Goldstein, R. M., \& Zebker, H. A. 1989. Mapping small elevation changes over large areas: differential radar interferometry. Journal of Geophysical Research, 94, 9183-9191.

Ghilani, C. D. \& Wolf, P. R. 2015. Elementary surveying an introduction to geomatics. Pearson Education, New Jersey.

Government of the Northwest Territories. 2008. NWT climate change impacts and adaptation report. Yellowknife: Canada

Grohmann, C. H., Smith, M. J., \& Riccomini, C. 2011. Multiscale analysis of topographic surface roughness in the midland valley, Scotland. IEEE Transactions on Geoscience and Remote Sensing, 49, 1200-1213.

Grosse, G., Harden, J., Turetsky, M., McGuire, A. D., Camill, P., Tarnocai, C., Striegl, R. G. 2011. Vulnerability of high-latitude soil organic carbon in North America to disturbance. Journal of Geophysical Research: Biogeosciences, $116,1-23$.

Gruber, S. 2012. Derivation and analysis of a high-resolution estimate of global permafrost zonation. The Cryosphere, 6, 221-233.

Gruszczynski, W., Matwij, W., \& Cwiakal, P. 2017. Comparison of low-altitude UAV photogrammetry with terrestrial laser scanning as data-source methods for terrain covered in low vegetation. Journal of Photogrammetry and Remote 
Sensing, 126, 168-179.

Guarnieri, A., Vettore, A., Pirotti, F., Menenti, M., \& Marani, M. 2009. Retrieval of small-relief morphology from terrestrial laser scanning, optimal spatial filtering, and laser return intensity. Geomorphology, 113, 12-20.

Haubrock, S., Kuhnert, M., Chabrillat, S., Gunter, A., \& Kaufmann, H. 2009. Spatiotemporal variations of soil surface roughness from in-situ laser scanning. Catena. 79, 128-139.

Heginbottom, J. A. 2002. Permafrost mapping: a review. Progress in Physical Geography 26, 623-642.

Heritage, G. L. \& Large, A. R. G. 2009. Laser scanning for the environmental sciences. Wiley-Blackwell: UK.

Hobson, R. D. 1967. Fortran IV programs to determine surface roughness in topography for the CDC 3400 computer (quantitative parameters of surface roughness for use in geologic remote sensing), University of Kansas: USA.

Hodgson, M. E. \& Bresnahan, P. 2004. Accuracy of airborne Lidar derived elevation: empirical assessment and error budget. Photogrammetric Engineering \& Remote Sensing, 70, 331-339.

Hu, X., Holubec, I., Wonnacott, J., Lock, R., \& Olive, R. 2003. Geomorphological, geotechnical and geothermal conditions at Diavik Mines. In Proceedings of the Eighth international conference on Permafrost, 437-442.

Hubbard, S. S., Gangodagamage, C., Dafflon, B., Wainwright, H., Peterson, J., Gusmeroli, A., Ulrich, C., Wu, Y., Wilson, C., Rowland, J., Tweedie, C., \& Wullschleger, S. D. 2013. Quantifying and relating land-surface and subsurface variability in permafrost environments using LiDAR and surface geophysical datasets. Hydrogeology Journal, 21, 149-169.

Iwahana, G., Uchida, M., Liu, L., Gong, W., Meyer, F., Guritz, R., Yamanokuchi, T., \& Hinzman, L. 2016. InSAR detection and field evidence for thermokarst after a tundra wildfire, using ALOS-PALSAR. Remote Sensing, 8, 218.

Iwata, Y., Hirota, T., Suzuk, T., \& Kuwao, K. 2012. Comparison of soil frost and 
thaw depths measured using frost tubes and other methods. Cold Regions Science and Technology, 71, 111-117.

Jafarov, E. E., Marchenko, S. S., \& Romanovsky, V. E. 2012. Numerical modeling of permafrost dynamics in Alaska using a high spatial resolution dataset. The Cryosphere, 6, 613-624.

Jester, W. \& Klik, A. 2005. Soil surface roughness measurement-methods, applicability, and surface representation. Catena. 64, 174-192.

IPCC. 2013. Summary for policymakers. In: climate change 2013: The physical science basis. Contribution of working group I to the fifth assessment report of the Intergovernmental Panel on Climate Change [Stocker, T.F., D. Qin, G. Plattner, M. Tignor, S.K. Allen, J. Boschung, A. Nauels, Y. Xia, V. Bex and P.M. Midgley (eds.)]. Cambridge University Press, Cambridge, United Kingdom and New York, NY, USA.

Jorgenson, M. T. \& Grosse, G. 2016. Remote sensing of landscape change in permafrost regions. Permafrost and Periglacial Processes, 27, 324-338.

Jorgenson, M. T. \& Osterkamp, T. E. 2005. Response of boreal ecosystems to varying modes of permafrost degradation. Canadian Journal of Forest Research. 35, 2100-2111.

Jorgenson, M. T., Shur, Y. L., \& Pullman, E. R. 2006. Abrupt increase in permafrost degradation in Arctic Alaska. Geophysical Research Letters, 33, L02503.

Kääb, A., Girod, L., \& Berthling, I. 2014. Surface kinematics of periglacial sorted circles using structure-from-motion technology. The Cryosphere, 8, 1041-1056.

Kääb, A. 2008. Remote sensing of permafrost-related problems and hazards. Permafrost and Periglacial Processes, 19, 107-136.

Kääb, A., Haeberli, W., \& Gudmundsson, G. H. 1997. Analysing the creep of mountain permafrost using high precision aerial photogrammetry: 25 years of monitoring Gruben rock glacier, Swiss Alps. Permafrost and Periglacial Processes 8, 409-426.

Kaasalainen, S., Jaakkola, A., Kaasalainen, M., Krooks, A., \& Kukko, A. 2011. 
Analysis of incidence angle and distance effects on terrestrial laser scanner intensity: search for correction methods. Remote Sensing, 3, 2207-2221.

Kane, D., Hinkel, K., Goering, D., Hinzman, L., \& Outcalt, S. 2001. Non-conductive heat transfer associated with frozen soils. Global Planet Change, 29, 275-292.

Kaplan, E. \& Hegarty, C. 2005. Understanding GPS principles and applications second edition. Artech House, Massachusetts, United States.

Kerr, D. E. \& Wilson, P. 2000. Preliminary surficial geology studies and mineral exploration considerations in the Yellowknife area, Northwest Territories. Geological Survey of Canada, 1-16.

Kociuba, W., Kubisz, W., \& Zagorski, P. 2014. Use of terrestrial laser scanning (TLS) for monitoring and modelling of geomorphic processes and phenomena at a small and medium spatial scale in Polar environment (Scott River Spitsbergen). Geomorphology, 212, 84-96.

Kokelj, S. V. \& Burn, C. R. 2005. Geochemistry of the active layer and near surface permafrost, Mackenzie delta region, Northwest Territories, Canada. Canadian Journal of Earth Sciences, 42, 37-48.

Kokelj, S. V., Tunnicliffe, J. F., Lacelle, D., Lantz, T. C., Chin, K. S., \& Fraser, R. 2015. Increased precipitation drives mega slump development and destabilization of ice-rich permafrost terrain, northwestern Canada. Global and Planetary Change. 129, 56-68.

Lague, D., Brodu, N., \& Leroux, J. 2013. Accurate 3D comparison of complex topography with terrestrial laser scanner: Application to the Rangitikei canyon (N-Z). Journal of Photogrammetry and Remote Sensing, 82, 10-26.

Lato, M. J., Hutchinson, D. J., Gauthier, D., Edwards, T., \& Ondercin, M. 2015. Comparison of airborne laser scanning, terrestrial laser scanning, and terrestrial photogrammetry for mapping differential slope change in mountainous terrain. Canadian Geotechnical Journal, 52, 129-140.

Lambiel, C. \& Delaloye, R. 2004. Contribution of real-time kinematic GPS in the study of creeping mountain permafrost: examples from the Western Swiss 
Alps. Permafrost and Periglacial Environments, 15, 229-241.

Leica CS10/CS15 \& GS sensors user manual. 2013. Leica Geosystems AG, Heerbrugg, Switzerland.

Leica Nova MS50 white paper. 2013. Leica Geosystems AG, Heerbrugg, Switzerland. Lichti, D. D., Stewart, M. P., Tsakiri, M., \& Snow, A.J. 2000. Calibration and testing of a terrestrial laser scanner. The International Archives of the Photogrammetry, Remote Sensing and Spatial Information Sciences, 33, 485492.

Little, J. D., Sandall, H., Walegur, M. T., \& Nelson, F. E. 2003. Application of differential GPS to monitor frost heave and ground subsidence in tundra environments. Permafrost and Periglacial Environments, 14, 349-357.

Liu, L., Schaefer, K., M., Chen, A., C., Gusmeroli, A., Zebker, H. A., \& Zhang, T. 2015. Remote sensing measurements of thermokarst subsidence using InSAR. Journal of Geophysical Research: Earth Surface, 120, 1935-1948.

Mackay, J. R. 1970. Disturbances to the tundra and forest tundra envrionment of the western arctic. Canadian Geotechical Journal, 7, 420-432.

Mackay, J. R. 1972. The world of underground ice. Annals of the Association of American Geographers. 63, 1-22.

Mackay, J. R. 1973a. A frost tube for the determination of freezing in the active layer above permafrost. Canadian Geotechnical Journal, 10, 392-396.

Mackay, J. R. 1973b. The growth of pingos, western Arctic coast, Canada. Canadian Journal of Earth Sciences, 10, 979-1004.

Mackay J. R. 1976. Pulsating pingos, Tuktoyaktuk Peninsula, N.W.T.. Canadian Journal of Earth Sciences, 23, 543-549.

Mackay, J. R. 1983. Downward water movement into frozen ground, western arctic coast, Canada. Canadian Journal of Earth Sciences. 20, 120-134.

Mackay, J, R. 1984. The frost heave of stones in the active layer above permafrost with downward and upward freezing. Arctic and Alpine Research. 16, 439-446. 
Mackay, J, R. 1995. Active layer changes (1968 to 1993) following the forest-tundra fire near Inuvik, N.W.T., Canada. Arctic and Alpine Research. 27, 323-336. Marmy, A., Rajczak, J., Delaloye, R., Hilbich, C., Hoelzle, M., Kotlarski, S., Lambiel, C., Noetzli, J., Phillips, M., Salzmann, N., Staub, B., \& Hauck, C. 2016. Semi-automated calibration method for modelling of mountain permafrost evolution in Switzerland. The Cryosphere, 10, 2693-2719.

Massonnet, D. \& Feigl, K. 1998. Radar interferometry and its application to changes in the earth's surface. Reviews of Geophysics, 36, 441-500.

McRoberts, E. C. \& Morgenstern, N. R. 1974. The Stability of thawing slopes. Canadian Geotechnical Journal, 11, 447-469.

McRoberts, E. C. \& Morgenstern, N. R. 1975. Pore water expulsion during freezing. Canadian Geotechnical Journal, 12, 130-141.

Meng, X., Currit, N, \& Zhao, K. 2010. Ground filtering algorithms for airborne LiDAR data: a review of critical issues. Remote Sensing, 2, 833-860.

Meng, X., Wang, L., Silvan-Cardenas, J. L., \& Currit, N. 2009. A multi-directional ground filtering algorithm for airborne LIDAR. Journal of Photogrammetry and Remote Sensing, 64, 117-124.

Melvin, A. M., Larsen, P., Boehlert, B., Neumann, J. E., Chinowsky, P., Espinet, X., Martinichf, J., Baumannc, M. S., Rennelsc L., Bothnerc, A., Nicolskyg, D. J. \& Marchenkog, S. 2016. Climate change damages to Alaska public infrastructure and the economics of proactive adaptation. Proceedings of the National Academy of Sciences of the United States of America, 114, 122-131.

Minke, M., Donner, N., Karpov, N., de Klerk, P., \& Joosten, H. 2009. Patterns in vegetation composition, surface height and thaw depth in polygon mires in the Yakutian Arctic (NE Siberia): a microtopographical characterisation of the active layer. Permafrost and Periglacial Processes, 20, 357-368.

Morgenstern, N. R. \& Nixon, J. F. 1971. One-dimensional consolidation of thawing soils. Canadian Geotechnical Journal, 8, 558-565.

Murton, J. B., Peterson, R., \& Ozouf, J-C. 2006. Bedrock fracture by ice segregation 
in cold regions. Science, 314, 1127-1129.

National Snow and Ice Data Center. Circum-Arctic map of permafrost and ground-ice conditions, version 2. Boulder, Colorado USA. [Date Accessed: January 13, 2018.]

National Research Council. 2014. Opportunities to use remote sensing in understanding permafrost and related ecological characteristics: report of a workshop. Washington, USA.

Nelson, F. E. 1989. Permafrost zonation in eastern Canada: a review of published maps. Physical Geography, 10, 233-248.

Nelson, F. E., Anisimov, O. A., \& Shiklomanov, N. I. 2001. Subsidence risk from thawing permafrost. Nature, 410, 889-890.

Nelson, F. E., Hinkel K. M., Shiklomanov, N. I., \& Walker, D. A. 1998. Active-layer thickness in north central Alaska: systematic sampling, scale, and spatial autocorrelation. Journal of Geophysical Research, 103, 28963-28973.

Nelson, F. E., Shiklomanov, N. I., \& Mueller, G. R. 1999. Variability of active-layer thickness at multiple spatial scales, north-central Alaska, U.S.A. Arctic, Antarctic, and Alpine Research, 31, 158-165.

Nixon, F, M. 2000. Thaw depth monitoring. In the physical environment of the Mackenzie Valley: a baseline for the assessment of environmental change. Geological Survey of Canada, 547, 119-126.

Nixon, J. F. \& Morgenstern, N. R. 1973. Thaw-consolidation test on undisturbed fine-grained permafrost. Canadian Geotechnical Journal, 11, 202-214.

Nolan, M., \& Fatland, D. 2003. Penetration depth as a DInSAR observable and proxy for soil moisture. IEEE Transactions on Geoscience and Remote Sensing, 41, 532-537.

Northwest Territories Geological Survey. 2015. Slave province surficial materials and permafrost study. http://www.nwtgeoscience.ca/project/summary/slave -province-surficial-materials-and-permafrost-study. [Date accessed: May 10, $2015]$. 
Nouwakpo, S. K. \& Huang, C. 2012. A simplified close range photogrammetric technique for soil erosion assessment. Soil Science Society of America Journal, $76,70-84$.

Nouwakpo, S. K., Weltz, M. A., \& McGwire, K. 2016. Assessing the performance of structure from motion photogrammetry and terrestrial LiDAR for reconstructing soil surface microtopography of naturally vegetated plots. Earth Surface Processes and Landforms, 44, 308-322.

Oliver, M. A. \& Webster, M. 1986. Combining nested and linear sampling for determining the scale and form of spatial variation of regionalized variables. Geographical Analysis, 18, 227-242.

Overduin, P. P. \& Kane, D. L. 2006. Frost boils and soil ice content: field observations. Permafrost and Periglacial Processes, 17, 291-307.

Patterson, D. E. \& Smith, M. W. 1981. The measurement of unfrozen water content by time domain reflectometry: results from laboratory tests. Canadian Geotechnical Journal, 18, 131-144.

Pourali, H., Arrowsmith, C., Chrisman, N., \& Matkan, A. 2014. Vertical accuracy assessment of LiDAR ground points using minimum distance approach. Research at Locate, 86-96.

Quinton, W. L., Hayashi, M. \& Chasmer, L. E. 2011. Permafrost-thaw-induced land-cover change in the Canadian subarctic: implications for water resources. Hydrological Processes, 25, 152-158.

Rempel, A. W., Wettlaufer, J. S., \& Worster, M. G. 2004. Premelting dynamics in a continuum model of frost heave. Journal of Fluid Mechanics, 498, 227-244.

Rodriguez-Caballero, E., Afana, A., Chamizo, S., Sole-Benete, A., \& Canton, Y. 2016. A new adaptive method to filter terrestrial laser scanner point clouds using morphological filters and spectral information to conserve surface microtopography. Journal of Photogrammetry and Remote Sensing, 117, 141-148. Romanovsky, V. E., Marchenko, S. S., Daanen, R., Sergeev, D. O., \& Walker, D. A. 2008. Soil climate and frost heave along the permafrost/ecological North 
American arctic transect. Proceedings of the Ninth International Conference on Permafrost, 1519-1524.

Romanovsky, V. E., Drozdov, D. S., Oberman, N. G., Malkova, G. V., Kholodov, A. L., Marchenko, S. S., \& Vasiliev, A. A. 2010. Thermal state of permafrost in Russia. Permafrost and Periglacial Processes, 21, 136-155.

Singhroy, V., Alasset, P. J., Couture, R., \& Poncos, V. 2007. InSAR monitoring of landslides on permafrost terrain in Canada. IEEE International Geoscience and Remote Sensing Symposium, 2451-2454.

Sharma, M., Paige, G. B., \& Miller, S. N. 2010. DEM development from ground-based LiDAR data: a method to remove non-surface objects. Remote Sensing, 2, 2629-2642.

Shiklomanov, N. I., Streletskiy, D. A, Nelson, F. E., Hollister, R. D., Romanovsky, V. E., Tweedie, C. E., Bockheim, J. G., \& Brown, J. 2010. Decadal variations of active-layer thickness in moisture-controlled landscapes, Barrow Alaska, Journal of Geophysical Research, 115, G00I04.

Shiklomanov, N. I., Streletskiy, D. A., Little, J. D., \& Nelson, F. E. 2013. Isotropic thaw subsidence in undisturbed permafrost landscapes, Geophysical Research Letters, 40, 6356-6361.

Short, N., Brisco, B., Couture, N., Pollard, W., Murnaghan, K., \& Budkewitsch, P. 2011. A comparison of TerraSAR-X, RADARSAT-2 and ALOS-PALSAR interferometry for monitoring permafrost environments, case study from Herschel Island, Canada. Remote Sensing of Environment. 115, 3491-3506.

Short, N., LeBlanc, A., Sladen, W., \& Brisco, B. 2013. RADARSAT-2 InSAR for Monitoring permafrost environments: Pangnirtung and Iqaluit. IEEE Radar Conference, Ottawa, ON, 1-4.

Shur, Y., Hinkel, K. M., \& Nelson, F. E. 2005. The transient layer: implications for geocryology and climate-change science. Permafrost and Periglacial Processes, 16, 5-17.

Shur, Y. L., Jorgenson, M. T. 2007. Patterns of permafrost formation and degradation 
in relation to climate and ecosystems. Permafrost and Periglacial Processes, $18,7-19$.

Smith, D. G. 1994. Glacial lake McConnell: paleogeography, age, duration, and associated river deltas, Mackenzie River Basin, western Canada. Quaternary Science Reviews, 13, 829-843.

Smith, D. J. 1987. Frost-Heave Activity in the Mount Rae Area, Canadian Rocky Mountains. Arctic and Alpine Research, 19, 155-166.

Smith, M. W. 1975. Microclimatic influences on ground temperatures and permafrost distribution, Mackenzie Delta, Northwest Territories. Canadian Journal of Earth Sciences, 12, 1421-1438.

Smith, M. W. 1985. Observations of soil freezing and frost heave at Inuvik, Northwest Territories, Canada. Canadian Journal of Earth Sciences, 22, 283-290.

Smith, M. W. \& Riseborough, D. W. 2002. Climate and the limits of permafrost: a zonal analysis. Permafrost and Periglacial Processes, 13, 1-15.

Smith, M. W. 2015. 2.1.5. Direct acquisition of elevation data: terrestrial laser scanning geomorphological of TLS applications, 1, 1-14.

Smith, S. L., Romanovsky, V. E., Lewkowicz, A. G., Burn, C. R., Allard, M., Clow, G. D., \& Throop, J. 2010. Thermal state of permafrost in North America: a contribution to the international polar year. Permafrost and Periglacial Processes, 21, 117-135.

Soudarissanane, S., Lindenbergh, R., Menenti, M., \& Teunissen, P. 2011. Scanning geometry: Influencing factor on the quality of terrestrial laser scanning points. Journal of Photogrammetry and Remote Sensing, 66, 389-399.

Statistics Canada. 2016. Census agglomeration of Yellowknife, Northwest Territories. http://www12.statcan.gc.ca/census-recensement/2011/as-sa/fogs-spg/Factscma-eng.cfm?LANG=Eng\& GK=CMA\& GC=995. [Date accessed: April 6, 2017].

Stevens, C. W. \& Wolfe, S. A. 2012. High-resolution mapping of wet terrain within discontinuous permafrost using LiDAR intensity. Permafrost and 
Periglacial Processes, 23, 334-341.

Sturm, M., McFadden, J. P., Liston, G. E., Chapin III, F. S., Racine, C. H., \& Holmgren, J. 2001. Snow-shrub interactions in arctic tundra: a hypothesis with climatic implications. Journal of Climate, 14, 336-344.

Subedi, R. Depth profiles of geochemistry and organic carbon from permafrost and active layer soils in tundra landscapes near Lac de Gras, Northwest Territories, Canada. M.Sc. Thesis, Carleton University, Ottawa, Canada.

Taber, S. 1930. The mechanics of frost heaving. Journal of Geology, 38, 303-317.

Tarnocai, C. \& Zoltai, S. C. 1978. Earth hummocks of the Canadian arctic and subarctic. Arctic and Alpine Research, 10, 581-594.

Thomsen, L. M., Baartman, J. E. M., Barneveld, R. J., Starkloff, T., \& Stolte, J. 2015. Soil surface roughness: comparing old and new measuring methods and application in a soil erosion model. Soil, 1, 399-410.

Ullman, S. 1979. The interpretation of structure from motion. Proceedings of the Royal Society London B, 405-426.

Vaughan, D.G., Comiso, J.C., Allison, I., Carrasco, J.,Kaser, G.,Kwok, R, Mote, P., Murray, T., Paul, F., Ren, J., Rignot, E., Solomina, O., Steffen, K., \& Zhang, T. 2013. Observations: Cryosphere. In: Climate Change 2013: The Physical Science Basis. Contribution of Working Group I to the Fifth Assessment Report of the Intergovernmental Panel on Climate Change [Stocker, T.F., D. Qin, G.-K. Plattner, M. Tignor, S.K. Allen, J. Boschung, A. Nauels, Y. Xia, V. Bex and P.M. Midgley (eds.)]. Cambridge University Press, Cambridge, United Kingdom and New York, NY, USA.

Vincent, W.F., Lemay, M., \& Allard, M. 2017. Arctic permafrost landscapes in transition: towards an integrated Earth system approach. Arctic Science, 3, 39-64.

Vosselman, G. \& Maas, H. G. 2010. Airborne and terrestrial laser scanning. Whittles Publishing, Dunbeath: Scotland.

Wang, C., Menenti, M., Stoll, M., Feola, A., Belluco, E., \& Marani, M. 2009. 
Separation of ground and low vegetation signatures in LiDAR measurements of salt marsh environments. IEEE Transactions on Geoscience and Remote Sensing, 47, 2014-2023.

Welch, B. L. 1947. The generalization of Student's problem when several different population variances are involved. Biometrika, 34, 28-35.

Westermann, S., Duguay, C. R., Grosse, G., \& Kääb, A. 2015. Remote sensing of permafrost and frozen ground. Remote Sensing of the Cryosphere, John Wiley \& Sons, 307-344.

Wheaton, J. M., Brasington, J., Darby, S. E., \& Sear, D. A. 2010. Accounting for uncertainty in DEMs from repeat topographic surveys: improved sediment budgets. Earth Surface Processes and Landforms, 35, 136-156.

Williams, P. J. \& Smith, M. W. 1989. The frozen earth: fundamentals of geocryology. Cambridge university press: England.

Wolfe, S. A. 1998. Living with frozen ground - a field guide to permafrost in Yellowknife. Geological Survey of Canada.

Wolfe, S. A., Short, N. H., Morse, P. D., Schwarz, S. H., \& Stevens, C. W. 2014. Evaluation of RADARSAT-2 DInSAR seasonal surface displacement in discontinuous permafrost terrain, Yellowknife, Northwest Territories, Canada. Canadian Journal of Remote Sensing, 40, 406-422.

Woo, M. 2012. Permafrost hydrology. Springer: New York.

Young, I. M. \& Crawford, J. W. 1991. The fractal structure of soil aggregates: its measurement and interpretation. Journal of Soil Science, 42, 187-192.

Yuen, K. K. 1947. The two-sample trimmed t for unequal population variances. Biometrika, 61, 165-170. 


\section{Appendix A}

\section{Field}

\section{A.1 Field form}

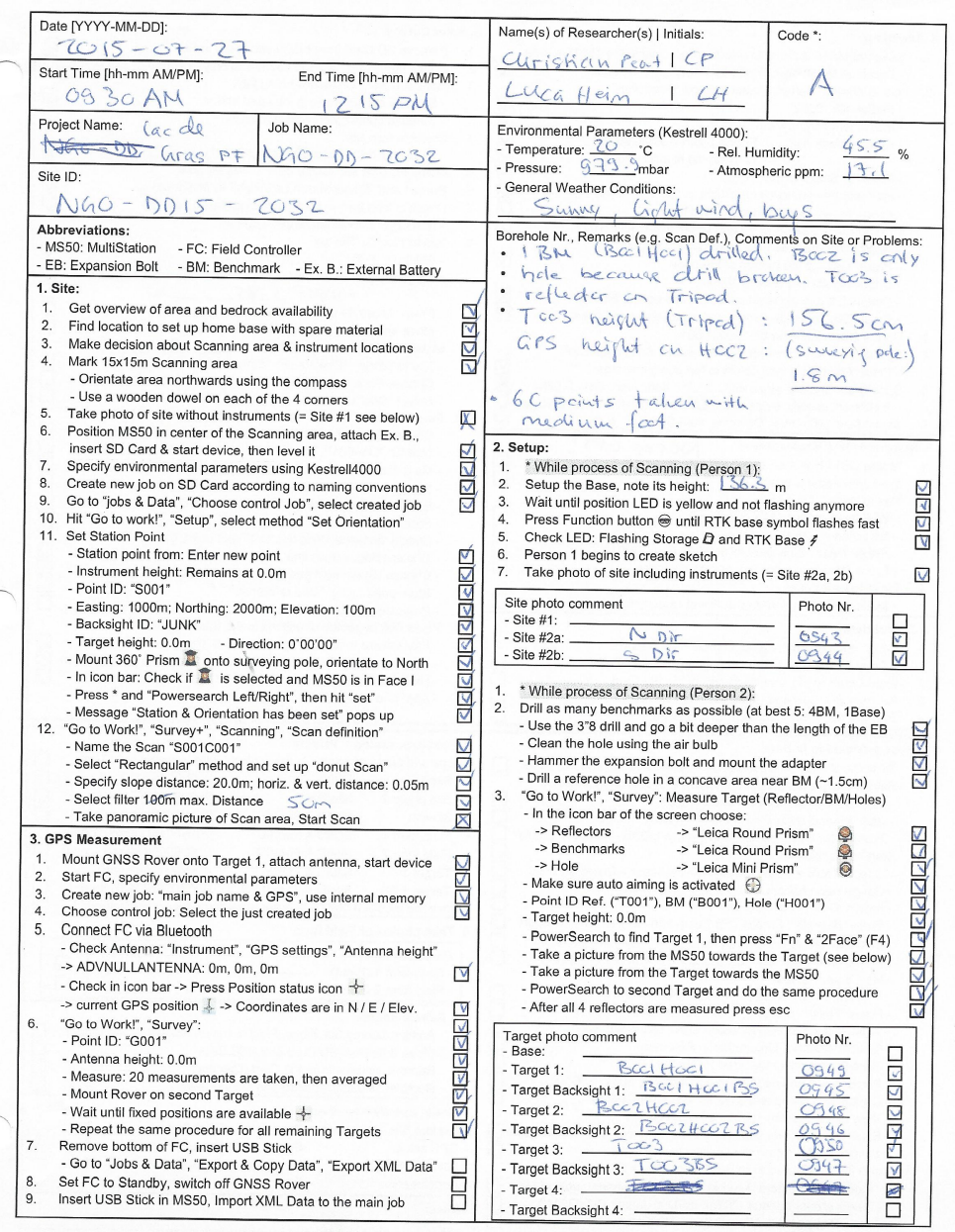




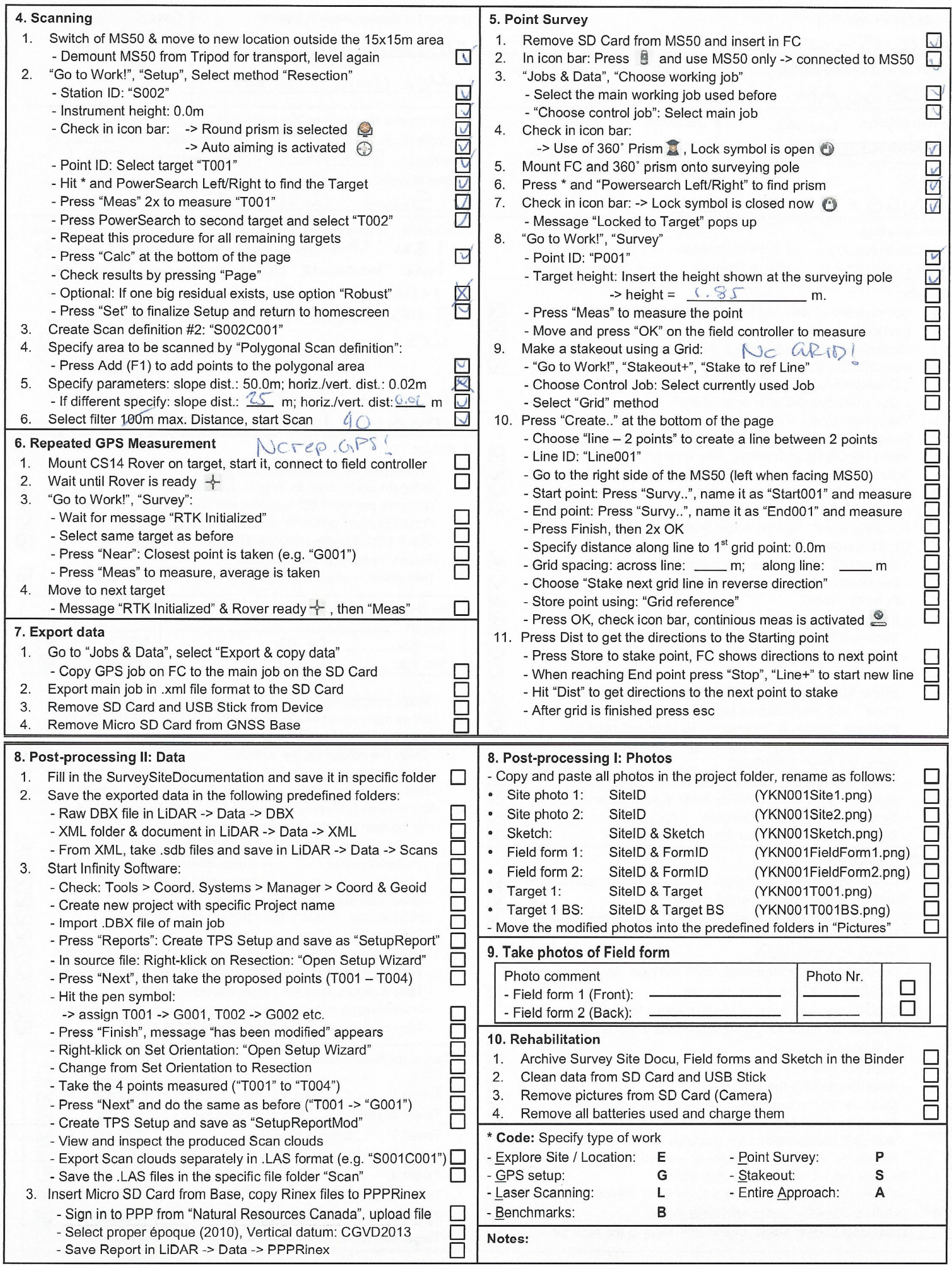




\section{A.2 Site specific characteristics}

Table A.1: Location of sites

\begin{tabular}{llll}
\hline Site & $\begin{array}{l}\text { Longitude } \\
\text { (Decimal Degrees) }\end{array}$ & $\begin{array}{l}\text { Latitude } \\
(\text { Decimal Degrees) }\end{array}$ & $\begin{array}{l}\text { Elevation } \\
(\mathrm{m})\end{array}$ \\
\hline NGO-DD-1004 & -110.238127 & 64.595127 & 471.401 \\
NGO-DD-1005 & -110.235542 & 64.599853 & 440.012 \\
NGO-DD-1010 & -110.439844 & 64.702748 & 426.212 \\
NGO-DD-2004 & -110.236447 & 64.596293 & 480.004 \\
NGO-DD-2005 & -110.233122 & 64.596657 & 471.732 \\
NGO-DD-2007 & -110.235505 & 64.598465 & 458.723 \\
NGO-DD-2008/2028 & -110.185064 & 64.600307 & 458.413 \\
NGO-DD-2009 & -110.216826 & 64.604114 & 446.402 \\
NGO-DD-2011 & -110.447846 & 64.702359 & 431.673 \\
NGO-DD-2013 & -110.450045 & 64.702772 & 435.446 \\
NGO-DD-2015 & -110.442076 & 64.703517 & 427.369 \\
NGO-DD-2016 & -110.444099 & 64.704523 & 432.619 \\
NGO-DD-2019 & -110.435624 & 64.702123 & 428.081 \\
NGO-DD-2020 & -110.402547 & 64.729835 & 485.729 \\
NGO-DD-2023 & -110.420613 & 64.820723 & 475.938 \\
NGO-DD-2026 & -110.345046 & 64.724568 & 436.812 \\
NGO-DD-2029 & -110.184591 & 64.600141 & 458.253 \\
NGO-DD-2030 & -110.469660 & 64.853042 & 479.501 \\
NGO-DD-2032 & -110.547688 & 64.629251 & 441.788 \\
NGO-DD-2033 & -110.215211 & 64.605420 & 457.875 \\
NGO-DD-2034 & -110.211796 & 64.604814 & 449.042 \\
NGO-DD-2035 & -110.234163 & 64.599938 & 445.574 \\
NGO-RC-164 & -110.347576 & 64.722144 & 430.853 \\
NGO-RC-165 & -110.347837 & 64.721574 & 430.583 \\
NGO-RC-166 & -110.260336 & 64.634593 & 442.747 \\
NGO-RC-168 & -110.220828 & 64.641140 & 452.941 \\
NGO-RC-170 & -110.190208 & 64.591785 & 429.627 \\
NGO-RC-171 & -110.188006 & 64.591575 & 434.999 \\
\hline
\end{tabular}


Table A.2: Maximum vertical error associated with resection per plot

\begin{tabular}{ll}
\hline ID & Maximum vertical error $(\mathrm{mm})$ expected from each resection \\
\hline NGO-DD-1004 & 9.9 \\
NGO-DD-1005 & 10.2 \\
NGO-DD-1010 & 12.7 \\
NGO-DD-2004 & 9.4 \\
NGO-DD-2005 & 9.4 \\
NGO-DD-2007 & 6.6 \\
NGO-DD-2008/2028 & 9.8 \\
NGO-DD-2009 & 4.2 \\
NGO-DD-2011 & 11.7 \\
NGO-DD-2013 & 5.7 \\
NGO-DD-2015 & 5.8 \\
NGO-DD-2016 & 10.2 \\
NGO-DD-2019 & 8.5 \\
NGO-DD-2020 & 3.6 \\
NGO-DD-2023 & 2.0 \\
NGO-DD-2026 & 10.2 \\
NGO-DD-2029 & 3.8 \\
NGO-DD-2030 & 0.7 \\
NGO-DD-2032 & 2.3 \\
NGO-DD-2033 & 9.5 \\
NGO-DD-2034 & 0.5 \\
NGO-DD-2035 & 3.4 \\
NGO-RC-164 & 6.0 \\
NGO-RC-165 & 9.2 \\
NGO-RC-166 & 2.5 \\
NGO-RC-168 & 2.5 \\
NGO-RC-170 & 8.3 \\
NGO-RC-171 & 10.0 \\
\hline
\end{tabular}




\title{
Appendix B
}

\section{Complementary results}

\author{
B.1 Complete results of data
}


Table B.1: All study sites with the different types of method used, the number of survey points/the number of grid cells with the minimum value, the mean elevation $(\mathrm{m})$, the deviation of the mean relative to the medium point attachment, the range of the scans means, the minimum vertical detection limit, and the confidence intervals. The total station methods are listed as PM, PR, PW, or PN for the respective attachments. The terrestrial LiDAR method is using all the combined scans as one scan.

\begin{tabular}{|c|c|c|c|c|c|c|c|c|c|}
\hline Site & Method & $\begin{array}{l}\text { Scan Cloud } \\
\text { Points }\end{array}$ & $\begin{array}{l}\text { Survey Points/ } \\
\text { Grid Cells } \\
\text { with Min Value }\end{array}$ & Mean $(\mathrm{m})$ & $\begin{array}{l}\text { Deviation of } \\
\text { Mean }(\mathrm{m})\end{array}$ & $\begin{array}{l}\text { TLS Range } \\
\text { of Means } \\
(\mathrm{cm})\end{array}$ & $\begin{array}{l}\text { Min } \\
\text { CI } \\
(\mathrm{m})\end{array}$ & $\begin{array}{l}\text { Max } \\
\text { CI } \\
(\mathrm{m})\end{array}$ & $\begin{array}{l}\text { Range } \\
\text { CI } \\
(\mathrm{cm})\end{array}$ \\
\hline 1004 & $\mathrm{PM}$ & $\mathrm{N} / \mathrm{A}$ & 50 & 98.612 & 0 & & 98.442 & 98.775 & 0.333 \\
\hline 1004 & Scans Combined & 1910975 & 256 & 98.281 & -0.331 & & 98.220 & 98.340 & 0.120 \\
\hline 1004 & $\mathrm{~S} 1$ & 1103119 & 252 & 98.289 & -0.323 & 23.8 & 98.225 & 98.353 & 0.128 \\
\hline 1004 & $\mathrm{~S} 2$ & 241160 & 199 & 98.527 & -0.085 & & 98.462 & 98.593 & 0.131 \\
\hline 1004 & $\mathrm{~S} 3$ & 366748 & 235 & 98.368 & -0.244 & & 98.306 & 98.434 & 0.128 \\
\hline 1004 & $\mathrm{~S} 4$ & 199948 & 205 & 98.470 & -0.142 & & 98.402 & 98.540 & 0.138 \\
\hline 1005 & $\mathrm{PM}$ & $\mathrm{N} / \mathrm{A}$ & 60 & 98.611 & 0 & & 98.450 & 98.774 & 0.324 \\
\hline 1005 & Scans Combined & 1819812 & 256 & 98.108 & -0.503 & & 98.080 & 98.130 & 0.050 \\
\hline 1005 & $\mathrm{~S} 1$ & 705801 & 247 & 98.127 & -0.484 & 7.5 & 98.104 & 98.150 & 0.046 \\
\hline 1005 & $\mathrm{~S} 2$ & 285556 & 210 & 98.202 & -0.409 & & 98.179 & 98.226 & 0.047 \\
\hline
\end{tabular}

Continued on next page 
Table B.1 - continued from previous page

\begin{tabular}{|c|c|c|c|c|c|c|c|c|c|}
\hline Site & Method & $\begin{array}{l}\text { Scan Cloud } \\
\text { Points }\end{array}$ & $\begin{array}{l}\text { Survey Points/ } \\
\text { Grid Cells } \\
\text { with Min Value }\end{array}$ & Mean (m) & $\begin{array}{l}\text { Deviation of } \\
\text { Mean }(\mathrm{m})\end{array}$ & $\begin{array}{l}\text { TLS Range } \\
\text { of Means } \\
(\mathrm{cm})\end{array}$ & $\begin{array}{l}\text { Min } \\
\text { CI } \\
(\mathrm{m})\end{array}$ & $\begin{array}{l}\text { Max } \\
\text { CI } \\
(\mathrm{m})\end{array}$ & $\begin{array}{l}\text { Range } \\
\text { CI } \\
(\mathrm{cm})\end{array}$ \\
\hline 1005 & S3 & 312619 & 234 & 98.168 & -0.443 & & 98.143 & 98.194 & 0.051 \\
\hline 1005 & $\mathrm{~S} 4$ & 515836 & 213 & 98.200 & -0.411 & & 98.178 & 98.223 & 0.045 \\
\hline 1010 & Scans Combined & 1325410 & 210 & 91.502 & -0.032 & & 91.490 & 91.510 & 0.020 \\
\hline 1010 & $\mathrm{~S} 1$ & 640117 & 206 & 91.508 & -0.026 & 7.9 & 91.498 & 91.518 & 0.020 \\
\hline 1010 & $\mathrm{~S} 2$ & 469252 & 208 & 91.550 & 0.016 & & 91.542 & 91.558 & 0.016 \\
\hline 1010 & S3 & 216041 & 184 & 91.587 & 0.053 & & 91.576 & 91.597 & 0.021 \\
\hline 2004 & $\mathrm{~S} 1$ & 1851279 & 246 & 98.383 & -0.032 & 6.5 & 98.374 & 98.392 & 0.018 \\
\hline 2004 & $\mathrm{~S} 2$ & 415557 & 232 & 98.448 & 0.033 & & 98.439 & 98.456 & 0.017 \\
\hline 2004 & S3 & 645196 & 250 & 98.419 & 0.004 & & 98.410 & 98.430 & 0.020 \\
\hline
\end{tabular}


Table B.1 - continued from previous page

\begin{tabular}{|c|c|c|c|c|c|c|c|c|c|}
\hline Site & Method & $\begin{array}{l}\text { Scan Cloud } \\
\text { Points }\end{array}$ & $\begin{array}{l}\text { Survey Points/ } \\
\text { Grid Cells } \\
\text { with Min Value }\end{array}$ & Mean (m) & $\begin{array}{l}\text { Deviation of } \\
\text { Mean }(\mathrm{m})\end{array}$ & $\begin{array}{l}\text { TLS Range } \\
\text { of Means } \\
(\mathrm{cm})\end{array}$ & $\begin{array}{l}\text { Min } \\
\text { CI } \\
(\mathrm{m})\end{array}$ & $\begin{array}{l}\text { Max } \\
\text { CI } \\
(\mathrm{m})\end{array}$ & $\begin{array}{l}\text { Range } \\
\text { CI } \\
(\mathrm{cm})\end{array}$ \\
\hline 2004 & $\mathrm{~S} 4$ & 728660 & 216 & 98.404 & -0.011 & & 98.395 & 98.413 & 0.018 \\
\hline 2004 & S5 & 612097 & 244 & 98.399 & -0.016 & & 98.388 & 98.408 & 0.020 \\
\hline 2005 & $\mathrm{PM}$ & $\mathrm{N} / \mathrm{A}$ & 50 & 98.307 & 0 & & 98.192 & 98.421 & 0.229 \\
\hline 2005 & Scans Combined & 1956742 & 256 & 98.318 & 0.011 & & 98.260 & 98.380 & 0.120 \\
\hline 2005 & $\mathrm{~S} 1$ & 708029 & 250 & 98.346 & 0.039 & 11.5 & 98.287 & 98.402 & 0.115 \\
\hline 2005 & $\mathrm{~S} 2$ & 175039 & 212 & 98.457 & 0.15 & & 98.400 & 98.515 & 0.115 \\
\hline 2005 & $\mathrm{~S} 3$ & 1073674 & 249 & 98.342 & 0.035 & & 98.281 & 98.406 & 0.125 \\
\hline 2007 & $\mathrm{PM}$ & $\mathrm{N} / \mathrm{A}$ & 50 & 97.762 & 0 & & 97.624 & 97.896 & 0.272 \\
\hline 2007 & Scans Combined & 2827220 & 256 & 98.266 & 0.504 & & 98.180 & 98.350 & 0.170 \\
\hline 2007 & $\mathrm{~S} 1$ & 706169 & 252 & 98.289 & 0.527 & 12.4 & 98.203 & 98.370 & 0.167 \\
\hline 2007 & $\mathrm{~S} 2$ & 521960 & 241 & 98.386 & 0.624 & & 98.307 & 98.463 & 0.156 \\
\hline 2007 & S3 & 1131362 & 243 & 98.267 & 0.505 & & 98.176 & 98.361 & 0.185 \\
\hline
\end{tabular}


Table B.1 - continued from previous page

\begin{tabular}{|c|c|c|c|c|c|c|c|c|c|}
\hline Site & Method & $\begin{array}{l}\text { Scan Cloud } \\
\text { Points }\end{array}$ & $\begin{array}{l}\text { Survey Points/ } \\
\text { Grid Cells } \\
\text { with Min Value }\end{array}$ & Mean $(\mathrm{m})$ & $\begin{array}{l}\text { Deviation of } \\
\text { Mean }(\mathrm{m})\end{array}$ & $\begin{array}{l}\text { TLS Range } \\
\text { of Means } \\
(\mathrm{cm})\end{array}$ & $\begin{array}{l}\text { Min } \\
\text { CI } \\
(\mathrm{m})\end{array}$ & $\begin{array}{l}\text { Max } \\
\text { CI } \\
(\mathrm{m})\end{array}$ & $\begin{array}{l}\text { Range } \\
\text { CI } \\
(\mathrm{cm})\end{array}$ \\
\hline 2007 & $\mathrm{~S} 4$ & 467729 & 229 & 98.262 & 0.5 & & 98.174 & 98.349 & 0.175 \\
\hline $2008 / 2028$ & PM & $\mathrm{N} / \mathrm{A}$ & 50 & 98.533 & 0 & & 98.520 & 98.547 & 0.027 \\
\hline $2008 / 2028$ & Scans Combined & 1953443 & 225 & 98.524 & -0.009 & & 98.510 & 98.530 & 0.020 \\
\hline $2008 / 2028$ & S1 & 686957 & 218 & 98.537 & 0.004 & 2.2 & 98.527 & 98.546 & 0.019 \\
\hline $2008 / 2028$ & $\mathrm{~S} 2$ & 849497 & 217 & 98.558 & 0.025 & & 98.546 & 98.569 & 0.023 \\
\hline $2008 / 2028$ & $\mathrm{~S} 3$ & 416989 & 204 & 98.559 & 0.026 & & 98.550 & 98.570 & 0.020 \\
\hline 2009 & $\mathrm{PM}$ & $\mathrm{N} / \mathrm{A}$ & 50 & 98.276 & 0 & & 98.141 & 98.417 & 0.276 \\
\hline 2009 & Scans Combined & 1432278 & 256 & 98.198 & -0.078 & & 98.140 & 98.250 & 0.110 \\
\hline 2009 & $\mathrm{~S} 1$ & 545110 & 245 & 98.207 & -0.069 & 14.4 & 98.151 & 98.262 & 0.111 \\
\hline 2009 & $\mathrm{~S} 2$ & 479561 & 225 & 98.170 & -0.106 & & 98.114 & 98.227 & 0.113 \\
\hline 2009 & S3 & 407607 & 233 & 98.314 & 0.038 & & 98.265 & 98.367 & 0.102 \\
\hline 2011 & $\mathrm{PM}$ & $\mathrm{N} / \mathrm{A}$ & 50 & 98.439 & 0 & & 98.410 & 98.468 & 0.058 \\
\hline
\end{tabular}


Table B.1 - continued from previous page

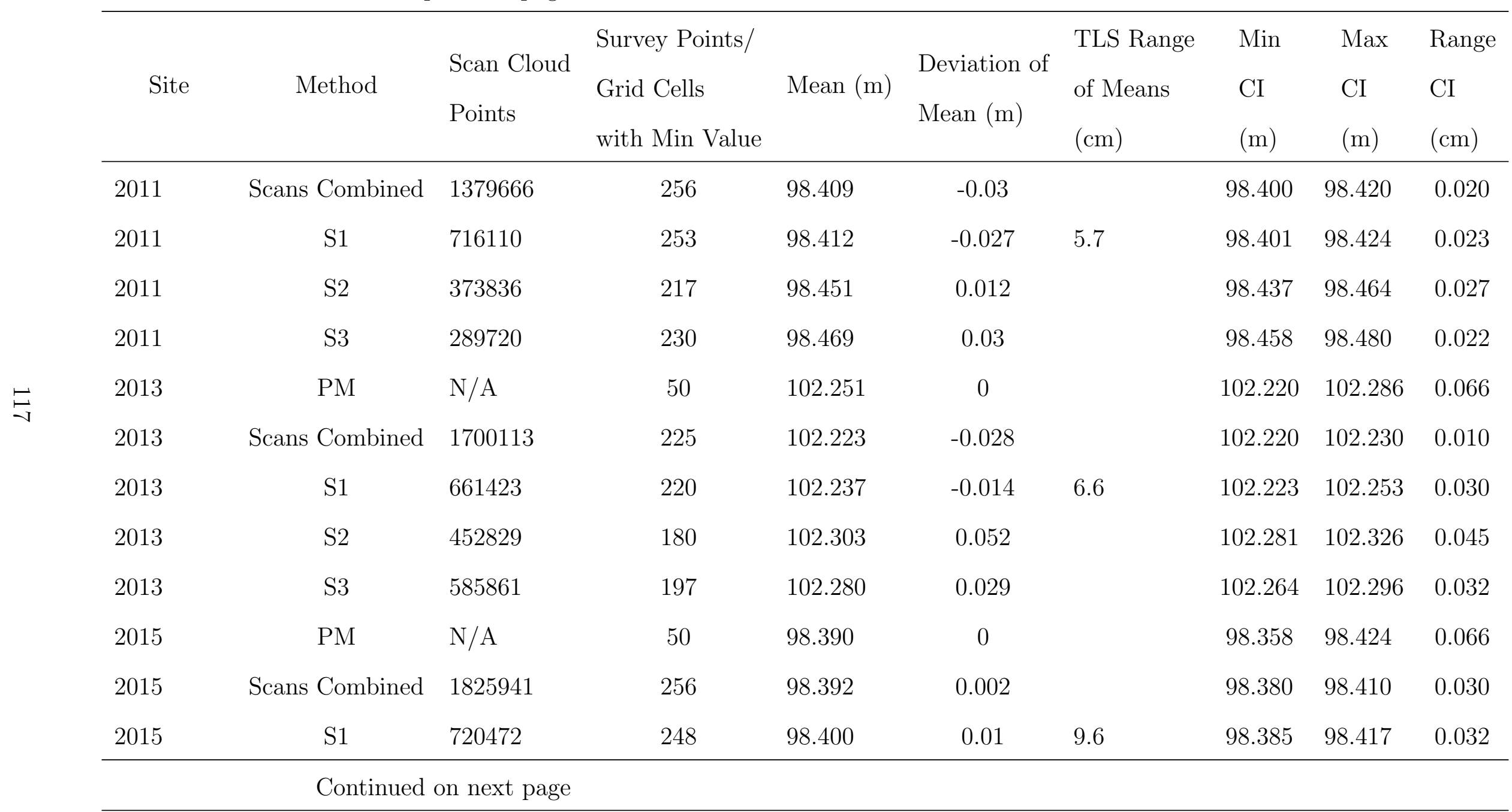


Table B.1 - continued from previous page

\begin{tabular}{|c|c|c|c|c|c|c|c|c|c|}
\hline Site & Method & $\begin{array}{l}\text { Scan Cloud } \\
\text { Points }\end{array}$ & $\begin{array}{l}\text { Survey Points/ } \\
\text { Grid Cells } \\
\text { with Min Value }\end{array}$ & Mean (m) & $\begin{array}{l}\text { Deviation of } \\
\text { Mean }(\mathrm{m})\end{array}$ & $\begin{array}{l}\text { TLS Range } \\
\text { of Means } \\
(\mathrm{cm})\end{array}$ & $\begin{array}{l}\text { Min } \\
\text { CI } \\
(\mathrm{m})\end{array}$ & $\begin{array}{l}\text { Max } \\
\text { CI } \\
(\mathrm{m})\end{array}$ & $\begin{array}{l}\text { Range } \\
\text { CI } \\
(\mathrm{cm})\end{array}$ \\
\hline 2015 & $\mathrm{~S} 2$ & 604663 & 244 & 98.465 & 0.075 & & 98.449 & 98.480 & 0.031 \\
\hline 2015 & S3 & 500806 & 237 & 98.496 & 0.106 & & 98.478 & 98.513 & 0.035 \\
\hline 2016 & PM & $\mathrm{N} / \mathrm{A}$ & 50 & 98.482 & 0 & & 98.396 & 98.572 & 0.176 \\
\hline 2016 & Scans Combined & 3143205 & 256 & 98.371 & -0.111 & & 98.340 & 98.400 & 0.060 \\
\hline 2016 & S1 & 692076 & 251 & 98.387 & -0.095 & 4.6 & 98.350 & 98.422 & 0.072 \\
\hline 2016 & $\mathrm{~S} 2$ & 355440 & 232 & 98.383 & -0.099 & & 98.347 & 98.422 & 0.075 \\
\hline 2016 & $\mathrm{~S} 3$ & 483271 & 237 & 98.414 & -0.068 & & 98.381 & 98.446 & 0.065 \\
\hline 2016 & $\mathrm{~S} 4$ & 1612418 & 237 & 98.368 & -0.114 & & 98.337 & 98.401 & 0.064 \\
\hline 2019 & $\mathrm{PM}$ & $\mathrm{N} / \mathrm{A}$ & 50 & 93.478 & 0 & & 93.439 & 93.517 & 0.078 \\
\hline 2019 & Scans Combined & 1653487 & 225 & 93.507 & 0.029 & & 93.490 & 93.520 & 0.030 \\
\hline 2019 & $\mathrm{~S} 1$ & 572796 & 212 & 93.524 & 0.046 & 5.2 & 93.505 & 93.544 & 0.039 \\
\hline 2019 & $\mathrm{~S} 2$ & 569672 & 206 & 93.576 & 0.098 & & 93.555 & 93.598 & 0.043 \\
\hline
\end{tabular}


Table B.1 - continued from previous page

\begin{tabular}{|c|c|c|c|c|c|c|c|c|c|}
\hline Site & Method & $\begin{array}{l}\text { Scan Cloud } \\
\text { Points }\end{array}$ & $\begin{array}{l}\text { Survey Points/ } \\
\text { Grid Cells } \\
\text { with Min Value }\end{array}$ & Mean (m) & $\begin{array}{l}\text { Deviation of } \\
\text { Mean }(\mathrm{m})\end{array}$ & $\begin{array}{l}\text { TLS Range } \\
\text { of Means } \\
(\mathrm{cm})\end{array}$ & $\begin{array}{l}\text { Min } \\
\text { CI } \\
(\mathrm{m})\end{array}$ & $\begin{array}{l}\text { Max } \\
\text { CI } \\
(\mathrm{m})\end{array}$ & $\begin{array}{l}\text { Range } \\
\text { CI } \\
(\mathrm{cm})\end{array}$ \\
\hline 2019 & $\mathrm{~S} 3$ & 511019 & 203 & 93.541 & 0.063 & & 93.521 & 93.561 & 0.040 \\
\hline 2020 & PM & $\mathrm{N} / \mathrm{A}$ & 50 & 98.075 & 0 & & 97.971 & 98.183 & 0.212 \\
\hline 2020 & $\mathrm{~S} 1$ & 618655 & 236 & 98.198 & 0.123 & 12.7 & 98.164 & 98.232 & 0.068 \\
\hline 2020 & $\mathrm{~S} 2$ & 173386 & 167 & 98.112 & 0.037 & & 98.054 & 98.170 & 0.116 \\
\hline 2020 & $\mathrm{~S} 3$ & 642348 & 180 & 98.239 & 0.164 & & 98.208 & 98.268 & 0.060 \\
\hline 2023 & $\mathrm{PM}$ & $\mathrm{N} / \mathrm{A}$ & 50 & 98.296 & 0 & & 98.214 & 98.381 & 0.167 \\
\hline 2023 & $\mathrm{~S} 2$ & 262821 & 209 & 98.192 & -0.104 & & 98.158 & 98.224 & 0.066 \\
\hline 2026 & $\mathrm{PM}$ & $\mathrm{N} / \mathrm{A}$ & 50 & 98.411 & 0 & & 98.318 & 98.510 & 0.192 \\
\hline 2026 & Scans Combined & 1042888 & 256 & 98.370 & -0.041 & & 98.330 & 98.410 & 0.080 \\
\hline
\end{tabular}


Table B.1 - continued from previous page

\begin{tabular}{|c|c|c|c|c|c|c|c|c|c|}
\hline Site & Method & $\begin{array}{l}\text { Scan Cloud } \\
\text { Points }\end{array}$ & $\begin{array}{l}\text { Survey Points/ } \\
\text { Grid Cells } \\
\text { with Min Value }\end{array}$ & Mean $(\mathrm{m})$ & $\begin{array}{l}\text { Deviation of } \\
\text { Mean }(\mathrm{m})\end{array}$ & $\begin{array}{l}\text { TLS Range } \\
\text { of Means } \\
(\mathrm{cm})\end{array}$ & $\begin{array}{l}\text { Min } \\
\text { CI } \\
(\mathrm{m})\end{array}$ & $\begin{array}{l}\text { Max } \\
\text { CI } \\
(\mathrm{m})\end{array}$ & $\begin{array}{l}\text { Range } \\
\text { CI } \\
(\mathrm{cm})\end{array}$ \\
\hline 2026 & $\mathrm{~S} 1$ & 684365 & 252 & 98.374 & -0.037 & 2.4 & 98.329 & 98.418 & 0.089 \\
\hline 2026 & $\mathrm{~S} 2$ & 250292 & 254 & 98.388 & -0.023 & & 98.345 & 98.429 & 0.084 \\
\hline 2029 & $\mathrm{PM}$ & $\mathrm{N} / \mathrm{A}$ & 60 & 98.334 & 0 & & 98.297 & 98.371 & 0.074 \\
\hline 2029 & Scans Combined & 1507426 & 256 & 98.304 & -0.03 & & 98.290 & 98.320 & 0.030 \\
\hline 2029 & $\mathrm{~S} 1$ & 703250 & 252 & 98.308 & -0.026 & 3.2 & 98.292 & 98.325 & 0.033 \\
\hline 2029 & $\mathrm{~S} 2$ & 288694 & 237 & 98.314 & -0.02 & & 98.297 & 98.332 & 0.035 \\
\hline 2030 & Scans Combined & 1363457 & 255 & 98.292 & -0.159 & & 98.240 & 98.340 & 0.100 \\
\hline 2030 & $\mathrm{~S} 1$ & 142258 & 63 & 98.671 & 0.22 & 37.142 & 98.631 & 98.713 & 0.082 \\
\hline 2030 & $\mathrm{~S} 1 \mathrm{C} 1$ & 706630 & 251 & 98.300 & -0.15142 & & 98.240 & 98.340 & 0.100 \\
\hline
\end{tabular}


Table B.1 - continued from previous page

\begin{tabular}{|c|c|c|c|c|c|c|c|c|c|}
\hline Site & Method & $\begin{array}{l}\text { Scan Cloud } \\
\text { Points }\end{array}$ & $\begin{array}{l}\text { Survey Points/ } \\
\text { Grid Cells } \\
\text { with Min Value }\end{array}$ & Mean $(\mathrm{m})$ & $\begin{array}{l}\text { Deviation of } \\
\text { Mean }(\mathrm{m})\end{array}$ & $\begin{array}{l}\text { TLS Range } \\
\text { of Means } \\
(\mathrm{cm})\end{array}$ & $\begin{array}{l}\text { Min } \\
\text { CI } \\
(\mathrm{m})\end{array}$ & $\begin{array}{l}\text { Max } \\
\text { CI } \\
(\mathrm{m})\end{array}$ & $\begin{array}{l}\text { Range } \\
\text { CI } \\
(\mathrm{cm})\end{array}$ \\
\hline 2030 & $\mathrm{~S} 2$ & 299038 & 214 & 98.301 & -0.15 & & 98.247 & 98.355 & 0.108 \\
\hline 2030 & S3 & 215531 & 212 & 98.437 & -0.014 & & 98.391 & 98.482 & 0.091 \\
\hline 2032 & $\mathrm{PM}$ & $\mathrm{N} / \mathrm{A}$ & 60 & 98.435 & 0 & & 98.370 & 98.497 & 0.127 \\
\hline 2032 & Scans Combined & 992755 & 256 & 98.341 & -0.094 & & 98.320 & 98.370 & 0.050 \\
\hline 2032 & S1 & 690873 & 252 & 98.344 & -0.091 & 9.9 & 98.316 & 98.370 & 0.054 \\
\hline 2032 & $\mathrm{~S} 2$ & 155339 & 219 & 98.387 & -0.048 & & 98.360 & 98.415 & 0.055 \\
\hline 2032 & $\mathrm{~S} 3$ & 146543 & 230 & 98.443 & 0.008 & & 98.420 & 98.465 & 0.045 \\
\hline 2033 & $\mathrm{PM}$ & $\mathrm{N} / \mathrm{A}$ & 60 & 109.825 & 0 & & 109.760 & 109.898 & 0.138 \\
\hline 2033 & Scans Combined & 1348158 & 225 & 109.787 & -0.038 & & 109.780 & 109.800 & 0.020 \\
\hline 2033 & $\mathrm{~S} 1$ & 651400 & 220 & 109.794 & -0.031 & 6.8 & 109.767 & 109.821 & 0.054 \\
\hline 2033 & $\mathrm{~S} 2$ & 337285 & 206 & 109.846 & 0.021 & & 109.815 & 109.878 & 0.063 \\
\hline 2033 & S3 & 359473 & 207 & 109.862 & 0.037 & & 109.836 & 109.889 & 0.053 \\
\hline
\end{tabular}


Table B.1 - continued from previous page

\begin{tabular}{|c|c|c|c|c|c|c|c|c|c|}
\hline Site & Method & $\begin{array}{l}\text { Scan Cloud } \\
\text { Points }\end{array}$ & $\begin{array}{l}\text { Survey Points/ } \\
\text { Grid Cells } \\
\text { with Min Value }\end{array}$ & Mean $(\mathrm{m})$ & $\begin{array}{l}\text { Deviation of } \\
\text { Mean }(\mathrm{m})\end{array}$ & $\begin{array}{l}\text { TLS Range } \\
\text { of Means } \\
(\mathrm{cm})\end{array}$ & $\begin{array}{l}\text { Min } \\
\text { CI } \\
(\mathrm{m})\end{array}$ & $\begin{array}{l}\text { Max } \\
\text { CI } \\
(\mathrm{m})\end{array}$ & $\begin{array}{l}\text { Range } \\
\text { CI } \\
(\mathrm{cm})\end{array}$ \\
\hline 2034 & $\mathrm{PM}$ & $\mathrm{N} / \mathrm{A}$ & 100 & 98.385 & 0 & & 98.266 & 98.519 & 0.253 \\
\hline 2034 & Scans Combined & 1441023 & 242 & 98.129 & -0.256 & & 98.050 & 98.210 & 0.160 \\
\hline 2034 & $\mathrm{~S} 1$ & 665674 & 228 & 98.157 & -0.228 & 20.6 & 98.072 & 98.240 & 0.168 \\
\hline 2034 & $\mathrm{~S} 2$ & 775349 & 159 & 97.951 & -0.434 & & 97.857 & 98.034 & 0.177 \\
\hline 2035 & $\mathrm{PM}$ & $\mathrm{N} / \mathrm{A}$ & 50 & 101.380 & 0 & & 101.257 & 101.502 & 0.245 \\
\hline 2035 & PR & $\mathrm{N} / \mathrm{A}$ & 50 & 100.875 & -0.505 & & 100.768 & 100.987 & 0.219 \\
\hline 2035 & Scans Combined & 2818880 & 204 & 100.908 & -0.472 & & 100.900 & 101.000 & 0.100 \\
\hline 2035 & S1 & 626628 & 160 & 100.922 & -0.458 & 32 & 100.876 & 100.966 & 0.090 \\
\hline 2035 & $\mathrm{~S} 2$ & 324145 & 125 & 101.242 & -0.138 & & 101.182 & 101.306 & 0.124 \\
\hline 2035 & $\mathrm{~S} 3$ & 889072 & 83 & 100.923 & -0.457 & & 100.804 & 101.038 & 0.234 \\
\hline 2035 & $\mathrm{~S} 4$ & 979035 & 162 & 101.035 & -0.345 & & 100.984 & 101.087 & 0.103 \\
\hline 164 & $\mathrm{PM}$ & $\mathrm{N} / \mathrm{A}$ & 50 & 98.350 & 0 & & 98.296 & 98.401 & 0.105 \\
\hline
\end{tabular}


Table B.1 - continued from previous page

\begin{tabular}{|c|c|c|c|c|c|c|c|c|c|}
\hline Site & Method & $\begin{array}{l}\text { Scan Cloud } \\
\text { Points }\end{array}$ & $\begin{array}{l}\text { Survey Points/ } \\
\text { Grid Cells } \\
\text { with Min Value }\end{array}$ & Mean (m) & $\begin{array}{l}\text { Deviation of } \\
\text { Mean }(\mathrm{m})\end{array}$ & $\begin{array}{l}\text { TLS Range } \\
\text { of Means } \\
(\mathrm{cm})\end{array}$ & $\begin{array}{l}\text { Min } \\
\text { CI } \\
(\mathrm{m})\end{array}$ & $\begin{array}{l}\text { Max } \\
\text { CI } \\
(\mathrm{m})\end{array}$ & $\begin{array}{l}\text { Range } \\
\text { CI } \\
(\mathrm{cm})\end{array}$ \\
\hline 164 & Scans Combined & 983829 & 254 & 98.208 & -0.142 & & 98.170 & 98.240 & 0.070 \\
\hline 164 & S1 & 646754 & 249 & 98.219 & -0.131 & 9.5 & 98.184 & 98.253 & 0.069 \\
\hline 164 & S3 & 151455 & 189 & 98.314 & -0.036 & & 98.276 & 98.353 & 0.077 \\
\hline 165 & $\mathrm{PM}$ & $\mathrm{N} / \mathrm{A}$ & 50 & 98.182 & 0 & & 98.124 & 98.241 & 0.117 \\
\hline 165 & Scans Combined & 2061941 & 235 & 98.200 & 0.018 & & 98.170 & 98.230 & 0.060 \\
\hline 165 & S1 & 595322 & 211 & 98.275 & 0.093 & 11.6 & 98.238 & 98.310 & 0.072 \\
\hline 165 & $\mathrm{~S} 4$ & 94907 & 102 & 98.368 & 0.186 & & 98.340 & 98.397 & 0.057 \\
\hline 166 & $\mathrm{PM}$ & $\mathrm{N} / \mathrm{A}$ & 60 & 98.155 & 0 & & 98.100 & 98.214 & 0.114 \\
\hline 166 & Scans Combined & 957719 & 250 & 98.137 & -0.018 & & 98.110 & 98.170 & 0.060 \\
\hline
\end{tabular}


Table B.1 - continued from previous page

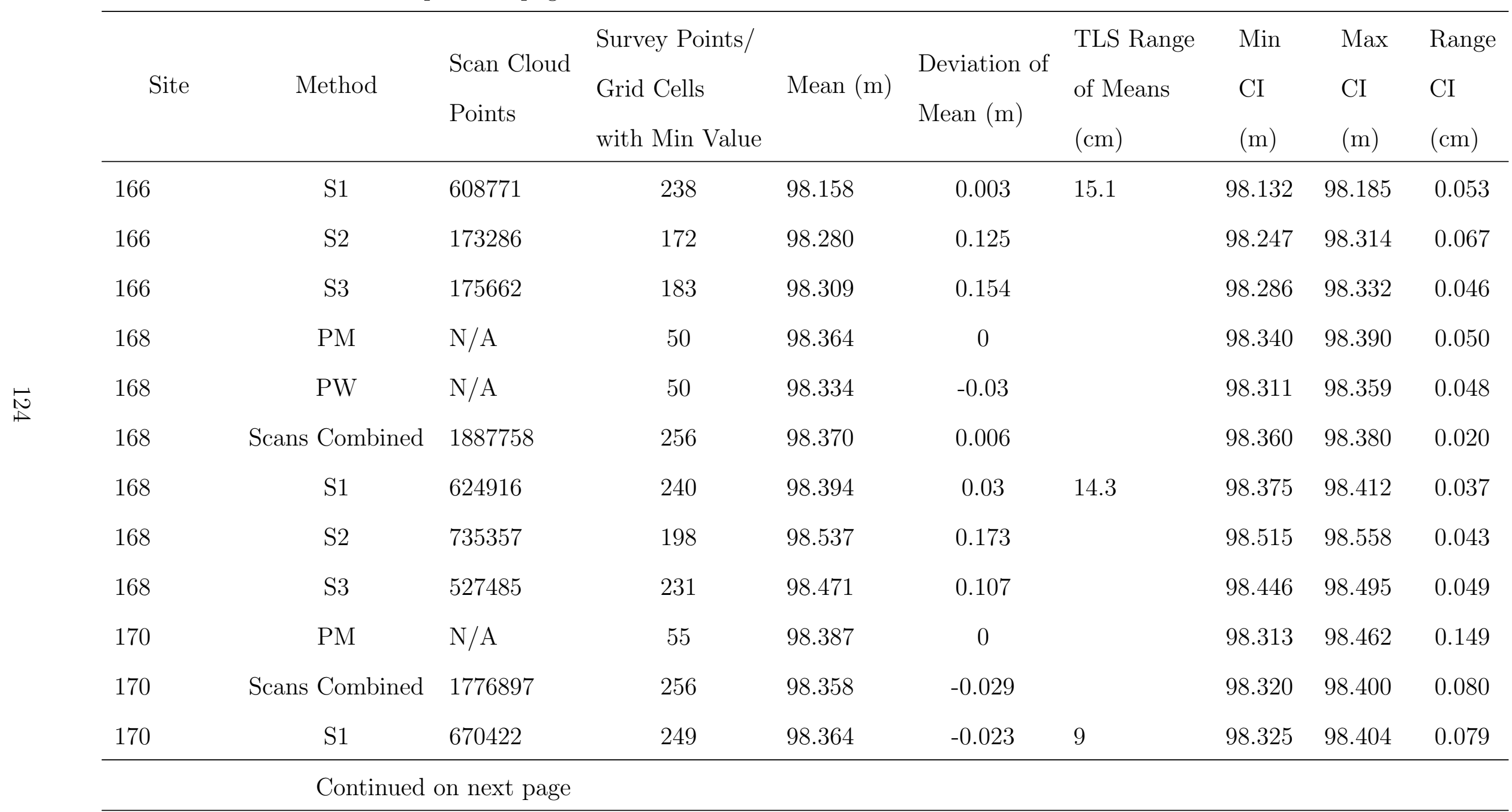


Table B.1 - continued from previous page

\begin{tabular}{|c|c|c|c|c|c|c|c|c|c|}
\hline Site & Method & $\begin{array}{l}\text { Scan Cloud } \\
\text { Points }\end{array}$ & $\begin{array}{l}\text { Survey Points/ } \\
\text { Grid Cells } \\
\text { with Min Value }\end{array}$ & Mean (m) & $\begin{array}{l}\text { Deviation of } \\
\text { Mean }(\mathrm{m})\end{array}$ & $\begin{array}{l}\text { TLS Range } \\
\text { of Means } \\
(\mathrm{cm})\end{array}$ & $\begin{array}{l}\text { Min } \\
\text { CI } \\
(\mathrm{m})\end{array}$ & $\begin{array}{l}\text { Max } \\
\text { CI } \\
(\mathrm{m})\end{array}$ & $\begin{array}{l}\text { Range } \\
\text { CI } \\
(\mathrm{cm})\end{array}$ \\
\hline 170 & $\mathrm{~S} 2$ & 449381 & 215 & 98.454 & 0.067 & & 98.419 & 98.490 & 0.071 \\
\hline 170 & S3 & 657094 & 185 & 98.419 & 0.032 & & 98.375 & 98.464 & 0.089 \\
\hline 171 & $\mathrm{PM}$ & $\mathrm{N} / \mathrm{A}$ & 60 & 102.003 & 0 & & 101.953 & 102.057 & 0.104 \\
\hline 171 & Scans Combined & 1171892 & 240 & 102.021 & 0.018 & & 102.010 & 102.030 & 0.020 \\
\hline 171 & S1 & 649496 & 235 & 102.023 & 0.02 & 2.6 & 101.998 & 102.050 & 0.052 \\
\hline 171 & $\mathrm{~S} 2$ & 522396 & 222 & 102.049 & 0.046 & & & & \\
\hline
\end{tabular}




\section{Appendix C}

\section{Acronyms}

ACGR - Associate Committee on Geotechnical Research

ASCII - American Standard Code for Information Interchange

ALS - Airborne Laser Scanner or Airborne Laser Scanning

CALM - Circumpolar Active Layer Monitoring

CI - Confidence Interval

DEM - Digital elevation model

DGPS - Differential Global Positioning System

DInSAR - Differential Interferometry Synthetic Aperture Radar

GPS - Global Positioning System

GNSS - Global Navigation Satellite System

InSAR - Interferometric Synthetic Aperture Radar

IPCC - Intergovernmental Panel on Climate Change

LiDAR - Light Detection and Ranging

NWT - Northwest Territories

Radar- Radio Detection and Ranging

RTK - Real-time kinematic

SAR - Synthetic Aperture Radar

SfM - Structure from Motion

TLS - Terrestrial Laser Scanner or Terrestrial Laser Scanning

UAV - unmanned aerial vehicle 
WFD - wave form digitizing technology 